\title{
Case Histories of Mass Concrete Thermal
} Studies

Stephen B. Tatro, Anthony A. Bombich, and John R. Hess 
The contents of this report are not to be used for advertising, publication, or promotional purposes. Citation of trade names does not constitute an official endorsement or approval of the use of such commercial products.

The findings of this report are not to be construed as an official Department of the Army position, unless so designated by other authorized documents. 
ERDC/SL TR-00-8

September 2000

\title{
Case Histories of Mass Concrete Thermal Studies
}

\author{
by Stephen B. Tatro \\ U.S. Army Engineer District, Walla Walla \\ 201 North Third Street \\ Walla Walla, WA 99362-1876 \\ Anthony A. Bombich \\ Structures Laboratory \\ U.S. Army Engineer Research and Development Center \\ 3909 Halls Ferry Road \\ Vicksburg, MS 39180-6199 \\ John R. Hess \\ U.S. Army Engineer District, Sacramento \\ 111222 Street, NW \\ Sacramento, CA 99999
}

Final report

Approved for public release; distribution is unlimited 


\section{Contents}

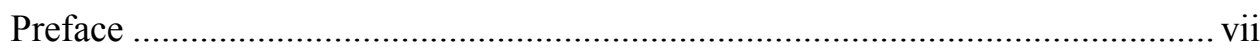

Conversion Factors, Non-SI to SI Units of Measurement .................................. viii

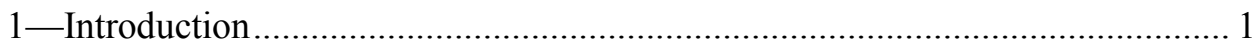

What the Report Contains.................................................................... 1

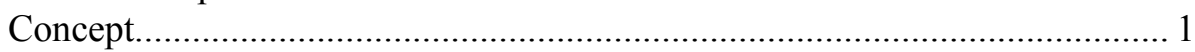

Thermal Analysis Objectives ................................................................... 2

Thermal Cracking Prevention Measures...................................................... 3

General Thermal Analysis Process ......................................................... 3

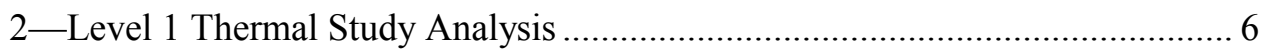

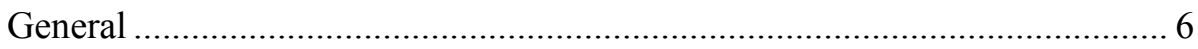

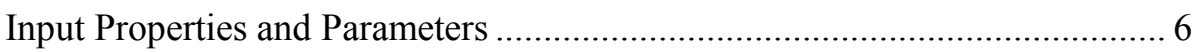

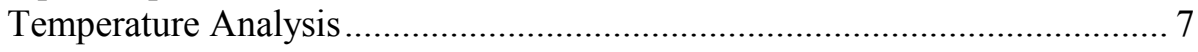

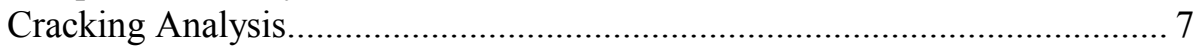

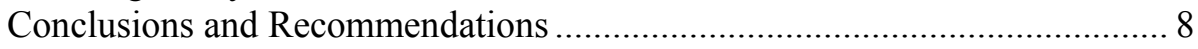

3-Level 1 Analysis, Cache Creek Detention Basin Weir ................................... 9

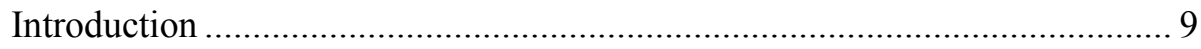

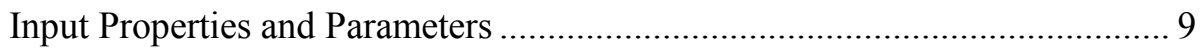

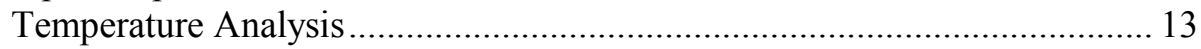

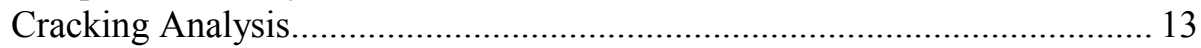

Conclusions and Recommendations ............................................................ 14

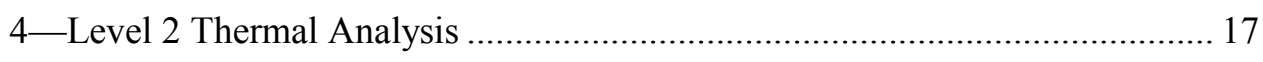

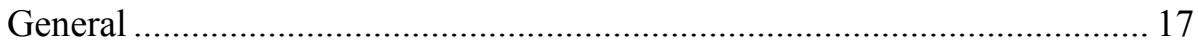

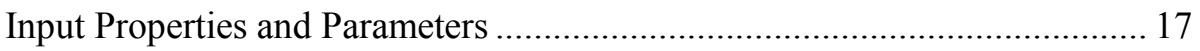

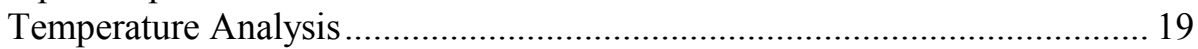

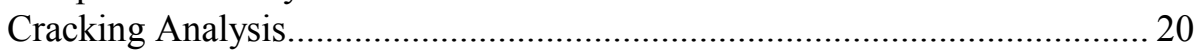

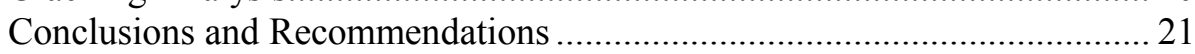

5-Level 2 Analysis, American River RCC Gravity Dam................................. 22

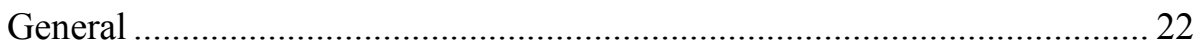

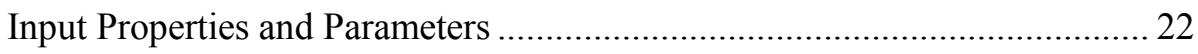

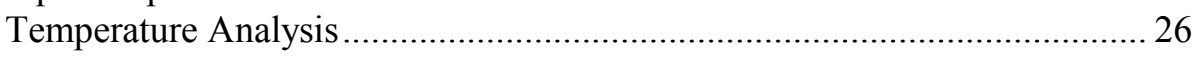




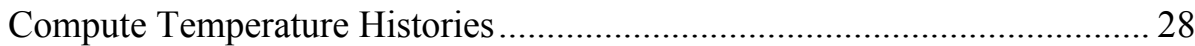

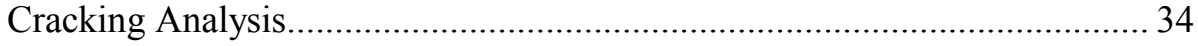

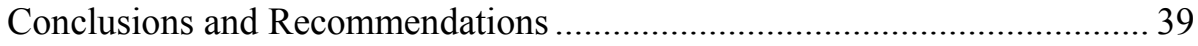

6-Level 2 Analysis, Locks and Dams 2, 3, and 4 Monongahela River.............. 41

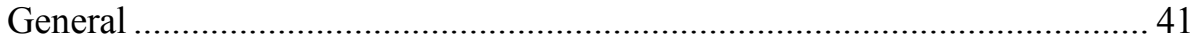

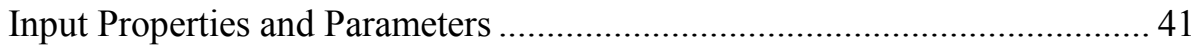

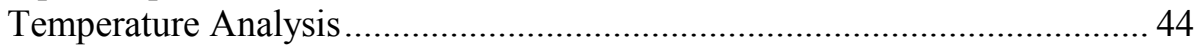

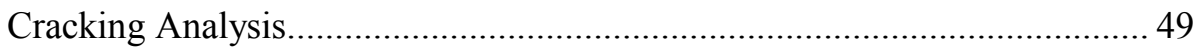

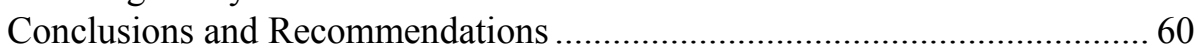

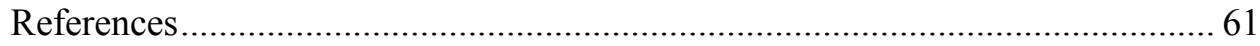

Appendix A: Determination of Tensile Strain Capacity (TSC)........................ A1

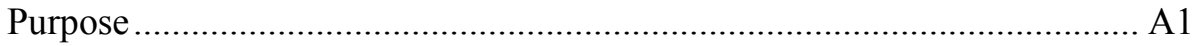

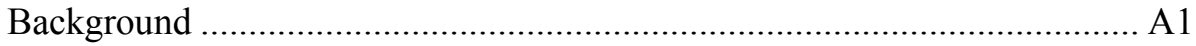

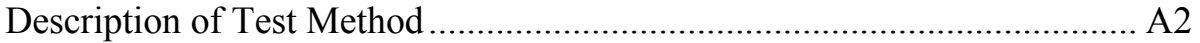

Tensile Strain Capacity Test Results …................................................. A2

Use of TSC for Mass Gradient Cracking Analyses.................................... A2

Use of TSC for Surface Gradient Cracking Analyses.................................. A3

SF 298

\section{List of Figures}

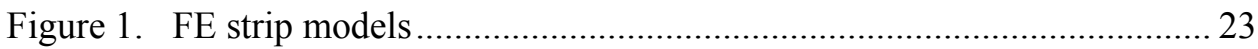

Figure 2. Daily ambient temperature cycles …................................................ 24

Figure 3. Estimated elastic and creep properties ............................................... 25

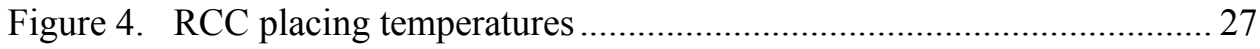

Figure 5. Mass gradient temperature histories for 1 January start ...................... 29

Figure 6. Mass gradient peak temperatures for 1 January start ......................... 29

Figure 7. Mass gradient temperature histories for 1 October start ......................30

Figure 8. Mass gradient peak temperatures for 1 October start ........................ 30

Figure 9. Mass gradient temperature histories for 1 July start ............................ 31

Figure 10. Mass gradient peak temperatures for 1 July start ............................. 31

Figure 11. Mass gradient temperature histories for 1 April start........................ 32

Figure 12. Mass gradient peak temperatures for 1 April start ........................... 32 
Figure 13. Temperature history for selected nodes from surface gradient model

Figure 14. Surface gradient temperature distribution ........................................ 33

Figure 16. Lock wall section used in example ................................................ 42

Figure 17. Mean daily ambient temperatures and concrete placement

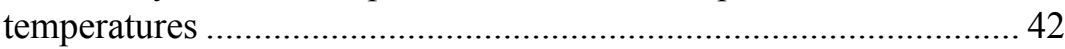

Figure 18. Adiabatic temperature rise for Level 2 thermal analysis 2-D example

Figure 19. Finite element model of lock wall example

Figure 20. Typical temperature histories at locations of mass gradient analysis .....

Figure 21. Temperature distributions across lift 6 used in surface gradient analysis

Figure 22. Temperature differences in lift 6 for surface gradient analysis 52

Figure 23. Balanced temperature difference distributions in lift 6 for surface gradient analysis

Figure 24. Evaluation of surface gradient cracking potential by comparing induced tensile strain with slow-load tensile strain capacity..... 59

\section{List of Tables}

Table 1. Thermal Study Process ….............................................................. 4

Table 2. NOAA Temperature Data, Woodland, CA...................................... 10

Table 3. Cache Creek Weir Placing Temperature Computation ..................... 11

Table 4. Cache Creek Weir Thermal Analysis Summary …............................ 12

Table 5. RCC Material Properties for Mixtures............................................. 24

Table 6. Summary of Locations of Mass Gradient Thermal Cracks ............... 36

Table 7. Concrete and Foundation Thermal Properties ................................. 43

Table 8. Concrete and Foundation Mechanical Properties ............................. 43

Table 9. Summary of Surface Heat Transfer Coefficients for FE Thermal Analyses 
Table 10. Temperature Distribution in Lift 6 for Surface Gradient Analysis

Table 11. Temperature Differences Referenced to Temperature at 0.5

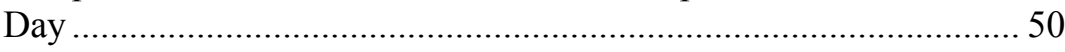

Table 12. Temperature Differences Normalized in Reference to Surface Temperature Differences for Surface Gradient Analysis 53

Table 13. Balanced or Effective Temperature Differences to Determine " $H$ " and Surface Gradients Strains ................................................. 55

Table 14. Mass Gradient Cracking Analysis ................................................. 57

Table 15. Surface Gradient Cracking Analysis................................................5 


\section{Preface}

This report contains examples of Level 1 and Level 2 thermal analyses. The analyses were conducted in conjunction with U.S. Army Corps of Engineers projects and individually funded from project funds. These analyses were originally assembled as annexes to ETL 1110-2-542, Thermal Studies of Mass Concrete Structures.

The analyses were performed over a period of several years during the design of Cache Creek Detention Basin Weir by Sacramento District, the preliminary design of American River Dam for Sacramento District, and for various design efforts for Locks 2, 3, and 4 for Pittsburgh District.

Mr. Stephen B. Tatro, Walla Walla District, was responsible for the thermal analysis of Cache Creek Detention Basin Weir and for American River Dam. Mr. John R. Hess, Sacramento District, provided consultation during certain phases of the work. Mr. Tatro and Mr. Anthony A. Bombich, Structures Laboratory (SL), U.S. Army Engineer Research and Development Center (ERDC), were responsible for various phases of the Locks 2, 3, and 4 analyses. Messrs. Tatro and Bombich prepared the major element of this report. Final review was provided by Mr. Hess. Dr. Michael J. O’Connor was Acting Director of SL.

At the time of publication of this report, Dr. James R. Houston was Director of ERDC, and COL James S. Weller, EN, was Commander.

The contents of this report are not to be used for advertising, publication, or promotional purposes. Citation of trade names does not constitute an official endorsement or approval of the use of such commercial products. 


\section{Conversion Factors, Non-SI to SI Units of Measurement}

Non-SI units of measurement used in this report can be converted to SI units as follows:

\begin{tabular}{|c|c|c|}
\hline Multiply & By & To Obtain \\
\hline Fahrenheit degrees & $5 / 9$ & Celsius degrees or kelvins ${ }^{1}$ \\
\hline feet & 0.3048 & meters \\
\hline inches & 0.0254 & meters \\
\hline
\end{tabular}




\section{Introduction}

\section{What the Report Contains}

This report presents examples of mass concrete thermal studies performed for several U.S. Army Corps of Engineers projects. The examples are preceded by a brief explanation of the components of each study and other relevant information. This chapter provides an introduction to the concepts, objectives, and process for performing a thermal analysis and identifies measures to control thermal cracking.

The example thermal studies were generally performed as outlined in Engineer Technical Letter (ETL) 1110-2-542, Thermal Studies of Mass Concrete Structures. This ETL is no longer in print, but the major elements of the document are now contained in Engineer Manual (EM) 1110-2-2000, Standard Practice for Concrete for Civil Works Structures. This report serves as a companion document to the EM. More detailed explanations of the general provisions for performing mass concrete thermal studies are contained in EM 1110-2-2000.

The procedure for a Level 1 analysis is presented herein along with an example of the thermal study conducted for Cache Creek Sedimentation Basin. The procedure for a Level 2 analysis is also presented. The preliminary thermal analysis for the American River Dam provides an example of a one-dimensional Level 2 thermal analysis, including an example using simple finite element (FE), one-dimensional (1-D) strip models. The thermal analysis for Locks and Dams 2, 3 , and 4 on the Monongahela River provides an example of a Level 2 analysis using more complex two-dimensional (2-D), FE methodology. Appendix A presents the current practice for determination of concrete tensile strain capacity (TSC) for use in cracking analysis.

\section{Concept}

Mass concrete is defined by the American Concrete Institute (ACI) as "any volume of concrete with dimensions large enough to require that measures be taken to cope with generation of heat from hydration of the cement and attendant volume change to minimize cracking." When portland cement combines with water, the ensuing exothermic (heat-releasing) chemical reaction causes a temperature rise in the concrete mass. The actual temperature rise in a mass concrete structure (MCS) depends upon the heat-generating characteristics of the mass 
concrete mixture, its thermal properties, environmental conditions, geometry of the MCS, and construction conditions. Usually the peak temperature is reached in a few days to weeks after placement, followed by a slow reduction in temperature. Over a period of several months to several years, the mass eventually cools to some stable temperature, or to a stable temperature cycle for thinner structures. A change in volume occurs in the MCS proportional to the temperature change and the coefficient of thermal expansion of the concrete. If volume change is restrained during cooling of the mass by the foundation, the previously placed concrete, or the exterior surfaces, sufficient tensile strain can develop to cause cracking. Cracking generally occurs in the main body or at the surface of the MCS. These two principal cracking phenomena are termed mass gradient and surface gradient cracking, respectively. ACI 207.1R contains detailed information on heat generation, volume change, restraint, and cracking in mass concrete.

\section{Thermal Analysis Objectives}

A thermal analysis is necessary to attain any of the following design objectives:

To develop materials and structural and construction procedure requirements for use in feasibility evaluation, design, cost engineering, specifications, and construction of new MCS. Thermal studies provide a rational basis for specifying construction requirements. A thermal study provides a guide for formulating advantageous design features, optimizing concrete mixture proportions, and implementing necessary construction requirements.

To provide cost savings by revising the structural configuration, material requirements, or construction sequence. Construction requirements for concrete placement temperature, mixture proportions, placement rates, insulation requirements, and schedule constraints that are based on arbitrarily selected parameters can create costly operations. Cost savings may be achieved through items such as eliminating unnecessary joints, allowing increased placing temperatures, increased lift heights, and reduced insulation requirements.

To develop structures with improved performance where existing similar structures have exhibited unsatisfactory behavior (such as extensive cracking) during construction or operation. Cracking which requires remedial repairs would be considered unsatisfactory behavior. Cracking which does not affect the overall structural behavior or some function of the structure would not be classified as unsatisfactory behavior.

To more accurately predict behavior of unprecedented structures for which limited experience is available, such as structures with unusual structural configuration, extreme loadings, unusual construction constraints, or severe operational requirements. 


\section{Thermal Cracking Prevention Measures}

Provisions to counteract predicted thermal cracking are discussed in ACI 207 documents and typically include:

a. Changes in construction procedures, including placing times and temperatures.

b. Changes in concrete materials and thermal properties.

c. Precooling of concrete materials.

d. Limit concrete placement temperatures.

e. Postcooling of concrete.

f. Construction of joints (with waterstops where necessary) to control location of cracks.

g. Construction of water barrier membranes to prevent water from entering cracks.

$h$. Alteration of structure geometry to avoid or control cracking.

$i$. Use and careful removal of insulation.

\section{General Thermal Analysis Process}

The thermal study process at any level consists of several steps that are summarized in Table 1. These steps are similar for all three levels of analysis. The steps can be subdivided among three general tasks: data collection, temperature analysis, and cracking analysis. The specific efforts within each of these tasks can vary considerably, depending upon the level of analysis selected for the thermal study. Data collection includes those steps that provide input data and preparation of input for subsequent analysis tasks. Data collection may include information retrieval and testing. Temperature analysis generates the temperatures or temperature histories for the MCS, which are possible scenarios of thermal loadings during construction and subsequent cooling. Cracking evaluation uses temperature data from the temperature analysis, other sources of loading, material properties, concrete/foundation interaction, geometry, construction parameters, etc., to compute strains and evaluate the potential for cracking in the MCS. This process is directly applicable for evaluating mass gradient and surface gradient cracking for thermal studies (Levels 1 and 2) and for advanced FE thermal studies such as nonlinear incremental structural analysis (NISA) (Level 3). At all levels of thermal analysis, parametric studies are an important part of thermal analysis and are used to assist the engineer in making proper decisions for design and construction. 


\begin{tabular}{|c|c|c|}
\hline Data Collection & Temperature Analysis & Cracking Analysis \\
\hline Levels 1-3 & Levels 1-3 & Levels 1 and 2 \\
\hline $\begin{array}{l}\text { Determine Ambient } \\
\text { Conditions }\end{array}$ & Prepare Temperature Model & Determine Restraint \\
\hline $\begin{array}{l}\text { Climatological conditions } \\
\text { Foundation temperature } \\
\text { Water temperatures } \\
\text { Solar radiation }\end{array}$ & $\begin{array}{l}\text { Compute surface heat transfer } \\
\text { coefficients and other } \\
\text { boundary conditions } \\
\text { Establish calculation } \\
\text { increments } \\
\text { Prepare FE model (mesh) or } \\
\text { prepare step-by-step method } \\
\text { (spreadsheet) } \\
\end{array}$ & $\begin{array}{l}\text { Compute } K_{f} \text { and } K_{R} \text { for: mass } \\
\text { gradient analysis and surface } \\
\text { gradient analysis }\end{array}$ \\
\hline $\begin{array}{l}\text { Determine Material } \\
\text { Properties }\end{array}$ & & Determine Thermal Strains \\
\hline $\begin{array}{l}\text { Concrete } \\
\text { Foundation }\end{array}$ & & $\begin{array}{l}\text { Strain }-\left(C_{t h}\right)(\Delta T)\left(K_{R}\right) \text { for: } \\
\text { mass gradient analysis and } \\
\text { surface gradient analysis } \\
\end{array}$ \\
\hline $\begin{array}{l}\text { Determine Construction } \\
\text { Parameters }\end{array}$ & $\begin{array}{l}\text { Compute Temperature } \\
\text { Histories }\end{array}$ & Estimate Cracking \\
\hline \multirow[t]{4}{*}{$\begin{array}{l}\text { Geometry/lift height } \\
\text { Lift placement rate } \\
\text { Concrete placement } \\
\text { temperature } \\
\text { Concrete postcooling } \\
\text { Construction start date(s) } \\
\text { Formwork and insulation usage }\end{array}$} & $\begin{array}{l}\text { Mass Gradient Analysis: } \\
\text { Determine peak and ultimate } \\
\text { stable temperatures } \\
\text { Surface Gradient Analysis: } \\
\text { Determine temperature } \\
\text { history at surfaces } \\
\text { Determine depth of tensile zone } \\
\text { for } K_{R} \\
\end{array}$ & $\begin{array}{l}\text { Mass Gradient Cracking: Use } \\
\text { mass gradient strains \& slow } \\
\text { load tensile strain cracking } \\
\text { (TSC) } \\
\text { Surface Gradient Cracking: } \\
\text { Use surface gradient strains } \\
\text { \& age-modified TSC }\end{array}$ \\
\hline & & Level 3 \\
\hline & & $\begin{array}{l}\text { FE Method: ABAQUS } \\
\text { w/ANACAP-U }\end{array}$ \\
\hline & & $\begin{array}{l}\text { Conclusions \& } \\
\text { Recommendations }\end{array}$ \\
\hline
\end{tabular}

\section{Level 1 analysis}

This type of analysis is the least complex. It is a simplified or "quick and dirty" methodology, using little or no laboratory testing, and incorporating broad assumptions for site conditions and placement constraints. The approach is to estimate the worst reasonable combination of material properties and site conditions, so that if conditions are acceptable, no further analysis is necessary. If conditions are not acceptable, then more accurate data and possibly a more detailed analysis are necessary. Temperature calculations are limited to simple determinations of peak concrete temperature based on summation of placement temperature and temperature rise produced by heat from the concrete mixture. Cooling from the peak temperature is assumed to progress to the ambient average annual temperature or a cyclic temperature range. Strain, length change, and cracking are computed based on temperature change in the MCS from peak to average ambient, using simple methods for determination of restraint. Other MCS loading conditions are evaluated separately from the thermal analysis at this level. A detailed description of a Level 1 thermal analysis using average monthly temperatures is shown in the next chapter. 


\section{Level 2 analysis}

Level 2 thermal analysis is characterized by a more rigorous determination of concrete temperature history in the structure and the use of a wide range of temperature analysis tools. Placement temperatures are usually determined based on ambient temperatures and anticipated material processing and handling measures. The temperature history of the concrete mass is approximated by using step-bystep iteration using the Schmidt or Carlson methods or by FE analysis using simple 1-D models, termed "strip" models, or using 2-D models representing cross sections of a structure. Evaluation of thermal cracking within the interior of an MCS, termed mass gradient cracking, and cracking at the surface of an MCS, termed surface gradient cracking, are appropriate at this level. Detailed cracking evaluation of complex shapes or loading conditions other than thermal loads is not performed at this level.

\section{Level 3 analysis}

A Level 3 analysis is also known as a nonlinear incremental structural analysis (NISA). NISA is performed using the FE method, exclusively, to compute incremental temperature histories, thermal stress-strain, stress-strain from other loading, and cracking prediction results. Significant effort is necessary to collect environmental data, assess and implement applicable construction parameters, acquire foundation materials properties, determine appropriate construction scenarios, and perform testing required for thermal and nonlinear material properties input. Preparation of FE models and conducting temperature and thermal stress analyses which generate significant volumes of data are generally extensive and costly efforts. ETL 1110-2-365 describes the computational methodology and application of Level 3 (NISA) analysis. Hollenbeck and Tatro (2000) present an example of a 2-D NISA application to analyze cracking for Zintel Canyon Dam, a roller compacted concrete (RCC) dam constructed in 1992. 


\section{Level 1 Thermal Study Analysis}

\section{General}

This chapter summarizes each step in a Level 1 thermal study mass gradient analysis of a MCS. An example of how this procedure was applied for a modestsize MCS is presented in Chapter 3. Although alternative approaches can be used, this method is in common use for this level MCS thermal analysis. Surface gradient thermal analysis is seldom conducted at this level of analysis.

\section{Input Properties and Parameters}

Step 1: Determine ambient conditions. Simple analyses conducted for a Level 1 analysis are typically based on average monthly temperature data.

Step 2: Determine material properties. Laboratory test results on material properties are seldom available for this level of thermal analysis. Material properties are generally estimated from published data in sources such as ACI documents, technical publications, and engineering handbooks. Often known information such as compressive strength and aggregate type is used to predict other material properties from published data. The minimum properties required are the coefficient of thermal expansion $\left(C_{t h}\right)$, the adiabatic temperature rise $\left(\Delta T_{a d}\right)$, and the tensile strain capacity $\left(\varepsilon_{t c}\right)$.

Step 3: Determine construction parameters. Concrete placement temperature is the essential construction parameter needed for this level of thermal analysis. A first approximation is to assume that concrete placement temperatures $\left(T_{p}\right)$ directly parallel the average monthly temperature. A more accurate method is to modify the average monthly temperature based upon production time period and extent of production or to use actual placement temperature data from similar projects. 


\section{Temperature Analysis}

Step 4: Mass gradient temperature analysis. For Level 1 mass gradient analysis, no elaborate "model" is used to develop temperature history. The longterm temperature change is simply calculated as the peak concrete temperature minus the ultimate stable concrete temperature.

a. Determine peak temperature. This is the sum of the concrete placement temperature and the adiabatic temperature rise.

b. Determine ultimate stable temperature. Large structures cool to a stable temperature equal to the average ambient temperature. However, smaller concrete structures cool to a stable annual temperature cycle, since there is insufficient mass to provide complete insulation of the interior. ACI 207.1R provides a plot relating temperature variation with depth to determine this internal temperature cycle. It is assumed that the concrete temperature cycles about the average annual temperature.

c. Determine long-term temperature change. The sum of the placing temperature plus adiabatic temperature rise provides a quick peak temperature of the MCS. Then subtracting the ultimate stable temperature provides the long-term temperature change used for strain and cracking evaluation.

\section{Cracking Analysis}

Step 5: Mass gradient cracking analysis. Using long-term temperature change and ACI formulas, mass gradient strain is approximated. These strains are compared to estimates of tensile strain capacity to determine if and when cracking may occur.

a. Determine mass gradient restraint conditions. The structure restraint factor $\left(K_{R}\right)$ and the foundation restraint factor $\left(K_{f}\right)$ (in ACI 207.2R termed "Multiplier for foundation rigidity") are determined as described in Equation 5 (see Chapter 6) and in ACI 207.2R.

b. Determine mass gradient thermal strain. The total induced strain is the product of the long-term temperature change, the coefficient of thermal expansion, and restraint factors.

Total strain $=\left(C_{t h}\right)(d T)\left(K_{R}\right)\left(K_{f}\right)$

where

$$
\begin{aligned}
& \text { Total strain }=\text { induced strain (millionths) } \\
& \qquad \begin{aligned}
C_{t h} & =\text { coefficient of thermal expansion } \\
d T & =\text { temperature differential }
\end{aligned}
\end{aligned}
$$




$$
\begin{aligned}
K_{R} & =\text { structure restraint factor } \\
K_{f} & =\text { foundation restraint factor }
\end{aligned}
$$

Cracking strain is computed by subtracting tensile strain capacity from the total strain. The remainder is the strain that must be accommodated in cracks at some spacing and width across the MCS.

c. Estimate mass gradient cracking. Foundation conditions (restraint) control the spacing of cracks and the crack width. If the foundation is stiffer, tightly spaced cracks of small width can be expected. If the foundation is relatively soft (low restraint), widely spaced and wider cracks can be anticipated. Multiply the MCS length by the cracking strain to determine the total width of cracking to be accommodated in the MCS. Estimate a crack width based on foundation conditions and divide the total width of cracking by the assumed crack width to determine the total number of cracks.

\section{Conclusions and Recommendations}

These typically include expected maximum temperatures for starting placement in different seasons, expected transverse and longitudinal cracking without temperature or other controls, recommended concrete placement temperature limitations, anticipated concrete precooling measures, need for adjustment in concrete properties, joint spacing, and sensitivity of the thermal analysis to changes in parameters. 


\section{Level 1 Analysis, Cache Creek Detention Basin Weir}

\section{Introduction}

This example, based on a thermal study for the Cache Creek Detention Basin Weir, illustrates one way to estimate concrete placing temperature based on ambient air temperatures and material processing schemes and schedules. The study evaluates mass gradient cracking only. The Cache Creek Detention Basin in California is a RCC overflow weir section in a levee system. The structure is $4.6 \mathrm{~m}(15 \mathrm{ft})$ high, $3.6 \mathrm{~m}(12 \mathrm{ft})$ wide at the top, has 0.8 to 1 slopes upstream and downstream, and is $530 \mathrm{~m}(1,740 \mathrm{ft})$ long. Compacted sands and silts were placed against the full height of the upstream face. The purpose of the study was to determine the adequacy of contraction joints spaced at 30-m (100-ft) intervals and, if necessary, provide recommendations for alternate configurations. Also addressed is the adequacy of a maximum placing temperature of $29 \mathrm{deg} \mathrm{C}$ ( $85 \mathrm{deg}$ F) for the RCC. The following paragraphs provide explanation on the selection criteria and determination of the parameters used to summarize thermal study.

\section{Input Properties and Parameters}

Step 1: Determine ambient conditions. Data were provided from climatological data summaries for Woodland, CA, prepared by the National Oceanic and Atmospheric Administration (NOAA), shown in Table 2. The average annual temperature used was $16.1 \mathrm{deg} \mathrm{C}$ ( $61 \mathrm{deg} \mathrm{F}$ ), and monthly mean and average monthly maximum and minimum temperatures were used for other computations.

\section{Step 2: Determine material properties.}

a. Coefficient of thermal expansion. Coefficient of thermal expansion was estimated using handbook data (Fintel 1985) for the sandstone and metasandstone aggregate concrete planned for the project:

$C_{t h}=9.9$ millionths $/ \operatorname{deg} \mathrm{C}$ (5.5 millionths/deg F) 


\begin{tabular}{||l|l|l|l||}
\hline \multicolumn{4}{||l||}{$\begin{array}{l}\text { Table 2 } \\
\text { NOAA Temperature Data, Woodland, CA }\end{array}$} \\
\hline \hline Month & $\begin{array}{l}\text { Monthly avg. max. - deg } \\
\text { C (deg F) }\end{array}$ & $\begin{array}{l}\text { Monthly avg. min. - deg } \\
\text { C (deg F) }\end{array}$ & $\begin{array}{l}\text { Monthly avg. -deg C } \\
\text { (deg F) }\end{array}$ \\
\hline \hline Jan & $11.7(53)$ & $2.8(37)$ & $7.2(45)$ \\
\hline Feb & $15.5(60)$ & $4.4(40)$ & $10.0(50)$ \\
\hline Mar & $18.9(66)$ & $5.5(42)$ & $12.2(54)$ \\
\hline Apr & $23.3(74)$ & $7.2(45)$ & $15.0(59)$ \\
\hline May & $27.8(82)$ & $10.0(50)$ & $18.9(66)$ \\
\hline Jun & $32.2(90)$ & $12.8(55)$ & $22.8(73)$ \\
\hline Jul & $35.5(96)$ & $13.9(57)$ & $25.0(77)$ \\
\hline Aug & $34.4(94)$ & $13.3(56)$ & $23.9(75)$ \\
\hline Sep & $32.2(90)$ & $12.2(54)$ & $22.2(72)$ \\
\hline Oct & $26.1(79)$ & $9.4(49)$ & $17.8(64)$ \\
\hline Nov & $18.3(65)$ & $5.5(42)$ & $11.7(53)$ \\
\hline Dec & $12.2(54)$ & $2.8(37)$ & $7.8(46)$ \\
\hline Annual & - & $-1(61)$ \\
\hline \hline
\end{tabular}

b. Adiabatic temperature rise. The study was performed using an RCC mixture with a Type I/II cement content of $119 \mathrm{~kg} / \mathrm{m}^{3}(200 \mathrm{lb} / \mathrm{cy})$ and a Class F pozzolan content of $39 \mathrm{~kg} / \mathrm{m}^{3}$ ( $\left.66 \mathrm{lb} / \mathrm{cy}\right)$. ACI 207.1R suggests that pozzolan can be assumed to have a heat-generating capacity about one-half that of cement. Using ACI 207.1R adiabatic temperature rise curves and an equivalent cement content of $138 \mathrm{~kg} / \mathrm{m}^{3}$ (233 lb/cy), this mixture should produce an adiabatic temperature rise of about $22.2 \mathrm{deg} \mathrm{C}$ (40 deg F). From ACI 207.1R:

$\Delta t_{a d}$ for $223 \mathrm{~kg} / \mathrm{m}^{3}(376 \mathrm{lb} / \mathrm{cy})$ cement at 28 days $=36.1 \mathrm{deg} \mathrm{C}(65 \mathrm{deg} \mathrm{F})$

$\Delta t_{a d}$ for $138 \mathrm{~kg} / \mathrm{m}^{3}(233 \mathrm{lb} / \mathrm{cy})$ equiv. cement at 28 days $=(36.1 \mathrm{deg} \mathrm{C})$ $(138) /(223)=22.2 \operatorname{deg} \mathrm{C}(40 \operatorname{deg} \mathrm{F})$

c. Tensile strain capacity. ACI $207.5 \mathrm{R}$ suggests that values of tensile strain capacity ranging from 50 to 200 millionths are achievable for early age, slow-load testing. Lean RCC mixes typically range from 60 to 90 millionths. Since the cement content of $119 \mathrm{~kg} / \mathrm{m}^{3}(200 \mathrm{lb} / \mathrm{cy})$ is higher than most lean RCC mixes and the coarse aggregate is crushed, a value of 80 millionths was selected.

Step 3: Determine construction parameters. RCC placing temperature was calculated using the average annual temperature modified by rule-of-thumb 
temperature effects during construction, as shown in Table 3. In Table 3, the placing temperature is the composite temperature of the aggregate source, (assumed to be the average annual temperature), plus the added heat during aggregate production, plus the added heat during RCC production. Stockpile aggregate temperatures are the base temperature, plus the ambient addition, plus crushing and production energy. Similarly, RCC production temperatures are the stockpile temperature plus ambient additions and mixer energy additions. The ambient temperature additions are calculated as 0.67 , an empirical correction factor, times the differential temperature of the aggregates and the air. The complete thermal study is summarized in Table 4. A May placing temperature was used for the following calculations:

$$
T_{p}=18.9 \operatorname{deg} \mathrm{C}(66 \operatorname{deg} \mathrm{F})
$$

\begin{tabular}{|c|c|c|c|c|c|}
\hline \multicolumn{6}{|c|}{$\begin{array}{l}\text { Table } 3 \\
\text { Cache Creek Weir Placing Temperature Computation }\end{array}$} \\
\hline \multirow[b]{2}{*}{ Factor } & \multicolumn{4}{|c|}{ Temperature, deg C } & \multirow[b]{2}{*}{ Comments } \\
\hline & May & Jun & Jul & Aug & \\
\hline Avg. annual temperature(deg C) & 16.1 & 16.1 & 16.1 & 16.1 & Base temperature, from NOAA data \\
\hline Previous month temperature & 15.0 & 18.9 & 22.6 & 24.8 & From NOAA data \\
\hline Added ambient temperature & -1.1 & 2.8 & 6.5 & 8.7 & $(0.67)$ (Annual temp. - prev. month temp.) \\
\hline Aggregate subtotal temperature & 15.4 & 18.0 & 20.5 & 21.9 & Avg. annual temp. + added amb. temp. \\
\hline Added processing temperature & +1.1 & +1.1 & +1.1 & +1.1 & Processing and crushing energy \\
\hline Aggregate stockpile temperature & 16.5 & 19.1 & 21.6 & 23.0 & N/A \\
\hline Current ambient temperature & 18.9 & 22.6 & 24.8 & 23.9 & From NOAA data \\
\hline Added ambient temperature & +1.7 & +2.3 & +2.1 & +0.6 & (0.67)(Curr. temp.-agg. stock. temp.) \\
\hline Added mixer energy & +1.1 & +1.1 & +1.1 & +1.1 & N/A \\
\hline \multirow[t]{2}{*}{ Placement temperature } & 19.3 & 22.6 & 24.8 & 24.8 & Agg. stockpile temp. + added effects \\
\hline & \multicolumn{4}{|c|}{ Temperature, deg $\mathrm{F}$} & \\
\hline Avg. annual temperature (deg F) & 61.1 & 61.1 & 61.1 & 61.1 & Base temperature, from NOAA data \\
\hline Previous month temperature & 59.0 & 66.1 & 72.7 & 76.6 & From NOAA data \\
\hline Added ambient temperature & -1.4 & 3.3 & 7.8 & 10.4 & $(0.67)($ Annual temp. - prev. month temp.) \\
\hline Aggregate subtotal temperature & 59.7 & 64.5 & 68.9 & 71.5 & Avg. annual temp. + added amb. temp. \\
\hline Added processing temperature & +2.0 & +2.0 & +2.0 & +2.0 & Processing and crushing energy \\
\hline Aggregate stockpile temperature & 61.7 & 66.5 & 70.9 & 73.5 & N/A \\
\hline Current ambient temperature & 66.1 & 72.7 & 76.6 & 75.1 & From NOAA data \\
\hline Added ambient temperature & +3.0 & +4.2 & +3.8 & +1.1 & (0.67)(Curr. Temp.-Agg. Stock. Temp.) \\
\hline Added mixer energy & +2.0 & +2.0 & +2.0 & +2.0 & N/A \\
\hline Placement temperature & 66.7 & 72.7 & 76.7 & 76.6 & Agg. stockpile temp. + added effects \\
\hline
\end{tabular}




\begin{tabular}{|c|c|c|c|}
\hline \multicolumn{4}{|l|}{$\begin{array}{l}\text { Table } 4 \\
\text { Cache Creek Weir Thermal Analysis Summary }\end{array}$} \\
\hline & \multicolumn{3}{|c|}{ SI Units } \\
\hline Parameter & \begin{tabular}{|l}
$\begin{array}{l}\text { Spring } \\
\text { (May) }\end{array}$ \\
\end{tabular} & \begin{tabular}{|l|} 
Late Spring \\
(Jun)
\end{tabular} & $\begin{array}{l}\text { Summer } \\
\text { (Jul-Aug) }\end{array}$ \\
\hline \multicolumn{4}{|l|}{ Temperatures } \\
\hline RCC placement temperature $(\operatorname{deg} \mathrm{C})$ & 19.4 & 22.8 & 25.0 \\
\hline Adiabatic temperature rise $(\operatorname{deg} \mathrm{C})$ & 22.2 & 22.2 & 22.2 \\
\hline Peak internal temperature (deg C) (Place temp. + adiabatic temp.) & 41.7 & 45.0 & 47.2 \\
\hline Minimum temperature (deg C) (Based on annual temp. cycle) & 12.2 & 12.2 & 12.2 \\
\hline Differential temperature (deg C) (Peak temp. - min. temp.) & 29.4 & 32.8 & 35.0 \\
\hline \multicolumn{4}{|l|}{ Strain development } \\
\hline Induced strain (millionths) $\left(C_{t h}=9.9\right.$ millionths $/$ deg $\left.C, K_{f}=0.65, K_{R}=1.0\right)$ & 189 & 211 & 225 \\
\hline Strain capacity (millionths) & 80 & 80 & 80 \\
\hline Excess strain (millionths) & 109 & 131 & 145 \\
\hline \multicolumn{4}{|l|}{ Crack distribution (length of weir $=530 \mathrm{~m}$ ) (crack width $=4 \mathrm{~mm}$ ) } \\
\hline Axis length contraction $(\mathrm{mm})$ & 51 & 76 & 76 \\
\hline Number of cracks (Contraction/crack width) & 15 & 18 & 20 \\
\hline \multirow[t]{2}{*}{ Avg. crack spacing (m) (Weir length/number of cracks) } & 35 & 29 & 26 \\
\hline & \multicolumn{3}{|c|}{ Non-SI Units } \\
\hline \multicolumn{4}{|l|}{ Temperatures } \\
\hline RCC placement temperature (deg F) & 67 & 73 & 77 \\
\hline Adiabatic temperature rise (deg F) & 40 & 40 & 40 \\
\hline Peak internal temperature (deg F) (Place temp. + adiabatic temp.) & 107 & 113 & 117 \\
\hline Minimum temperature (deg F) (Based on annual temp. cycle) & 54 & 54 & 54 \\
\hline Differential temperature (deg F) (Peak temp. - min. temp.) & 53 & 59 & 63 \\
\hline \multicolumn{4}{|l|}{ Strain development } \\
\hline Induced strain (millionths) $\left(C_{t h}=5.5\right.$ millionths, $\left.K_{f}=0.65, K_{R}=1.0\right)$ & 189 & 211 & 225 \\
\hline Strain capacity (millionths) & 80 & 80 & 80 \\
\hline Excess strain (millionths) & 109 & 131 & 145 \\
\hline \multicolumn{4}{|l|}{ Crack distribution (length of weir $=1,740 \mathrm{ft}$.) $\quad$ (crack width=0.15 in.) } \\
\hline Axis length contraction (in.) & 2 & 3 & 3 \\
\hline Number of cracks (Contraction/crack width) & 15 & 18 & 20 \\
\hline Avg. crack spacing (ft) (Weir length/number of cracks) & 114 & 95 & 86 \\
\hline
\end{tabular}




\section{Temperature Analysis}

\section{Step 4: Mass gradient temperature analysis.}

a. Determine peak temperature. This is the sum of the initial RCC placement temperature and the adiabatic temperature rise:

$T_{p}+\Delta T_{a d}=18.9+22.2=41.1 \operatorname{deg} \mathrm{C}(106 \operatorname{deg} \mathrm{F})$

b. Determine ultimate stable temperature. Since the weir is a relatively thin MCS, it is expected to develop a stable temperature cycle, rather than a single stable temperature as in larger MCS's. The temperatures below were determined using the methodology in ACI 207.1R ("Temperature variation with depth"). Typical distance from the RCC surface to the interior was determined to be $4.6 \mathrm{~m}(15 \mathrm{ft})$. From ACI 207.1R figure:

$\frac{\text { Temp change through concrete }}{\text { Temp range at surface }}=0.24$

Temp range at surface

Temp range at surface $=24.8-7.3=17.5 \mathrm{deg} \mathrm{C}(31.5 \mathrm{deg} \mathrm{F})$

Temp change in concrete interior $=(0.24)(17.5 \mathrm{deg} \mathrm{C})$

$$
=4.2 \operatorname{deg} \mathrm{C}(7.6 \operatorname{deg} \mathrm{F})
$$

Temp range in concrete interior $=16.2 \pm 4.2 \mathrm{deg} \mathrm{C}(61.1 \pm 7.6 \mathrm{deg} \mathrm{F})$

$T_{\min }=$ minimum interior concrete temp.

$=16.2-4.2=12 \operatorname{deg} \mathrm{C}(53.5 \operatorname{deg} \mathrm{F})$

c. Determine long-term temperature change. This value is simply the peak RCC placement temperature less the stable minimum temperature. Assuming a May placement:

$\Delta T=T_{p}+T_{a d}-T_{\min }=41.1-11.9=29.2 \operatorname{deg} \mathrm{C}(53 \operatorname{deg} \mathrm{F})$

\section{Cracking Analysis}

\section{Step 5: Mass gradient cracking analysis.}

a. Determine mass gradient restraint conditions. Geometric restraint is conservatively set at $K_{R}=1.0$, since the structure has a low profile. Foundation restraint is set at $\mathrm{K}_{\mathrm{f}}=0.65$, since the base is not rock but rather compacted structural backfill. 
$K_{R}=1.0 \quad K_{f}=0.65$

b. Determine mass gradient thermal strain. The total induced strain in the mass RCC is the product of the long-term temperature change, the coefficient of thermal expansion, and restraint factors:

Total induced strain $=\left(C_{t h}\right)(\Delta T)\left(K_{R}\right)\left(K_{f}\right)$

$$
=(9.9 \text { millionths } / \operatorname{deg} \mathrm{C})(29.2 \operatorname{deg} \mathrm{C})(1.0)(0.65)
$$

$=189$ millionths

c. Estimate mass gradient cracking. The strain that results in cracking of the structure is the total induced strain less the tensile strain capacity $\left(\varepsilon_{s c}\right)$ of the material. The total crack width in the length of the structure is the cracking strain multiplied by the length of the structure. The estimated number of cracks are based on the assumed crack widths. Typical crack widths range from 0.002 to $5 \mathrm{~mm}$ ( 0.01 to 0.2 in.). The larger crack widths are typical of structures founded on flexible or yielding foundations. Since such a foundation exists here, a typical crack width of $4 \mathrm{~mm}$ (0.15 in.) was assumed:

Cracking strain $=$ total induced strain $-\varepsilon_{s c}=189-80=109$ millionths

Total crack width $=($ weir length $)($ cracking strain $)=(530 \mathrm{~m})(1,000$ $\mathrm{mm} / \mathrm{m})(109$ millionths $)=58 \mathrm{~mm}(2.3 \mathrm{in}$. $)$

Assumed crack widths $=4 \mathrm{~mm}(0.15$ in. $)$

Estimated cracks $=58 \mathrm{~mm} / 4 \mathrm{~mm}=15$ cracks

Estimated crack spacing $=530 \mathrm{~m} / 15$ cracks $=35 \mathrm{~m}(116 \mathrm{ft})$

Since contraction joints will be installed at $30-\mathrm{m}$ (100-ft) spacing, additional cracking is not expected. Occasional center cracks can be expected where conditions and restraint factors vary from those assumed.

\section{Conclusions and Recommendations}

\section{Conclusions}

Based on calculations similar to those shown above and on previous temperature analysis figures, and experience, the following conclusions were provided:

a. May placement schedule. RCC placement temperatures should be 19.4 to $21.1 \mathrm{deg} \mathrm{C}$ (67 to $70 \mathrm{deg} \mathrm{F}$ ) if aggregates are produced the preceding month. If aggregate processing is performed earlier, lower placement temperatures may result. Crack spacing in an unjointed structure is 
calculated to be $35 \mathrm{~m}(116 \mathrm{ft})$. The $30-\mathrm{m}(100-\mathrm{ft})$ contraction joint interval easily accommodates this volume change with joint widths of approximately $3 \mathrm{~mm}(0.13 \mathrm{in}$.).

b. June placement schedule. RCC placement temperatures should be 22.2 to $23.9 \operatorname{deg} \mathrm{C}$ ( 72 to $75 \mathrm{deg} \mathrm{F}$ ) if aggregates are produced the preceding month. If aggregate processing is performed earlier, lower placement temperatures may result. Crack spacing in an unjointed structure is calculated to be $29 \mathrm{~m}(97 \mathrm{ft})$. The $30-\mathrm{m}$ (100-ft) contraction joint interval just accommodates this volume change with joint widths of approximately $4 \mathrm{~mm}(0.15 \mathrm{in}$.).

c. July and August placement schedules. RCC placement temperatures should be 23.9 to $26.7 \mathrm{deg} \mathrm{C}$ ( 75 to $80 \mathrm{deg} \mathrm{F}$ ) if aggregates are produced the preceding month. If aggregate processing is performed earlier, lower placement temperatures may result. Crack spacing in an unjointed structure is calculated to be $26 \mathrm{~m}(87 \mathrm{ft})$. The $30-\mathrm{m}$ (100-ft) contraction joint interval is not quite adequate to accommodate this volume change at a fixed joint width of $4 \mathrm{~mm}$ ( $0.15 \mathrm{in}$.). Joint widths will increase or additional cracking will occur.

d. Since the anticipated period for RCC construction is during the late spring or summer months, the 29.4-deg C (85-deg F) placement temperature limitation specified could be a factor if unusually hot weather should occur. Under normal weather conditions, uncontrolled placing temperatures should range from 19.4 to $24.4 \mathrm{deg}$ C (67 to $76 \mathrm{deg}$ F) from May through August. In the event that abnormal weather causes average daily ambient temperature in excess of $29.4 \mathrm{deg}$ C ( $85 \mathrm{deg}$ F), RCC temperatures could exceed $29.4 \mathrm{deg}$ C ( $85 \mathrm{deg}$ F). Aggregate stockpile cooling and possible use of batch water chillers would be the most expedient solutions to this problem.

e. The current joint spacing of $30 \mathrm{~m}(100 \mathrm{ft})$ is adequate for RCC placements during May and June. Later placements in July and August will result in occasional centerline cracking of monoliths, possibly in as many as three or four monoliths. Lesser cracking is very probable since material properties were conservatively estimated.

f. During construction, RCC placement temperature was maintained at about $29.4 \operatorname{deg} \mathrm{C}$ ( $85 \mathrm{deg} \mathrm{F}$ ), and transverse contraction joints were spaced at $30-\mathrm{m}(100-\mathrm{ft})$ intervals. All the contraction joints opened properly during the first few months after construction, with no intermediate cracking. Crack widths varied from 1.5 to $6 \mathrm{~mm}(0.06$ to 0.25 in.).

g. Several material properties were applied conservatively. Small reductions of adiabatic temperature rise and coefficient of thermal expansion and small increases in tensile strain capacity could improve thermal cracking performance. If each of these properties were individually changed 10 percent, summer crack spacing would be around $30 \mathrm{~m}(100 \mathrm{ft})$. If 
these changes were cumulative, crack spacing would be over $40 \mathrm{~m}$ $(130 \mathrm{ft})$.

\section{Recommendations}

a. Maintain current 29.4-deg C (85-deg F) maximum placement temperature limitation. Consider allowing minor temperature violations so long as the time-weighted average of the RCC placement temperature is maintained below $26.7 \operatorname{deg} \mathrm{C}(80 \operatorname{deg} \mathrm{F})$.

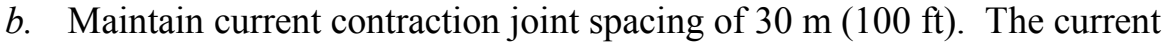
contraction joint configuration of $30-\mathrm{m}(100-\mathrm{ft})$ joint intervals is sufficient to accommodate the total anticipated axial contractions due to cement induced temperature fluctuations during May and June placements. Some transverse cracking will occur during the July and August placement schedule; however, the extent of cracking should not be of concern considering the upstream backfill and the frequency of use. 


\section{Level 2 Thermal Analysis}

\section{General}

This chapter summarizes typical steps in a Level 2 mass gradient and surface gradient thermal analysis of a MCS. Two examples of the procedure are presented in Chapters 5 and 6. Example 1 (Chapter 5) covers a simple onedimensional (1-D) (strip model) finite element (FE) mass gradient and surface gradient thermal analysis. Example 2 (Chapter 6) presents a more complex twodimensional (2-D) mass gradient and surface gradient thermal analysis. This procedure uses FE methodology only because of the widespread availability and use of this technology. Although other methods of conducting a Level 2 thermal analysis are available, these procedures are most commonly used.

\section{Input Properties and Parameters}

The level of data detail depends on the complexity of a Level 2 thermal analysis. Parametric analysis should be routinely conducted at this level, using a rational number and range of input properties and parameters to evaluate likely thermal problems.

Step 1: Determine ambient conditions. Level 2 analyses may be based upon average monthly temperatures for a less complex analysis, or on average expected daily temperatures for each month for a complex analysis. Wind velocity data are generally needed for computing heat transfer coefficients. Extreme ambient temperature input conditions, such as cold fronts and sudden cold reservoir temperatures, can and should be considered when appropriate to identify possible problems.

Step 2: Determine material properties. Thermal properties required for FE thermal analysis include thermal conductivity, specific heat, adiabatic temperature rise of the concrete mixture(s), and density of the concrete and foundation materials. Coefficient of thermal expansion is required for computing induced strain from temperature differences. Moduli of elasticity of concrete and foundation materials are required for determination of foundation restraint factors. Tensile strain capacity test results are important for cracking evaluation. When tensile strain capacity data are not available, the methodology presented in Appendix A may be used to estimate probable tensile strain capacity performance of the 
concrete. Creep test results are necessary to determine the sustained modulus of elasticity (or an estimate of $E_{\text {sus }}$ is made) if stress-based cracking analysis is used.

Step 3: Determine construction parameters. Construction parameters must be compiled which include information about concrete placement temperature, structure geometry, lift height, construction start dates, concrete placement rates, and surface treatment such as formwork and insulation that are possible during construction of the MCS. To determine concrete placement temperature, a first approximation is to assume that concrete placement temperatures directly parallel the mean daily ambient temperature curve for the project site. Actual placement temperature data from other projects can be used for prediction, modified by ambient temperature data differences between the different sites. The temperature of the aggregate stockpiles may change more slowly than does the ambient temperature in the spring and fall. Hence, placement temperatures during spring months may lag several degrees below mean daily air temperatures, while placement temperatures in the fall may lag several degrees above mean daily air temperatures.

a. Surface heat transfer coefficients. Surface heat transfer coefficients (film coefficients) are applied to all exposed surfaces to represent the convection heat transfer effect between a fluid (air or water) and a concrete surface, in addition to the conduction effects of formwork and insulation. The following equations are taken from the American Society of Heating, Refrigerating and Air Conditioning Engineers (ASHRAE) (1977). These equations may be used for computing the surface heat transfer coefficients to be included in any of the FE codes for modeling convection.

For surfaces without forms, the coefficients should be computed based on the following:

$$
\begin{aligned}
\text { for } V & <17.5 \mathrm{~km} / \mathrm{h}(10.9 \mathrm{mph}): h=a V^{b} \mathrm{~W} / \mathrm{m}^{2} \\
& -K\left(\text { Btu } / \text { day }-i n .^{2}-\mathrm{deg} . \mathrm{F}\right) \\
\text { for } V & >17.5 \mathrm{~km} / \mathrm{h}(10.9 \mathrm{mph}): h=\mathrm{c}+\mathrm{d}(V) \mathrm{W} / \mathrm{m}^{2} \\
& -K\left(\text { Btu } / \text { day }- \text { in. }^{2}-\mathrm{deg} . \mathrm{F}\right)
\end{aligned}
$$

where

$$
\begin{aligned}
& V=\text { wind velocity in } \mathrm{km} / \mathrm{h}(\mathrm{mph}) \\
& h=\text { surface heat transfer coefficient or film coefficient } \\
& a=2.6362(0.1132) \\
& b=0.8(0.8) \\
& c=5.622(0.165) \\
& d=1.086(0.0513)
\end{aligned}
$$


The wind velocity may be based on monthly average wind velocities at the project site. Data can be obtained for a given location and then generalized over a period of several months for input into the analysis.

b. Forms and insulation. If forms and insulation are in place, then the values for $h$ computed in the equations above should be modified as follows:

$$
\begin{aligned}
& h^{\prime}=\frac{1}{\left(\frac{b}{k}\right)_{\text {formwork }}+\left(\frac{b}{k}\right)_{\text {insulation }}+\left(\frac{1}{h}\right)} \\
& h^{\prime}=\frac{1}{R_{\text {formwork }}+R_{\text {insulation }}+\left(\frac{1}{h}\right)}
\end{aligned}
$$

where

$$
\begin{aligned}
h^{\prime} & =\text { revised surface heat transfer coefficient } \\
b & =\text { thickness of formwork or insulation } \\
k & =\text { conductivity of formwork or insulation } \\
R_{\text {formwork }} & =R \text { value of formwork } \\
R_{\text {insulation }} & =R \text { value of insulation }
\end{aligned}
$$

\section{Temperature Analysis}

\section{Step 4: Prepare temperature model.}

a. Various temperature analysis methods suitable for Level 2 thermal analysis are discussed in EM 1110-2-2000. Either step-by-step integration methods or FE models may be used for Level 2 temperature analysis or mass and surface gradients. If step-by-step integration methods are used, the computation or numerical model should be programmed into a personal computer spreadsheet. The decision on whether to use FE 1-D strip models or 2-D section analysis is generally based on complexity of the structure, complexity of the construction conditions, and on the stage of project design. Often 1-D strip models are used first for parametric analyses to identify concerns for more detailed 2-D analysis.

b. Compute temperature histories. Once computed, temperature data should be tabulated as temperature-time histories and temperature distributions to obtain good visual representations of temperature distribution in the structure. Hollenbeck and Tatro (2000) provide examples of temperature distribution plots. Appropriate locations can then be selected for 
temperature distribution histories at which mass gradient and surface gradient analyses will be conducted.

Step 5: Mass gradient temperature analysis. Temperature-time histories, showing the change in temperature with time at specific locations after placing, are generally used to calculate temperature differences for mass gradient cracking analysis. Temperature differences for mass gradient cracking analysis are generally computed as the difference between the peak concrete temperatures and the final stable temperatures that the cooling concrete will eventually reach.

Step 6: Surface gradient temperature analysis. The objective of surface gradient temperature analysis is to determine at desired critical locations the variation of surface temperatures with depth and with time. This can be performed effectively with 1-D strip models or with 2-D analysis. Thinner sections may require temperature distributions entirely across the structure, while large sections often only require temperature to be evaluated to some depth where temperature changes are relatively slow. Ideally, temperature distribution histories are generated for a single lift, tabulated from one surface to the other (or a stable interior) with each distribution representing temperatures for a specific time after placement.

\section{Cracking Analysis}

Step 7: Mass gradient cracking analysis. The mass gradient temperature differences are used with $C_{t h}$ and restraint factors $\left(K_{f}\right.$ and $\left.K_{R}\right)$ to evaluate mass gradient cracking potential, using Equation 1. Computed mass gradient strains are compared against tensile strain capacity to evaluate cracking potential. For a stress-based mass gradient cracking analysis, the sustained modulus of elasticity corresponding to the time frame of the analysis is used to convert strains calculated by Equation 1 to stresses. The use of the sustained modulus allows for the relief of temperature-induced stress due to creep. These stresses are compared to the tensile strength of the concrete at the appropriate age to determine where and when cracking may occur.

Step 8: Surface gradient cracking analysis. Surface gradient cracking analysis is based on higher temperature differences in the surface concrete compared to the more slowly cooling interior which creates areas of tension in the surface to some depth, $H$. Tensile strain is calculated based on $C_{t h}$, the temperature difference at some depth of interest, and the degree of restraint based on $H$.

a. Temperature differences are calculated using as a basis the temperature when the concrete first begins hardening, rather than a peak temperature as used in mass gradient computations. These temperature differences, with time and depth, allow determination of tensile and compression zones near the concrete surfaces. The point at which tension and compression zones balance is considered a stress-strain free boundary (located at $H$ from the surface) used to compute restraint for surface gradient 
analysis. This point is generally calculated by evaluating temperature differences at depth with respect to temperature differences at the surface.

$b$. Reference or initial temperatures for a surface gradient analysis are defined as the temperatures in the structure at the time when the concrete begins to harden and material properties begin to develop. Generally, this time is established at concrete ages of $0.25,0.5$, or 1.0 day. This age is dependent upon the rate at which the concrete achieves final set, the rate of subsequent cement hydration, and the properties of the mixture. For very lean concrete mixtures at normal temperature, a baseline time of 1.0 day may be reasonable. Mixtures that gain strength more rapidly at early ages may be better approximated by an earlier reference time of 0.25 or 0.33 day (6 or 8 hours).

c. Internal restraint factors, $K_{R}$, are computed using Equation 4.1 or 4.2 in ACI 207.2R, depending upon the ratio of $L / H$, where $L$ is the horizontal distance between joints or ends of the structure, and $H$ is the depth of the tension block. Induced tensile strains are computed at each analysis time from Equation 1 using the coefficient of thermal expansion, the temperature differences between the surface and interior concrete, and the computed internal restraint factors. $K_{R}$ is assumed to be equal to 1.0 for internal restraint conditions. These strains are compared with slow-load tensile strain capacity (selected or tested to correspond to the time that strains are generated) to determine cracking potential.

d. Stress-based surface gradient cracking analysis is often handled in a slightly different way, particularly in the way creep is accounted for in the analysis. Commonly, incremental temperature differences at different depths and times are computed. These incremental temperature differences are converted to incremental stresses, including creep effects, using the $C_{t h}, E_{s u s}$, and $K_{R}$. The incremental stresses generated during each time period are summed to determine the cumulative tensile stress in the surface concrete at various depths. These stresses are compared to the tensile strength of the concrete at the appropriate age to determine cracking potential.

\section{Conclusions and Recommendations}

Conclusions and recommendations typically include expected maximum temperatures for starting placement in different seasons, expected transverse and longitudinal cracking without temperature or other controls, recommended concrete placement temperature limitations, anticipated concrete precooling measures, need for adjustment in concrete geometry, properties, joint spacing, and the sensitivity of the thermal analysis to changes in parameters. Typical temperature control measures evaluated might include reduced lift heights, use of insulated forms, and reduction in mix cement content. The potential for thermal shock may be addressed. In addition, recommendations for further or more advanced thermal analysis should be provided and justified. 


\section{Level 2 Analysis, American River RCC Gravity Dam}

\section{General}

An example of a 1-D mass gradient and a surface gradient analysis in a Level 2 thermal study of an MCS is presented below. This example is based on preliminary 1-D analyses performed during feasibility studies on a proposed large flood-control RCC gravity dam on the American River in California. This dam was planned to be $146 \mathrm{~m}(480 \mathrm{ft})$ high, $792 \mathrm{~m}(2,600 \mathrm{ft})$ long, with a downstream face slope of $0.7 \mathrm{H}: 1.0 \mathrm{~V}$.

The 1-D analysis was used as a screening tool only to provide preliminary evaluation of several concerns and to develop information for more detailed analyses. These studies were conducted to ascertain the general extent of thermal cracking (cracking due to mass thermal gradients and surface thermal gradients), for guidance in selecting an appropriate joint spacing to accommodate transverse thermal cracking, to evaluate the possibility of longitudinal cracking in the structure, and for early planning and cost-estimating purposes. Figure 1 illustrates the 1-D strip models employed in this analysis and the overall dam proportions.

FE analysis in this study was used only to determine temperature history for the various schedule alternatives, using the FORTRAN program "THERM" (Wilson 1968). Stresses were determined by manual computational methods, based on temperature change computed by the FE temperature analysis, the coefficient of thermal expansion, the sustained modulus of elasticity, and the degree of restraint. To account for stress relief due to creep and because the mass concrete modulus of elasticity is very low at early ages, the analysis is segmented into several time spans, 1 to 3 days, 3 to 7 days, and 7 to 28 days. This allows use of changing material properties (modulus and creep) to be used for each time span, as well as changing $h$ and $H$ dimensions of the surface gradient tension block with time. Consequently, temperature changes were determined for each time span.

\section{Input Properties and Parameters}

At this early stage in the planning process, many of the details of the structure, materials performance, and placement constraints have not been determined and 


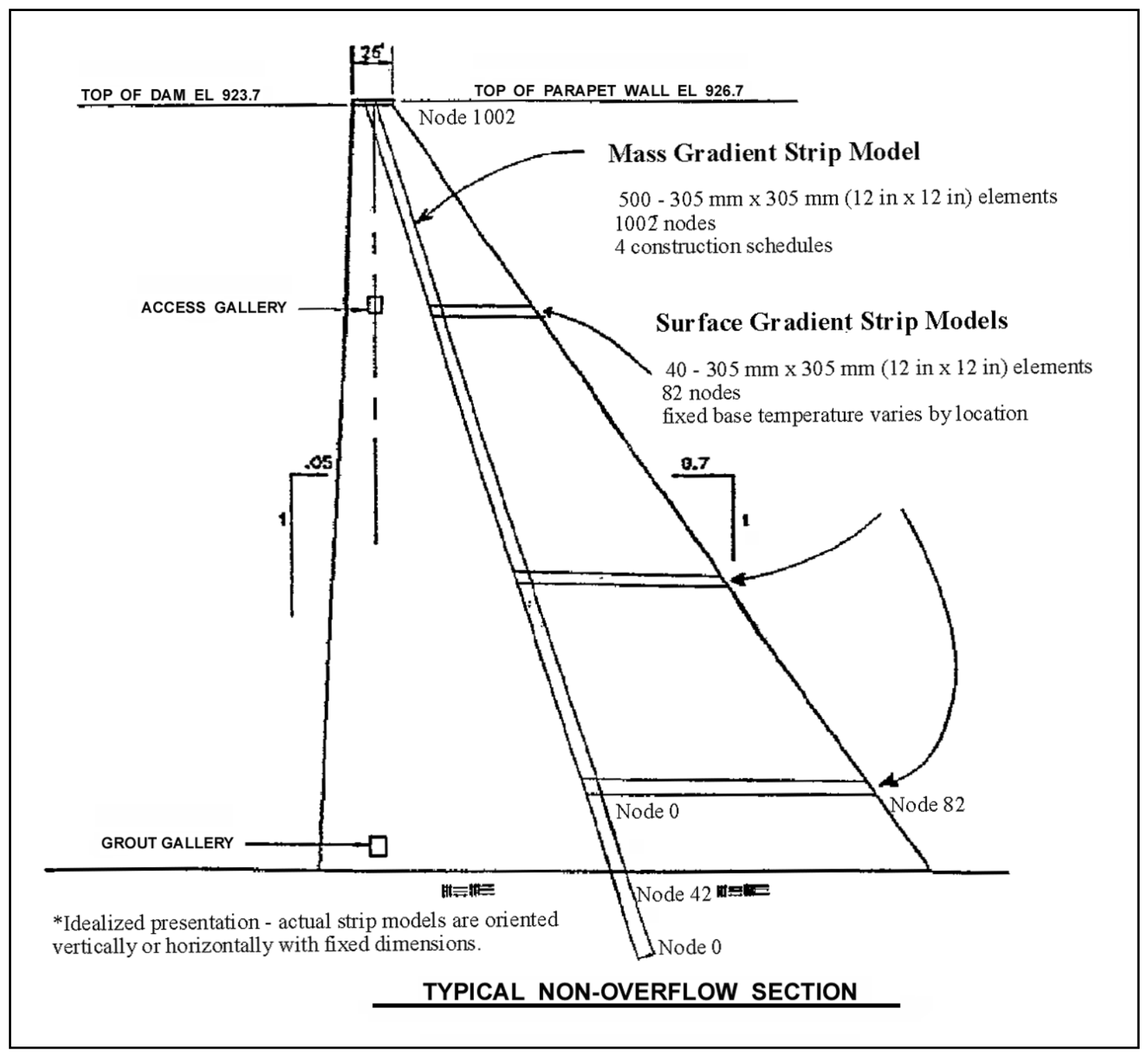

Figure 1. FE strip models

can only be approximated. It was decided that it would be prudent to make a reasonable estimate of those unknown parameters and limit the study to evaluating the effects of variations of only a few items. In this study, those items subject to variations are certain material properties and the placing schedule.

Step 1: Determine ambient conditions. Ambient air temperature data were produced from National Oceanic and Atmospheric Administration (NOAA) local climatological data. From these data, seven series of daily air temperature curves (shown in Figure 2) were developed, each representing the daily temperature cycle for one or more months. No data were available on how temperatures vary during each day. The curves are an estimate of the daily profile as it varies for each month throughout the year. No means of incorporating heat from solar gain was included in this analysis. 


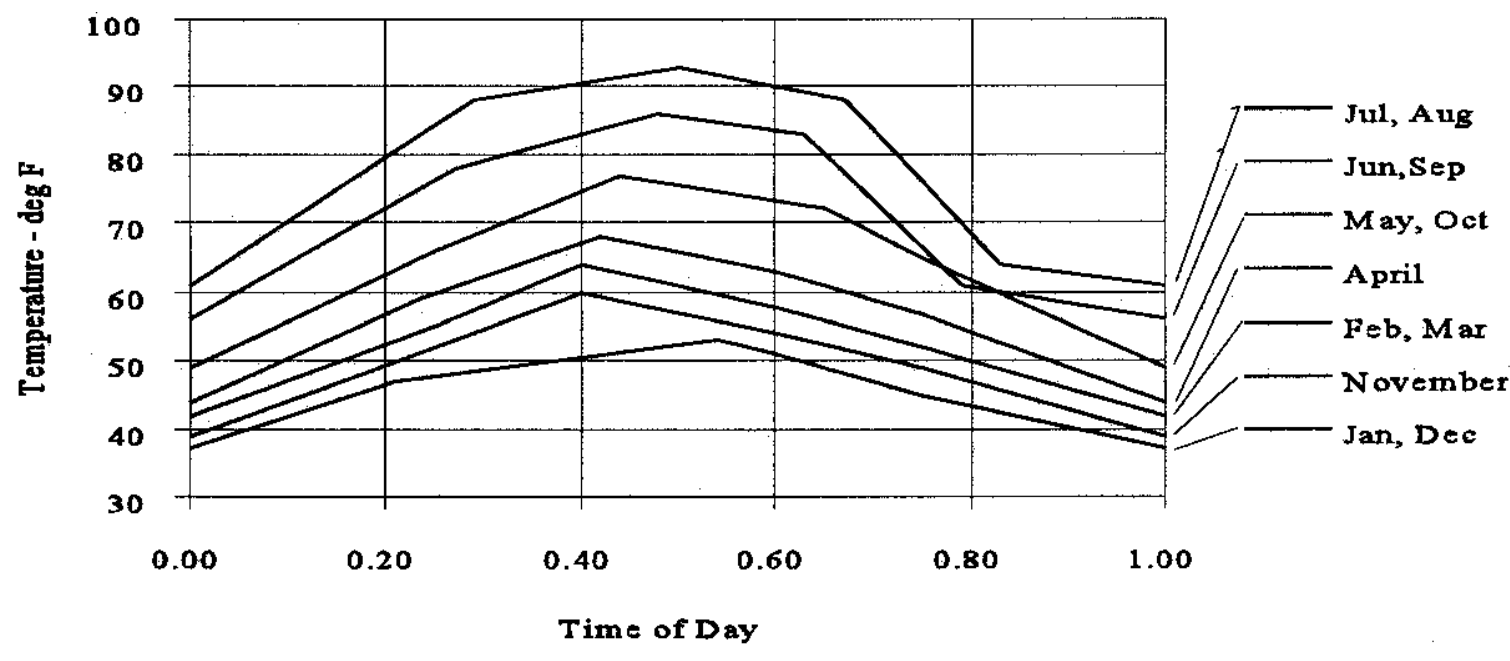

Figure 2. Daily ambient temperature cycles

Step 2: Determine material properties. Table 5 summarizes the applicable thermal and elastic properties of the materials considered for use in the structure. Most of the properties for the RCC and the foundation rock were estimated, or were the product of laboratory testing. Approximated values used for the modulus of elasticity, tensile strength, and creep rate are shown in Figure 3. Three materials were utilized for the analysis of the foundation and the dam construction. The foundation rock was assumed to provide thermal behavior similar to the amphibolite aggregate. The first 200 lifts of the dam use an RCC mixture with damsite alluvium aggregates. The remaining 280 lifts utilize an RCC mixture with amphibolite (metamorphosed sandstone) aggregate from the damsite.

\begin{tabular}{|c|c|c|c|}
\hline \multicolumn{4}{|c|}{$\begin{array}{l}\text { Table } 5 \\
\text { RCC Material Properties for Mixtures }\end{array}$} \\
\hline Property & Units & Damsite Alluvium & Damsite Amphibolite \\
\hline Coefficient of thermal expansion $\left(C_{t h}\right)^{1}$ & $\begin{array}{l}\text { millionths/deg C } \\
\text { (millionths/deg F) }\end{array}$ & $\begin{array}{l}7.2 \\
(4.00) \\
\end{array}$ & $\begin{array}{l}6.9 \\
(3.86) \\
\end{array}$ \\
\hline Thermal conductivity $(K)$ & W/m-K (Btu/ft-hr-deg F) & $2.42(1.4)$ & $2.77(1.6)$ \\
\hline Diffusivity $\left(h^{2}\right)$ & $\mathrm{m}^{2} / \mathrm{hr}\left(\mathrm{ft}^{2} / \mathrm{hr}\right)$ & $0.038(0.041)$ & $0.0039(0.042)$ \\
\hline Specific heat $\subset$ & $\mathrm{kJ} / \mathrm{kg}-\mathrm{K}(\mathrm{Btu} / \mathrm{lb}-\mathrm{deg} \mathrm{F})$ & $0.92(0.22)$ & $0.92(0.22)$ \\
\hline Cement content $^{1}$ & $\mathrm{~kg} / \mathrm{m}^{2}$ (lb/cy) & $107(180)$ & $107(180)$ \\
\hline Flyash content $^{1}$ & $\mathrm{~kg} / \mathrm{m}^{2}$ (Ib/cy) & $53(90)$ & $53(90)$ \\
\hline Adiabatic temperature rise $\left(\Delta T_{a d}\right)$ & $\operatorname{deg} C(\operatorname{deg} F)$ & $15(27)$ & $15(27)$ \\
\hline Density $^{1}$ & $\mathrm{~kg} / \mathrm{m}^{3}\left(\mathrm{Ib} / \mathrm{ft}^{3}\right)$ & $2,483(155)$ & $2,643(165)$ \\
\hline Tensile strain cap. $\left(\varepsilon_{\mathrm{tc}}\right) @ 7-90$ days & millionths & 100 & 100 \\
\hline
\end{tabular}




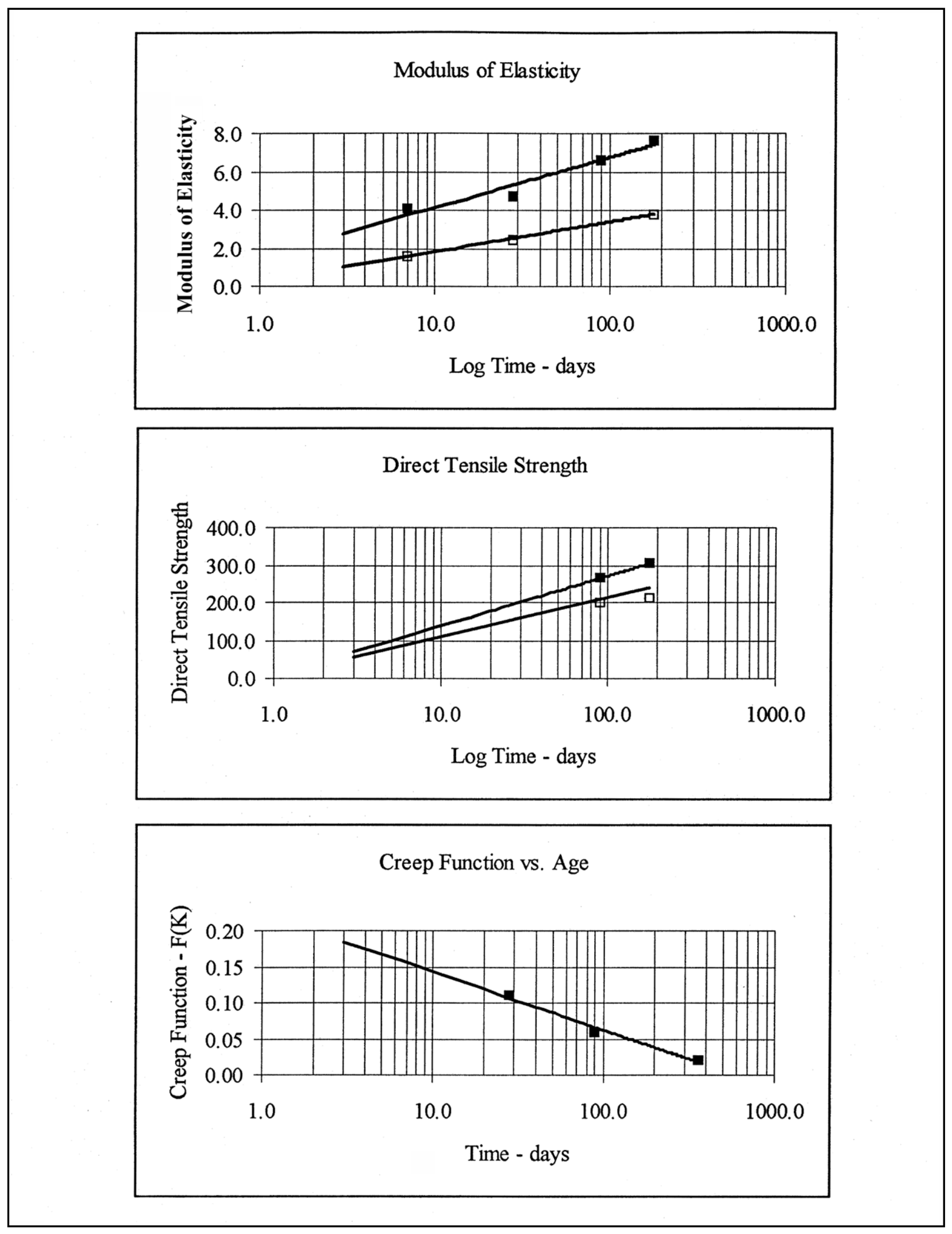

Figure 3. Estimated elastic and creep properties 


\section{Step 3: Determine construction parameters.}

a. Construction start dates. To evaluate the effects of different construction start dates, the placement of concrete was evaluated during four time intervals. The initiation of RCC placements was set at 1 January, 1 April, $1 \mathrm{July}$, and 1 October of each year for the mass gradient analysis. For the surface gradient analysis, a 1 January start date was assumed.

b. Concrete placing temperature. The temperature of the concrete aggregates has the greatest influence on the initial temperature of the fresh RCC. Because of the low volume of mix water, and the minor temperature differential of the water compared to the aggregate, the water temperature has a much less significant effect on overall temperature. Figure 4 provides the basis for the placing temperatures used in this study. Since aggregate production will be done concurrently with RCC placement and regional temperatures tend to be moderate, stockpile temperatures should closely parallel the average monthly ambient temperatures. Some heat is added because of screening, crushing, and transportation activities, as shown in Figure 4, based on experience.

c. Placement assumptions. The RCC structure will be composed of two RCC mixtures, as previously described. The RCC placement will be in a 610-mm (24-in.) lift operation. The FE model is dimensioned having elements $305 \mathrm{~mm}$ (12 in.) in height. This allows future evaluations of 305-mm (12-in.) placing schemes, if desired. The RCC placement was assumed to occur on a schedule of 6 days per week, 20 hours per day, for the duration of the placement.

\section{Temperature Analysis}

\section{Step 4: Prepare temperature model (FE).}

a. The FORTRAN FE program "THERM," developed originally by Wilson (Wilson 1968), was used on a PC for the temperature analysis in this example. An Excel spreadsheet was used for development of an input file for THERM. Output nodal temperatures were imported into Excel spreadsheets for further analysis of cracking and graphical output. The FE grid, termed the mesh, provides more realistic results as it more accurately simulates the geometry of the structure. Since 1-D models (strip models) were used for the mass gradient analysis, heat only flowed vertically in or out of the model. Lateral heat flow in the upstream or downstream direction was not modeled. It is anticipated that actual heat dissipation in the dam over the long term will be at a more rapid rate than the model predicts. Since RCC construction is the continuous placement of relatively thin lifts, it is best modeled with elements of a height equivalent to the lift height or less. Unfortunately, since the American River Dam is a very massive structure, a mesh that provides ample detail would be monumental. A mesh of this magnitude is not necessary for the extent of evaluations to be done at this stage. Consequently, it was determined 


\begin{tabular}{|c|c|c|c|c|c|c|c|c|c|c|}
\hline Month & $\begin{array}{l}\text { Mean } \\
\text { Temp }\end{array}$ & $\begin{array}{c}\text { Mean } \\
\text { Annual }\end{array}$ & Diff & 2/3 Diff & Sub Total & $\begin{array}{l}\text { Crush } \\
\text { Add }\end{array}$ & $\begin{array}{l}\text { Stock } \\
\text { Temp }\end{array}$ & $\begin{array}{c}\text { Mixing } \\
\text { Add }\end{array}$ & $\begin{array}{l}\text { Trans } \\
\text { Add }\end{array}$ & $\begin{array}{l}\text { Final } \\
\text { Terop }\end{array}$ \\
\hline & $\begin{array}{c}\operatorname{deg} C \\
(\operatorname{deg} F)\end{array}$ & $\begin{array}{c}\operatorname{deg} C \\
(\operatorname{deg} F)\end{array}$ & $\begin{array}{c}\operatorname{deg} C \\
(\operatorname{deg} F)\end{array}$ & $\begin{array}{c}\operatorname{deg} C \\
(\operatorname{deg} F)\end{array}$ & $\begin{array}{c}\mathrm{deg} C \\
(\operatorname{deg})\end{array}$ & $\begin{array}{c}\operatorname{deg} C \\
\text { (deg })\end{array}$ & $\begin{array}{c}\mathrm{deg} C \\
(\mathrm{deg} F)\end{array}$ & $\begin{array}{c}\text { degc } \\
\text { (degr) }\end{array}$ & $\begin{array}{r}\operatorname{deg} C \\
(\operatorname{deg} F)\end{array}$ & $\begin{array}{c}\mathrm{degC} \\
(\mathrm{deg})\end{array}$ \\
\hline Jan & $\begin{array}{c}7.1 \\
(44.8)\end{array}$ & $\begin{array}{c}15.5 \\
(60.0)\end{array}$ & $\begin{array}{c}-8.4 \\
(-15.2)\end{array}$ & $\begin{array}{c}-5.6 \\
(-10.1)\end{array}$ & $\begin{array}{c}9.9 \\
(49.9)\end{array}$ & $\begin{array}{c}1.1 \\
(2.0)\end{array}$ & $\begin{array}{c}11.1 \\
(51.9)\end{array}$ & $\begin{array}{c}1.1 \\
(2.0)\end{array}$ & $\begin{array}{r}-0.6 \\
(-1.0)\end{array}$ & $\begin{array}{l}11.7 \\
(53)\end{array}$ \\
\hline Feb & $\begin{array}{c}9.2 \\
(48.6)\end{array}$ & $\begin{array}{c}15.5 \\
(60.0)\end{array}$ & $\begin{array}{c}-6.3 \\
(-11.4)\end{array}$ & $\begin{array}{c}-4.2 \\
(-7.6)\end{array}$ & $\begin{array}{c}11.3 \\
(52.4)\end{array}$ & $\begin{array}{c}1.1 \\
(2.0)\end{array}$ & $\begin{array}{c}12.4 \\
(54.4)\end{array}$ & $\begin{array}{c}1.1 \\
(2.0)\end{array}$ & 0 & $\begin{array}{l}13.3 \\
(56)\end{array}$ \\
\hline Mar & $\begin{array}{c}10.5 \\
(50.9)\end{array}$ & $\begin{array}{c}15.5 \\
(60.0)\end{array}$ & $\begin{array}{c}-5.1 \\
(-9.1)\end{array}$ & $\begin{array}{c}-3.4 \\
(-6.1)\end{array}$ & $\begin{array}{c}12.2 \\
(53.9)\end{array}$ & $\begin{array}{c}1.1 \\
(2.0)\end{array}$ & $\begin{array}{c}13.3 \\
(55.9)\end{array}$ & $\begin{array}{c}1.1 \\
(2.0)\end{array}$ & $\begin{array}{c}0.6 \\
(1.0)\end{array}$ & $\begin{array}{l}15.0 \\
(59)\end{array}$ \\
\hline Apr & $\begin{array}{c}13.2 \\
(55.8)\end{array}$ & $\begin{array}{c}15.5 \\
(60.0)\end{array}$ & $\begin{array}{c}-2.3 \\
(-4.2)\end{array}$ & $\begin{array}{c}-1.6 \\
(-2.8)\end{array}$ & $\begin{array}{c}14.0 \\
(57.2)\end{array}$ & $\begin{array}{c}1.1 \\
(20)\end{array}$ & $\begin{array}{c}15.1 \\
(59.2)\end{array}$ & $\begin{array}{c}1.1 \\
(2.0)\end{array}$ & $\begin{array}{c}0.6 \\
(1.0)\end{array}$ & $\begin{array}{l}16.7 \\
(62)\end{array}$ \\
\hline May & $\begin{array}{c}17.0 \\
(62.6)\end{array}$ & $\begin{array}{c}15.5 \\
(60.0)\end{array}$ & $\begin{array}{c}1.4 \\
(2.6)\end{array}$ & $\begin{array}{c}0.9 \\
(11.7)\end{array}$ & $\begin{array}{c}16.5 \\
(61.7)\end{array}$ & $\begin{array}{c}1.1 \\
(2.0)\end{array}$ & $\begin{array}{c}17.6 \\
(63.7)\end{array}$ & $\begin{array}{c}1.1 \\
(2.0)\end{array}$ & $\begin{array}{c}1.1 \\
(2,0)\end{array}$ & $\begin{array}{l}20.0 \\
(68)\end{array}$ \\
\hline Jü & $\begin{array}{c}21.4 \\
(70.5)\end{array}$ & $\begin{array}{c}15.5 \\
(60.0)\end{array}$ & $\begin{array}{c}5.8 \\
(10.5)\end{array}$ & $\begin{array}{c}3.9 \\
(7.0)\end{array}$ & $\begin{array}{c}19.4 \\
(67.0)\end{array}$ & $\begin{array}{c}1.1 \\
(2.0)\end{array}$ & $\begin{array}{c}20.6 \\
(69.0)\end{array}$ & $\begin{array}{c}1.1 \\
(2.0)\end{array}$ & $\begin{array}{c}1.1 \\
(2.0)\end{array}$ & $\begin{array}{l}22.8 \\
(73)\end{array}$ \\
\hline Jul & $\begin{array}{c}25,1 \\
(77,2)\end{array}$ & $\begin{array}{c}15.5 \\
(60.0)\end{array}$ & $\begin{array}{c}9.6 \\
(17.2)\end{array}$ & $\begin{array}{c}6.4 \\
(11.5)\end{array}$ & $\begin{array}{c}21.9 \\
(71.5)\end{array}$ & $\begin{array}{c}1.1 \\
(2.0)\end{array}$ & $\begin{array}{c}23.1 \\
(73.5)\end{array}$ & $\begin{array}{c}1.1 \\
(2.0)\end{array}$ & $\begin{array}{c}1.7 \\
(3.0)\end{array}$ & $\begin{array}{l}25.6 \\
(78)\end{array}$ \\
\hline Ang & $\begin{array}{c}24.5 \\
(76.1)\end{array}$ & $\begin{array}{c}15.5 \\
(60.0)\end{array}$ & $\begin{array}{c}8.9 \\
(16.1)\end{array}$ & $\begin{array}{c}5.9 \\
(10.7)\end{array}$ & $\begin{array}{c}21.5 \\
(70.7)\end{array}$ & $\begin{array}{c}1.1 \\
(20)\end{array}$ & $\begin{array}{c}22.6 \\
(72.7)\end{array}$ & $\begin{array}{c}1.1 \\
(2.0)\end{array}$ & $\begin{array}{c}1.7 \\
(3.0)\end{array}$ & $\begin{array}{l}25.6 \\
(78)\end{array}$ \\
\hline Sep & $\begin{array}{c}22.1 \\
(71.8)\end{array}$ & $\begin{array}{c}15.5 \\
(60.0)\end{array}$ & $\begin{array}{c}6.5 \\
(11.8)\end{array}$ & $\begin{array}{c}4.4 \\
(7.9)\end{array}$ & $\begin{array}{c}19.9 \\
(67.9)\end{array}$ & $\begin{array}{c}1.1 \\
(2.0)\end{array}$ & $\begin{array}{c}21.1 \\
(69.9)\end{array}$ & $\begin{array}{c}1.1 \\
(2.0)\end{array}$ & $\begin{array}{c}1.1 \\
(2.0)\end{array}$ & $\begin{array}{l}23.3 \\
(74)\end{array}$ \\
\hline Oct & $\begin{array}{c}17.4 \\
(63.4)\end{array}$ & $\begin{array}{c}15.5 \\
(60.0)\end{array}$ & $\begin{array}{c}1.9 \\
(3.4)\end{array}$ & $\begin{array}{c}1.3 \\
(2.3)\end{array}$ & $\begin{array}{c}16.8 \\
(62.3)\end{array}$ & $\begin{array}{c}1.1 \\
(2.0)\end{array}$ & $\begin{array}{c}17.9 \\
(64.3)\end{array}$ & $\begin{array}{c}1.1 \\
(2.0)\end{array}$ & $\begin{array}{c}0.6 \\
(1.0)\end{array}$ & $\begin{array}{l}19.4 \\
(67)\end{array}$ \\
\hline Nov & $\begin{array}{c}11.5 \\
(52.7)\end{array}$ & $\begin{array}{c}15.5 \\
(60.0)\end{array}$ & $\begin{array}{c}-4.1 \\
(-7.3)\end{array}$ & $\begin{array}{c}-2.7 \\
(-4.9)\end{array}$ & $\begin{array}{c}12.8 \\
(55.1)\end{array}$ & $\begin{array}{c}1.1 \\
(2.0)\end{array}$ & $\begin{array}{c}13.9 \\
(57,1)\end{array}$ & $\begin{array}{c}1.1 \\
(2.0)\end{array}$ & 0 & $\begin{array}{l}15.0 \\
(59)\end{array}$ \\
\hline Dec & $\begin{array}{c}7.7 \\
(45.9)\end{array}$ & $\begin{array}{c}15.5 \\
(60.0)\end{array}$ & $\begin{array}{c}-7.8 \\
(-14.1)\end{array}$ & $\begin{array}{c}-5.2 \\
(-9.4)\end{array}$ & $\begin{array}{c}10.3 \\
(50.6)\end{array}$ & $\begin{array}{c}1.1 \\
(2.0)\end{array}$ & $\begin{array}{c}11.4 \\
(52.6)\end{array}$ & $\begin{array}{c}1.1 \\
(2.0)\end{array}$ & $\begin{array}{c}-0.6 \\
(-1.0)\end{array}$ & $\begin{array}{l}12.2 \\
(54)\end{array}$ \\
\hline
\end{tabular}

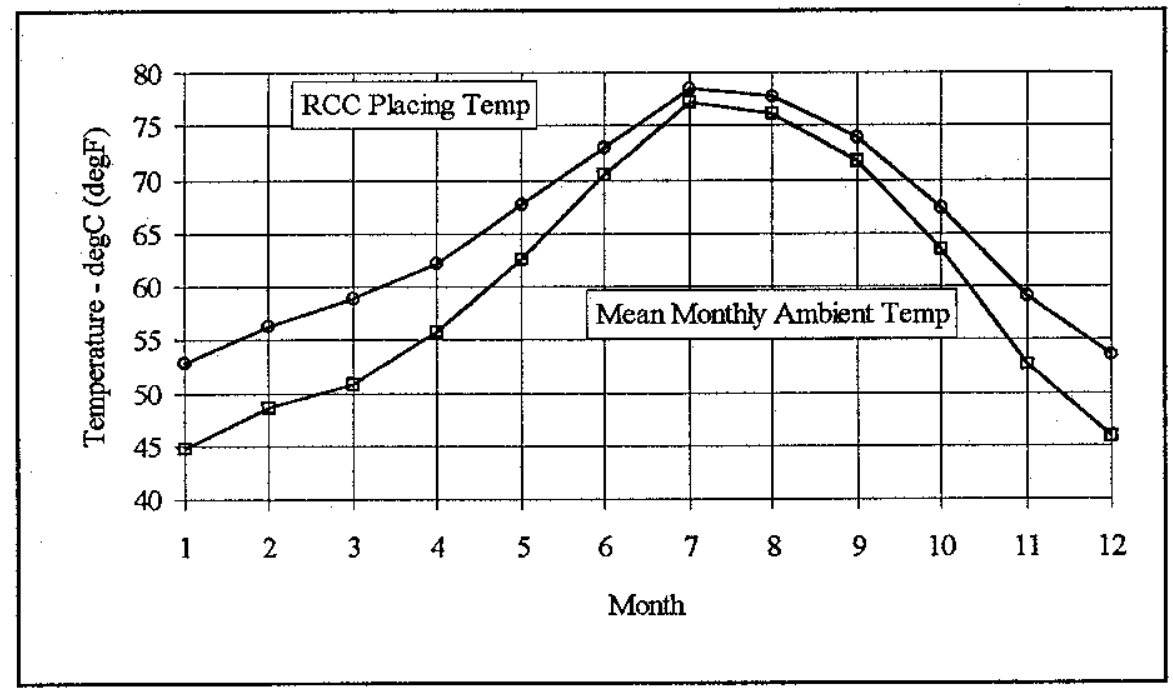

Figure 4. RCC placing temperatures 
that a reasonable determination of internal temperatures could be done using strip models. A strip model is simply a vertical or horizontal "strip" of elements, usually only one element wide. Heat flows through the ends of the strip, but no heat flows from the sides. The model is located where necessary to simulate the thermal activity at that location. While the effects of many factors cannot be easily modeled using this method, generalized behavior can be determined.

$b$. The primary mesh for mass gradient analysis, shown in Figure 1, is composed of 500 elements and 1,002 nodes. It simulates a strip through a cross section of the dam originating $6 \mathrm{~m}(20 \mathrm{ft})$ in the foundation rock. Elements 1 to 20 form the rock foundation with the bottom row of nodes set at a fixed temperature of $115.5 \operatorname{deg} \mathrm{C}(60 \mathrm{deg} F)$, the mean annual air temperature for the area. An arbitrary time of 30 days is allowed to elapse prior to concrete placement to allow the rock temperatures to stabilize.

c. The RCC at about dam midheight was evaluated for a surface temperature gradient. The surface gradient strip model spans from the exposed surface along a single lift to a point inside the structure where temperatures are assumed to not be influenced by ambient conditions. A small FE model was generated of approximately 82 nodes and 40 elements. Temperature histories of these nodes were then determined. The exterior surface of the surface gradient strip model was assumed to be fully exposed, with no insulation, using a heat transfer coefficient of $28.45 \mathrm{~W} / \mathrm{m}^{2}-\mathrm{K}$ (5.011 Btu/ $/ \mathrm{ft}^{2}-\mathrm{hr}-\mathrm{deg} \mathrm{F}$ ).

\section{Compute Temperature Histories}

Step 5: Mass gradient temperature analysis. Graphic representations for each of the four cases analyzed (one for each season) are shown in Figures 5 through 12. The first graph in each set is a time-history of nodal temperatures for selected nodes in the structure. This graph is useful to determine the time when certain zones in the structure reach certain temperatures. The second graph displays the maximum and minimum temperature experienced by each node. Note that these maximums and minimums occur at different times. The minimum temperatures of adjacent nodes fluctuate approximately $4 \operatorname{deg} \mathrm{C}(8 \mathrm{deg} \mathrm{F})$ because of ambient temperature fluctuations. This graph is useful in determining the maximum temperature differentials, as well as determining the critical zones.

Step 6: Surface gradient temperature analysis. Graphic representation of the single start date case analyzed is shown in Figure 13, and is comprised of families of curves representing temperature change with time for different depths from the exterior surface of the MCS. Figure 14 shows these temperatures converted to a family of curves of time versus distance from the surface on the $\mathrm{x}$-axis. This conversion is done to ease the subsequent cracking analysis computations. 


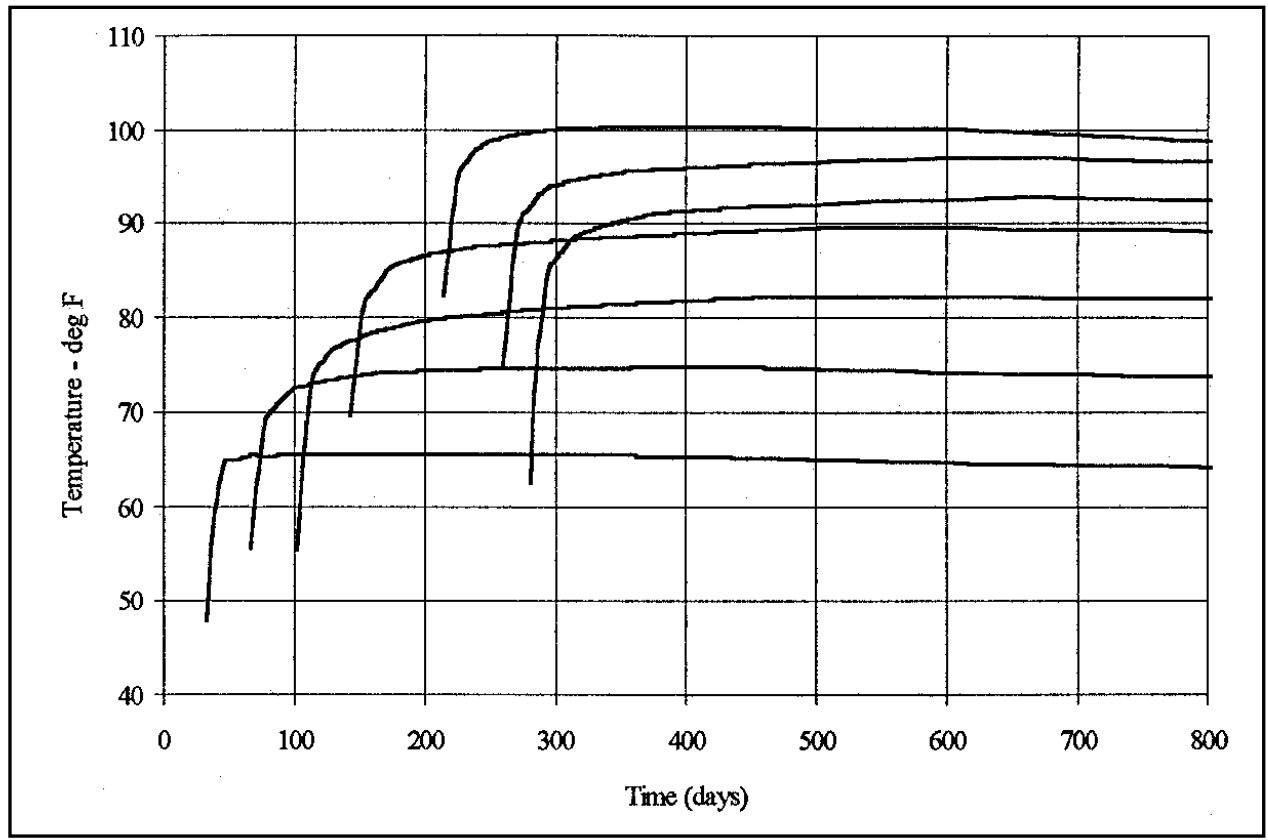

Figure 5. Mass gradient temperature histories for 1 January start

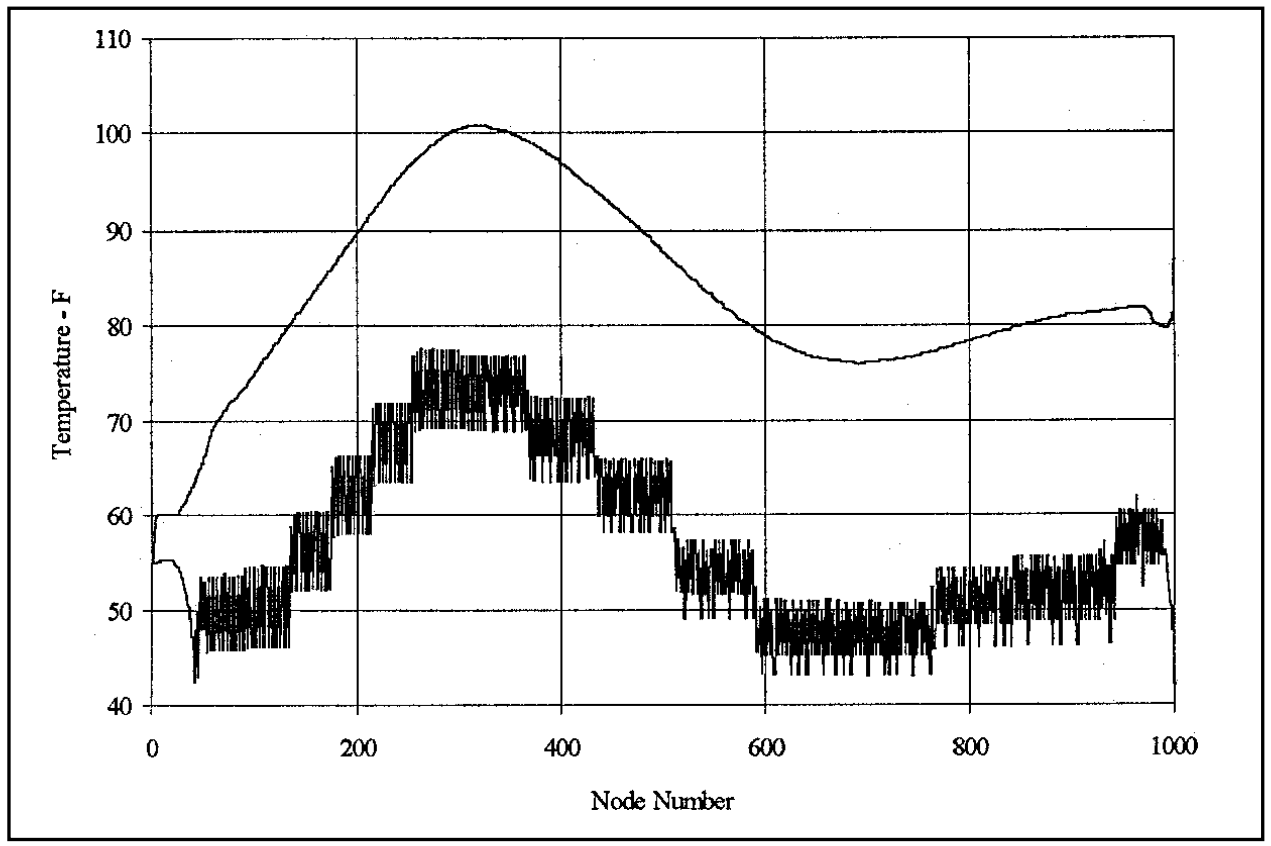

Figure 6. Mass gradient peak temperatures for 1 January start 


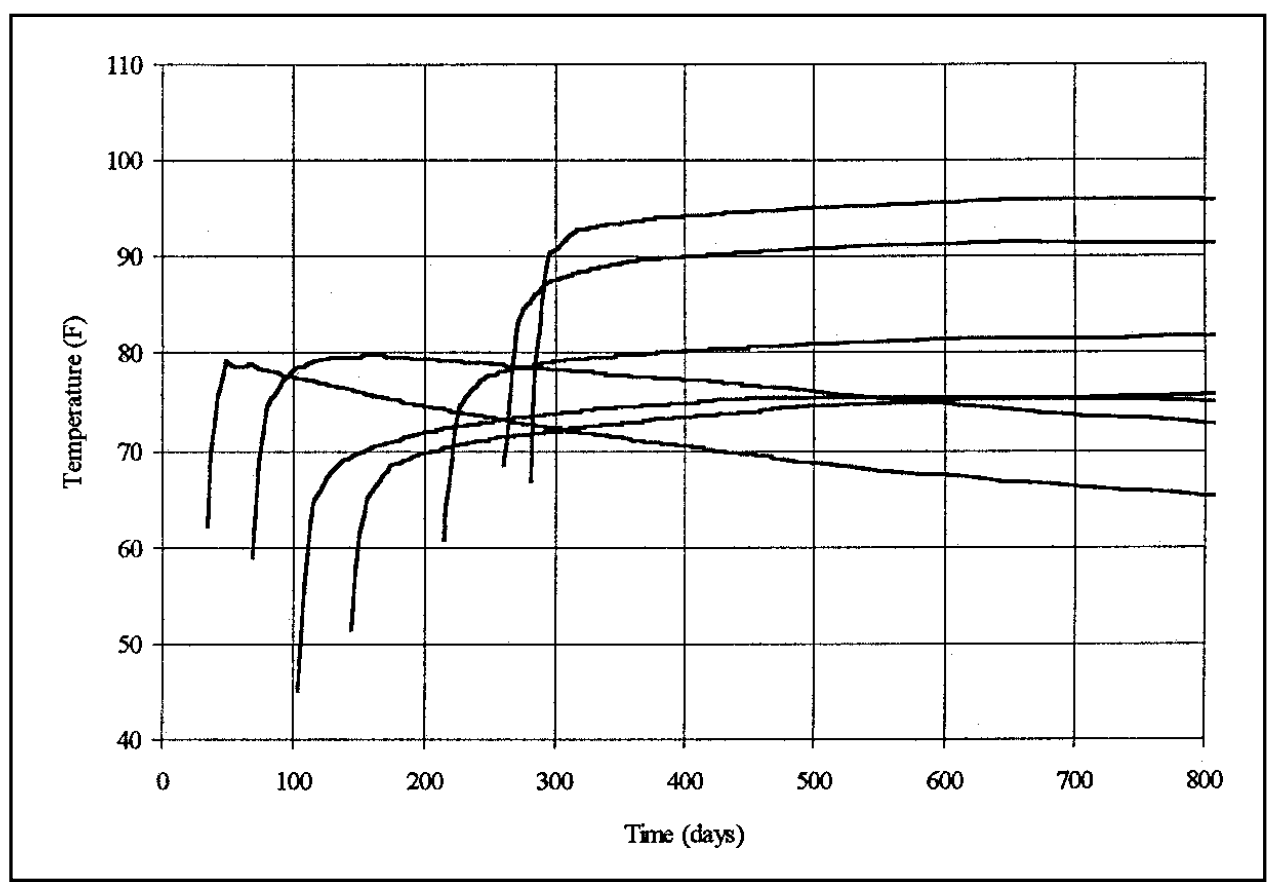

Figure 7. Mass gradient temperature histories for 1 October start

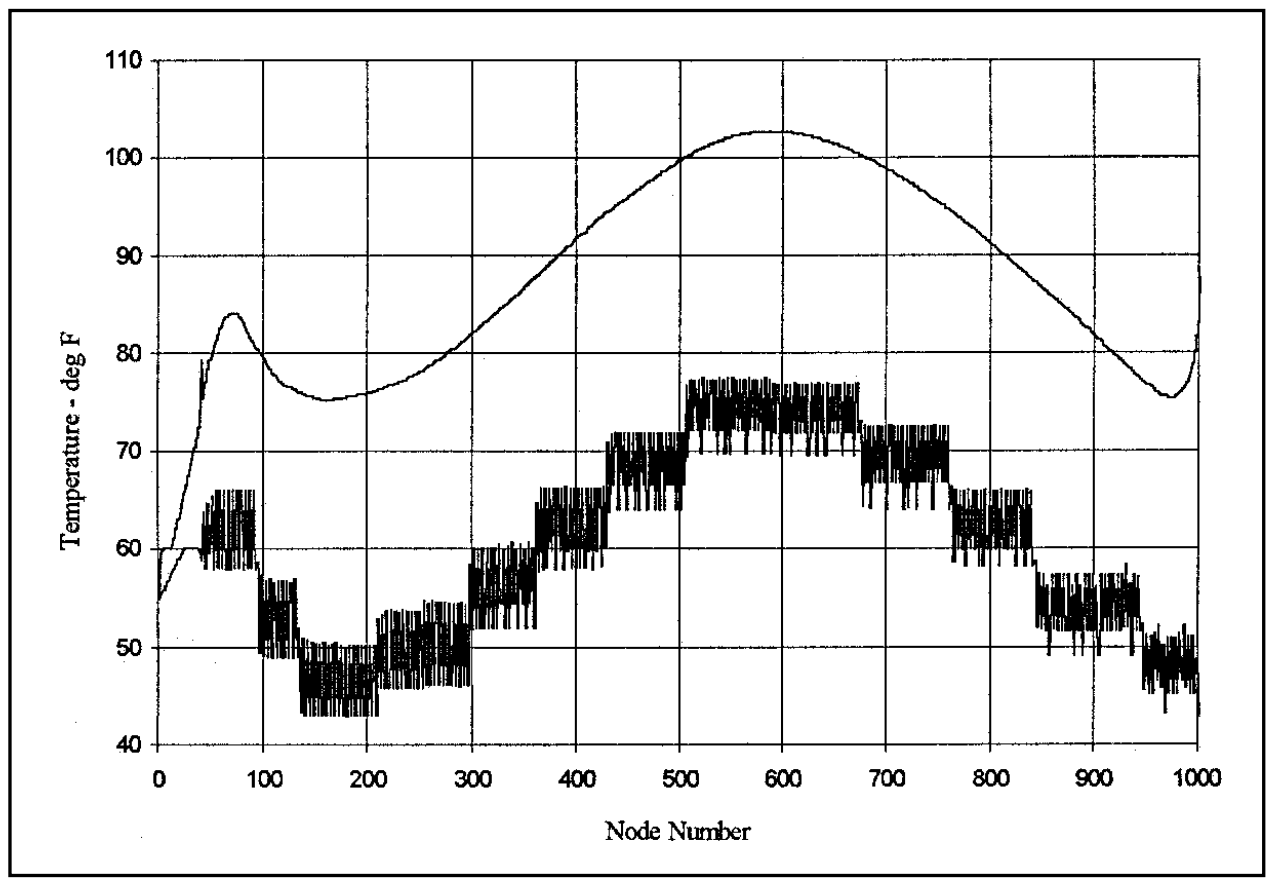

Figure 8. Mass gradient peak temperatures for 1 October start 


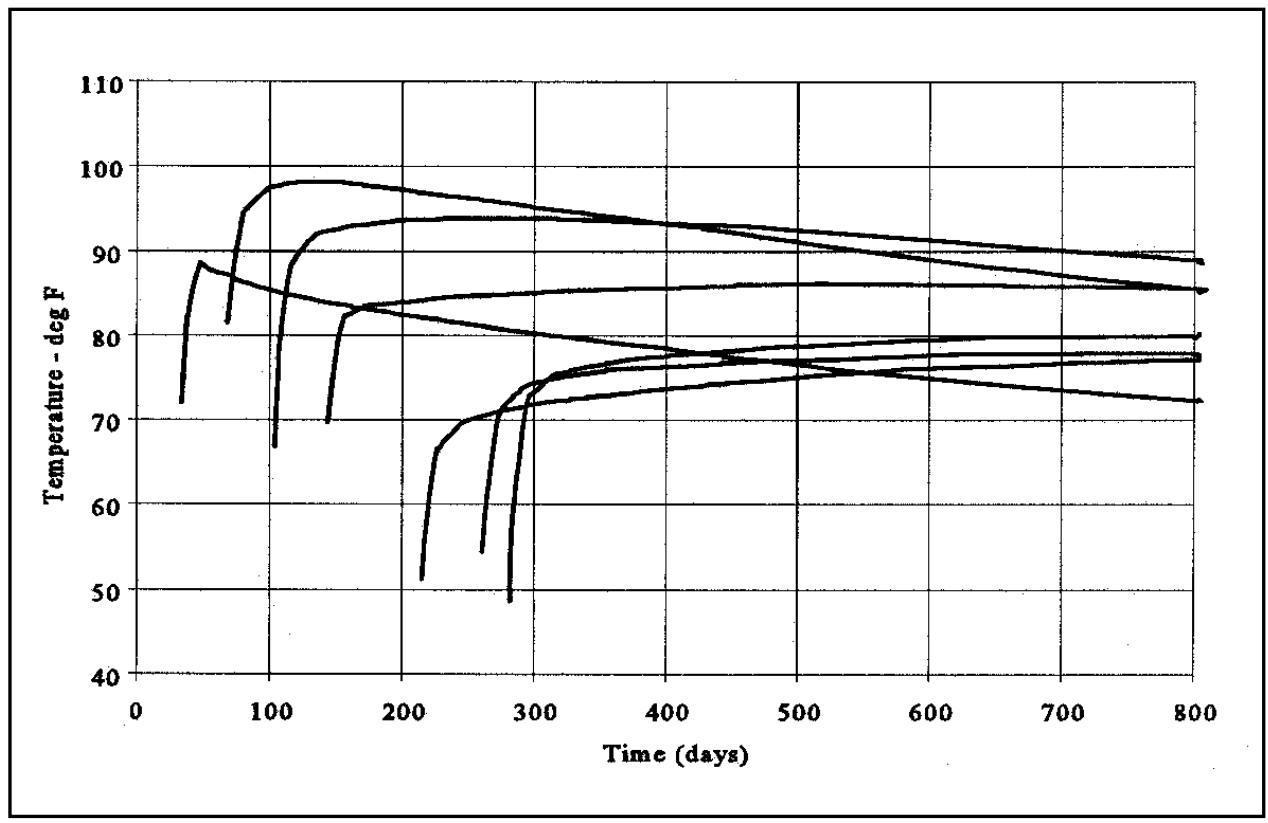

Figure 9. Mass gradient temperature histories for 1 July start

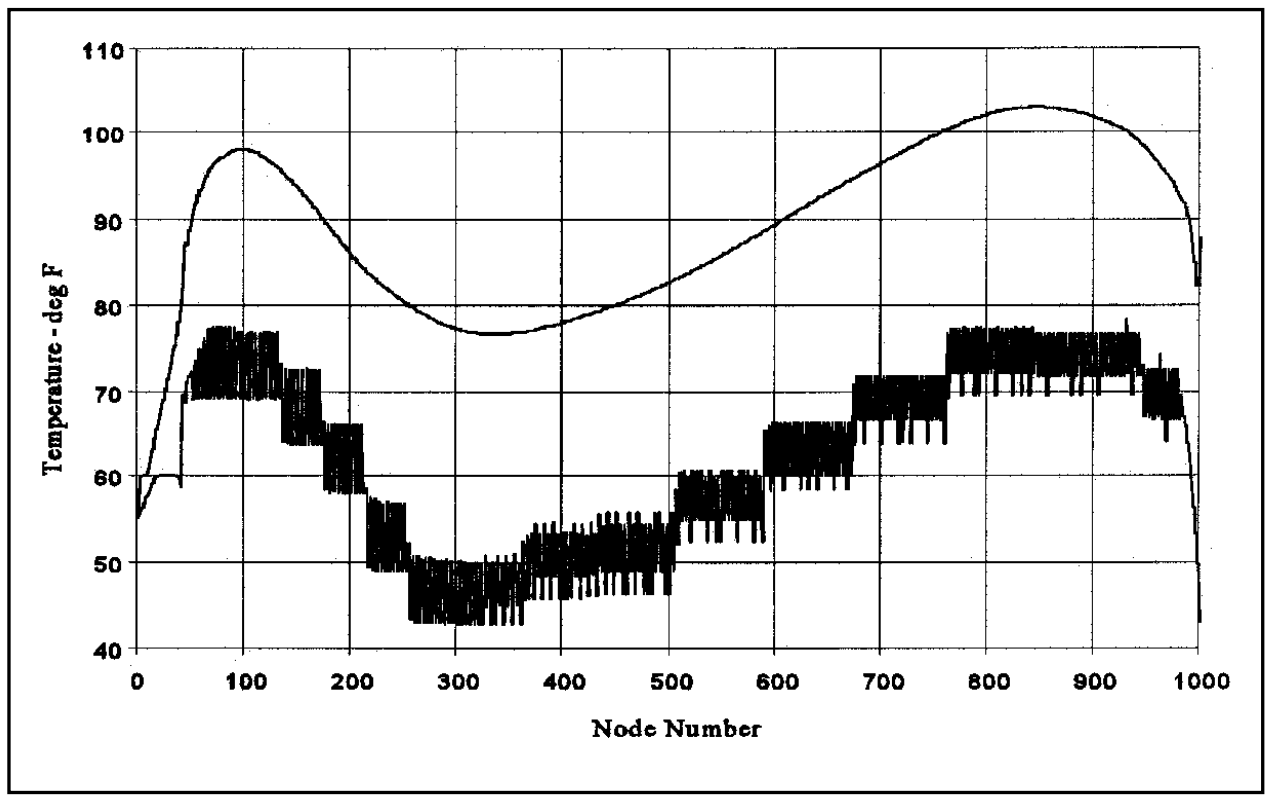

Figure 10. Mass gradient peak temperatures for 1 July start 


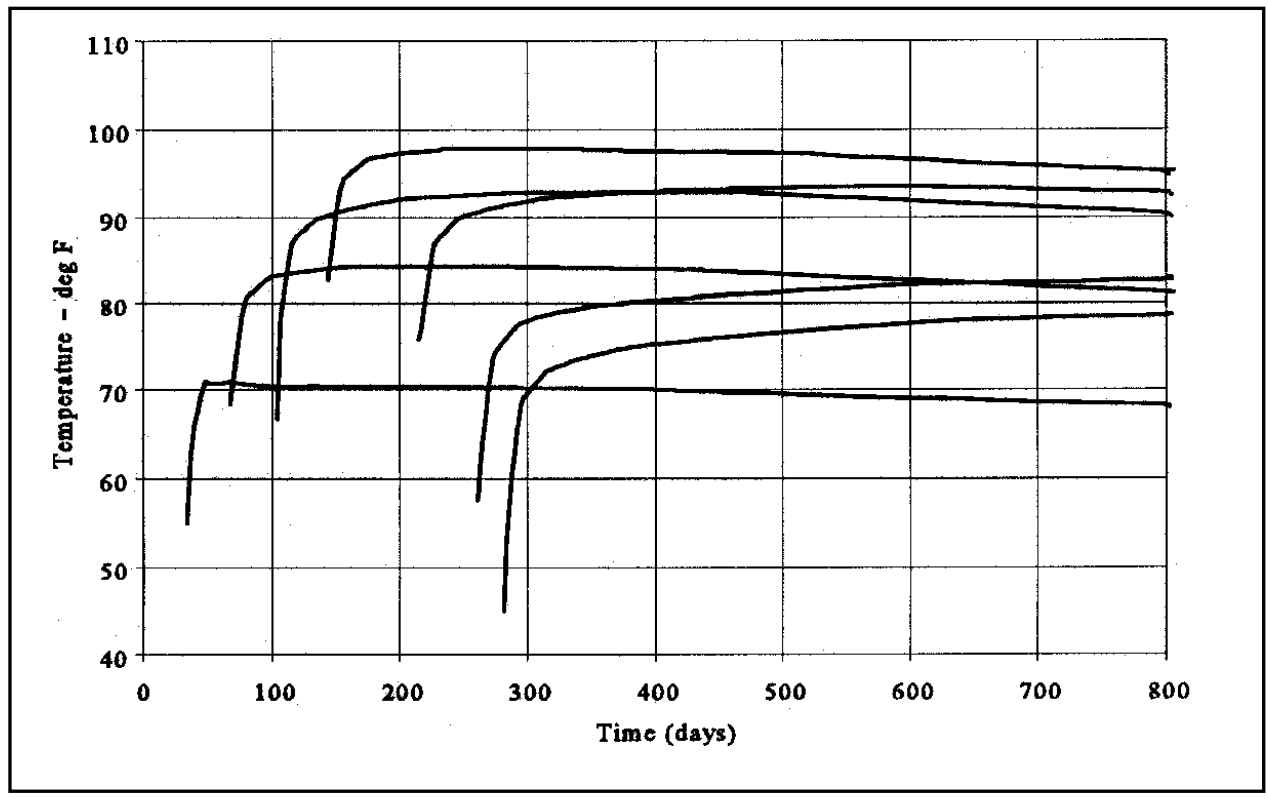

Figure 11. Mass gradient temperature histories for 1 April start

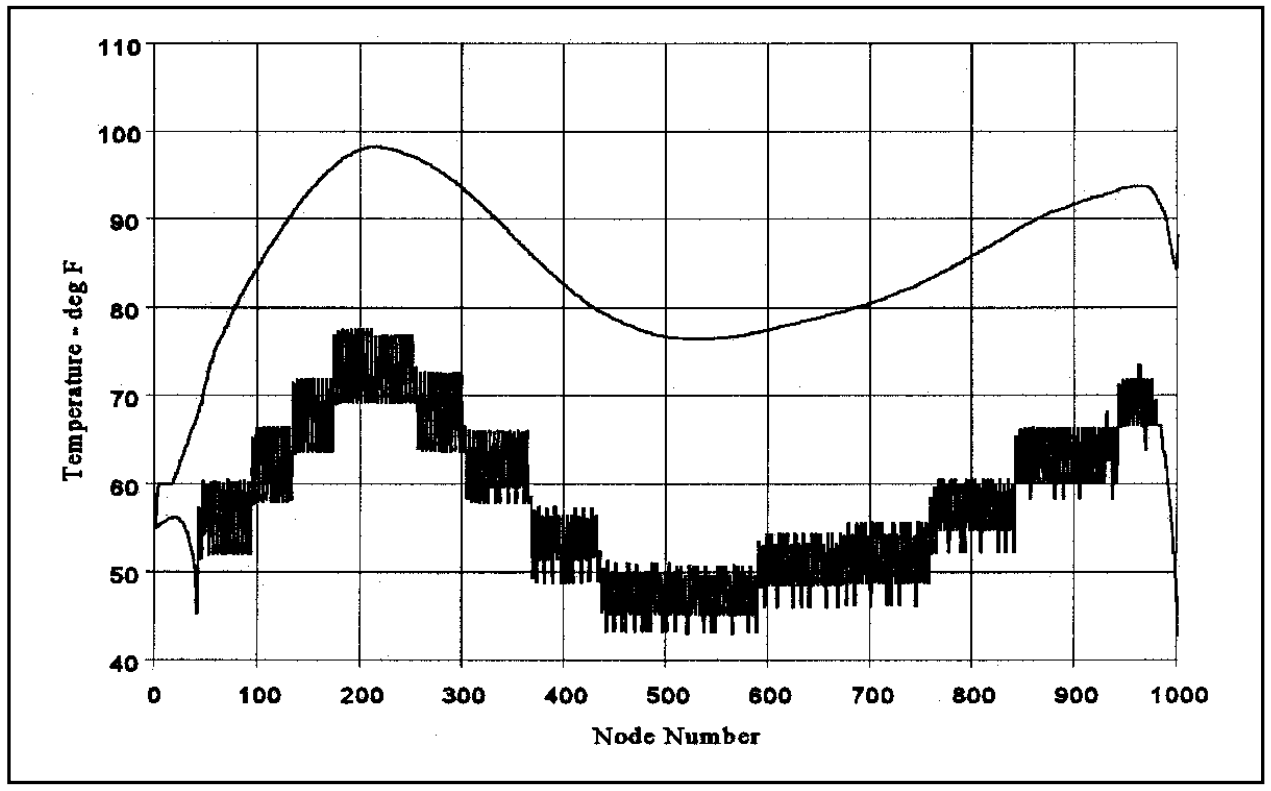

Figure 12. Mass gradient peak temperatures for 1 April start 


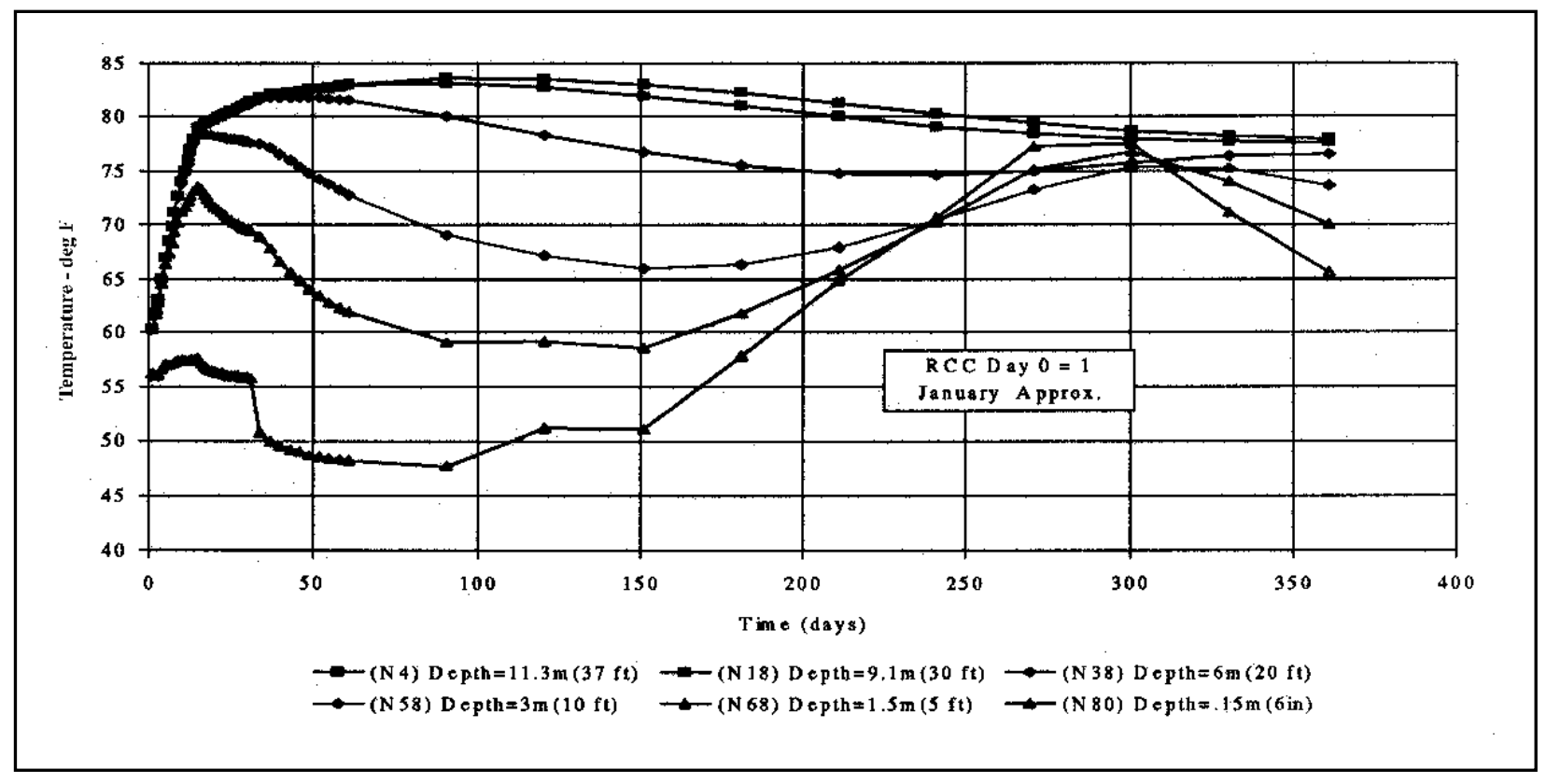

Figure 13. Temperature history for selected nodes from surface gradient model

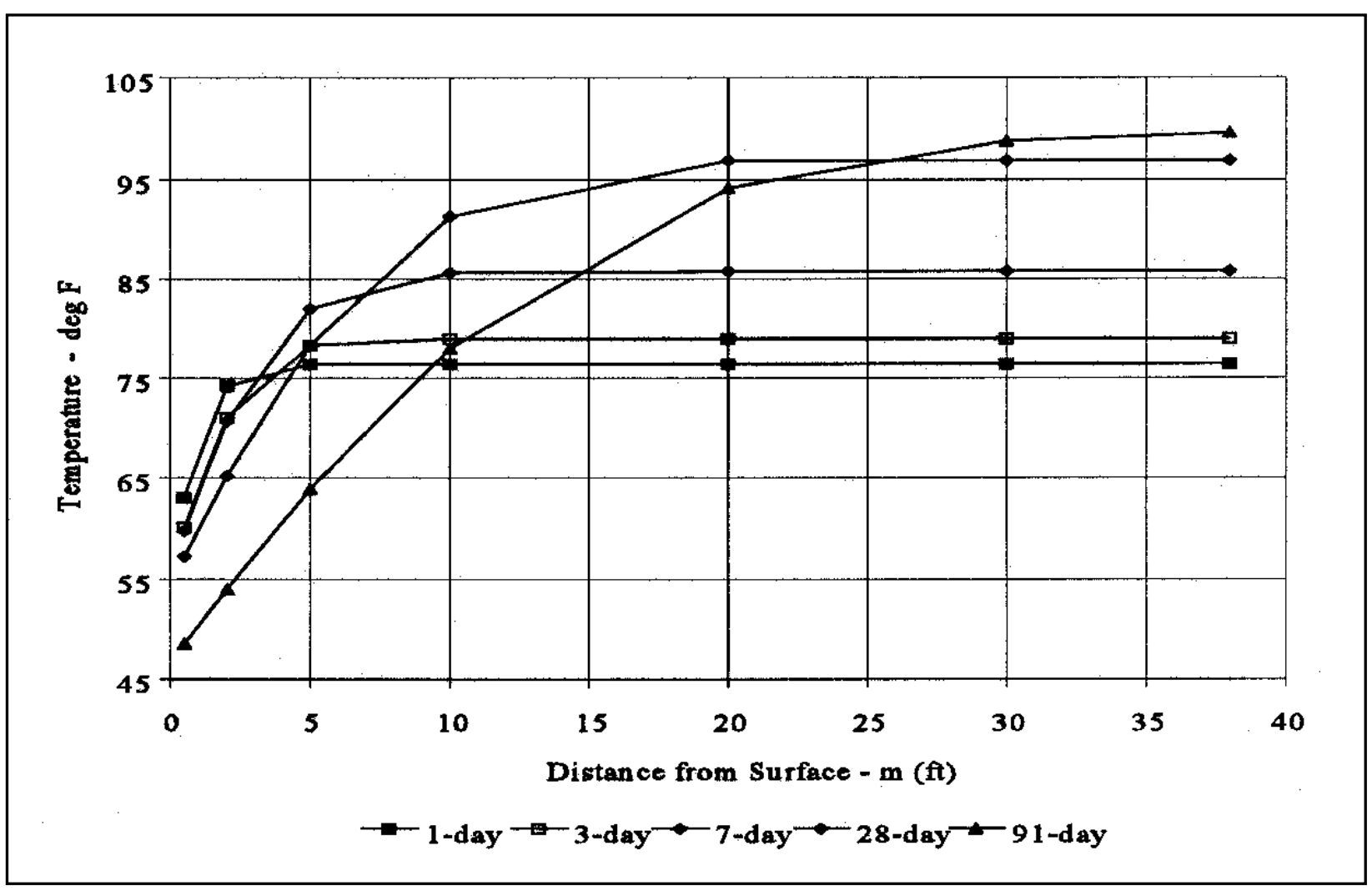

Figure 14. Surface gradient temperature distribution 


\section{Cracking Analysis}

It is assumed for the purposes of this study that the initial (baseline) temperatures of the hardened RCC are those temperatures when the RCC is 24 hours old. Any subsequent change in temperature from this base forms the temperature gradient. For surface gradient analysis, the shallowest interior nodes where temperatures do not change are assumed to be the location of the stress- and strain-free surface. The distance from the surface to the location under consideration is used to calculate restraint factors $\left(K_{R}\right)$ for both surface and mass gradient analysis.

Step 7: Mass gradient cracking analysis. Several general statements can be made regarding the data. At locations low in the structure near the foundation, restraint conditions are the greatest. Consequently, allowable temperature differentials are at a minimum there. Progressing up and away from the foundation, restraint decreases, allowing a greater temperature differential before the onset of cracking. The graphs (Figures 6, 8, 10, and 12) in each of the analysis sets represent sections for the full height of the structure. However, the data can be applied to dam sections founded at higher elevations (e.g., the abutments) by merely moving the y-axis to the right to a point corresponding to the appropriate foundation elevation. In this manner, the performance of the entire structure can be evaluated. In general, no cracking is expected if peak temperatures, low in the structure, do not exceed $29.4 \mathrm{deg} \mathrm{C}$ ( $85 \mathrm{deg} \mathrm{F}$ ) because long-term cooling of the structure to $15.5 \operatorname{deg} \mathrm{C}(60 \mathrm{deg} F)$ results in a 13.9-deg C (25-deg F ) differential. Where nodal temperatures approach $37.8 \mathrm{deg} \mathrm{C}(100 \mathrm{deg} \mathrm{F})$, they can be expected to remain above $29.4 \mathrm{deg} \mathrm{C}$ ( $85 \mathrm{deg} \mathrm{F}$ ) for at least 5 years, and final cooling of the interior to $15.5 \operatorname{deg} \mathrm{C}(60 \mathrm{deg} \mathrm{F})$ may take 15 to 20 years.

a. Placement start on 1 January (Figures 5 and 6). Peak temperatures of 29.4 to $37.8 \mathrm{deg} \mathrm{C}$ ( 85 to $100 \mathrm{deg}$ F) are realized in the part of the structure represented by nodes 200 to 500 . This peak occurs during the month of July, after approximately 200 days of placement. Initial placements for the large monoliths are performed during the cool part of the year (winter and early spring), resulting in crack-free performance. Higher in the structure, where peak temperatures exceed 29.4 deg C ( 85 deg F), cracking does not occur because foundation restraint is reduced. The placements generating peak temperatures and resultant strains that may initiate cracking are those placements on the abutments between elevation 90 and 240 for a January start. This can be seen in Figure 6. Nodes 200 to 500 exceed $29.4 \mathrm{deg}$ C ( $85 \mathrm{deg}$ F). These nodes are located 27 to $73 \mathrm{~m} \mathrm{(90} \mathrm{to}$ $240 \mathrm{ft}$ ) above the deepest foundation elevation.

b. Placement start on 1 October (Figures 7 and 8). Peak temperatures of 29.4 to $37.8 \mathrm{deg} C$ ( 85 to $100 \mathrm{deg}$ F) are realized in the part of the structure represented by nodes 300 to 900 . This peak occurs during the month of July, after approximately 300 days of placement. Initial placements for the large monoliths are performed during the cooler part of the year (fall, winter, and early spring), and peak temperatures never reach the critical level of $29.4 \operatorname{deg} \mathrm{C}$ ( $85 \mathrm{deg}$ F). However, higher in the structure, where temperatures do exceed $29.4 \operatorname{deg} \mathrm{C}$ ( $85 \mathrm{deg} \mathrm{F}$ ), cracking does not occur 
because foundation restraint is reduced. For an October start, the placements generating peak temperatures and resultant strains that may initiate cracking are those placements on the abutments at elevations 43 to $134 \mathrm{~m}$ (140 to $440 \mathrm{ft}$ ) from the lowest foundation elevation.

c. Placement start on 1 July (Figures 9 and 10). Peak temperatures of 29.4 to $37.8 \mathrm{deg} \mathrm{C}$ ( 85 to $100 \mathrm{deg} \mathrm{F}$ ) are realized in the part of the structure represented by nodes 50 to 200 and 500 to 1000 . This peak occurs after approximately 100 days of placement (during the month of July) for the early placements, and 1 year later for the upper dam placements. Initial placements for the large monoliths are performed during the warmest part of the year (the summer and early fall months), and peak temperatures exceed the critical level of $29.4 \operatorname{deg} \mathrm{C}$ ( $85 \mathrm{deg}$ F). However, higher in the structure, where temperatures do exceed 29.4 deg C ( 85 deg F), cracking does not occur because foundation restraint is reduced. For a July start, the additional placements generating peak temperatures and resultant strains that may initiate cracking are those placements on the abutments at elevations 73 to $146 \mathrm{~m}$ ( 240 to $480 \mathrm{ft}$ ) above the lowest foundation elevation.

d. Placement start on 1 April (Figures 11 and 12). Peak temperatures of 29.4 to $37.8 \operatorname{deg} \mathrm{C}$ ( 85 to $100 \mathrm{deg} \mathrm{F}$ ) are realized in the part of the structure represented by nodes 100 to 400 and 800 to 1000 . This peak occurs during the month of July, after approximately 100 days of placement for the early placements, and 1 year later for the upper dam placements. Initial placements for the large monoliths are performed during the moderate part of the year (the spring), avoiding cracking. Higher in the structure, where temperatures exceed $29.4 \mathrm{deg}$ C ( 85 deg F), cracking does not occur because foundation restraint is reduced. Additional placements generating peak temperatures and resultant strains that may initiate cracking are those placements on the abutments from an elevation 12 to $49 \mathrm{~m}$ (40 to $160 \mathrm{ft}$ ) above the lowest foundation elevation and placements near the top of the dam.

e. Mass gradient cracking analysis results. Table 6 summarizes, for each placing schedule evaluated, the nodes and the node locations where mass gradient thermal cracking is expected. The "Height Above Foundation" refers to those abutment foundation locations at elevations above the lowermost foundation elevation. For example, a January-start schedule results in probable cracking of nodes 200 to 400 , and foundation elevations located 27 to $73 \mathrm{~m}$ (90 to $240 \mathrm{ft}$ ) above the lowest foundation elevation.

Uncontrolled RCC placing temperatures will result in peak temperatures of $37.8 \mathrm{deg} \mathrm{C}(100 \mathrm{deg} \mathrm{F})$ and ultimate temperature differentials of $22.2 \mathrm{deg} \mathrm{C}$ (40 deg F). The maximum temperature differential calculated from tensile strain capacity and the coefficient of thermal expansions is $13.9 \operatorname{deg} \mathrm{C}(25 \mathrm{deg} F)$ for the near term, increasing to near $16.7 \mathrm{deg} \mathrm{C}$ ( $30 \mathrm{deg} \mathrm{F}$ ) for cooling periods of 15 years. Fall and winter placements result in cool placing temperatures, with peak temperatures for those placements of less than $29.4 \operatorname{deg} \mathrm{C}(85 \mathrm{deg} \mathrm{F})$. 


\begin{tabular}{|c|c|c|c|}
\hline \multicolumn{4}{|c|}{$\begin{array}{l}\text { Table } 6 \\
\text { Summary of Locations of Mass Gradient Thermal Cracks }\end{array}$} \\
\hline Schedule & Peak Temp, deg C (deg F) & Critical Nodes & Height Above Foundation, $\mathrm{m}$ (ft) \\
\hline Jan & $37.8(100)$ & $200-400$ & $27-73(90-240)$ \\
\hline Oct & $37.8(100)$ & $300-900$ & $43-134(140-440)$ \\
\hline July & $37.8(100)$ & $50-200$ and $500-1000$ & $73-146(240-480)$ \\
\hline April & $37.8(100)$ & $100-400$ and $800-1000$ & $12-49(40-160)$ and near top of dam \\
\hline
\end{tabular}

Spring and summer placements result in peak temperatures exceeding $29.4 \mathrm{deg}$ C ( $85 \mathrm{deg}$ F), making cracking very probable. Cracking is generally induced at the foundation, where full restraint occurs and progresses up until restraint conditions lessen to the point where the driving force behind the crack is reduced. Since the force to propagate an existing crack is less than the force necessary to initiate the crack, it seems appropriate to assume that existing cracks may propagate further. The values shown in Table 6 do not include this extra crack height. Longitudinal cracking of the RCC in the large sections is not expected to be a problem when placement is done during the cool periods of the year. If these placements are done during the hot periods of the year, longitudinal cracking may occur. As construction progresses, placement of smaller RCC sections (those placements founded on rock at higher elevations) during hot periods is unavoidable. Longitudinal cracking of RCC placed against higher elevation foundation areas during these periods may occur. The conditions that may initiate longitudinal cracking may also initiate transverse cracking. The occurrence of transverse cracks can be reduced by installing transverse joints, thereby reducing the restraint.

Step 8: Surface gradient cracking analysis. Surface gradient analysis was performed for several concrete placement start times, including the 1 January start time shown in this example. The effects of transverse joints at three different spacings were evaluated, including $30 \mathrm{~m}(100 \mathrm{ft}), 61 \mathrm{~m}(200 \mathrm{ft})$, and $91 \mathrm{~m}$ $(300 \mathrm{ft})$. The amphibolite aggregate RCC mixture was used in the evaluation. The procedure described here allows for consideration of changing concrete properties with age, such as $E$ and creep, as well as changing $h$ and $H$ dimensions of the surface gradient tension block with time.

a. Figure 13 presents the temperature data as a time-history plot for the conditions that should create the greatest surface gradient. Replotting the same data, based on nodal locations, yields Figure 14. Note that each curve represents the temperature cross section of the structure for a specific time. Each curve extends into the structure until the temperature becomes constant. Temperature differentials at specific locations are selected from Figure 14 and listed in Figure 15 for $91-\mathrm{m}$ (300-ft) joint spacing. Two basic assumptions are made in this analysis. First, temperatures of the RCC, at an age of 24 hours, are the baseline temperatures against which temperature change is determined. Second, the stress-strain free surface is assumed to be the depth at which the temperature change, measured from the baseline temperature, approaches 0 . Figure 15 shows 


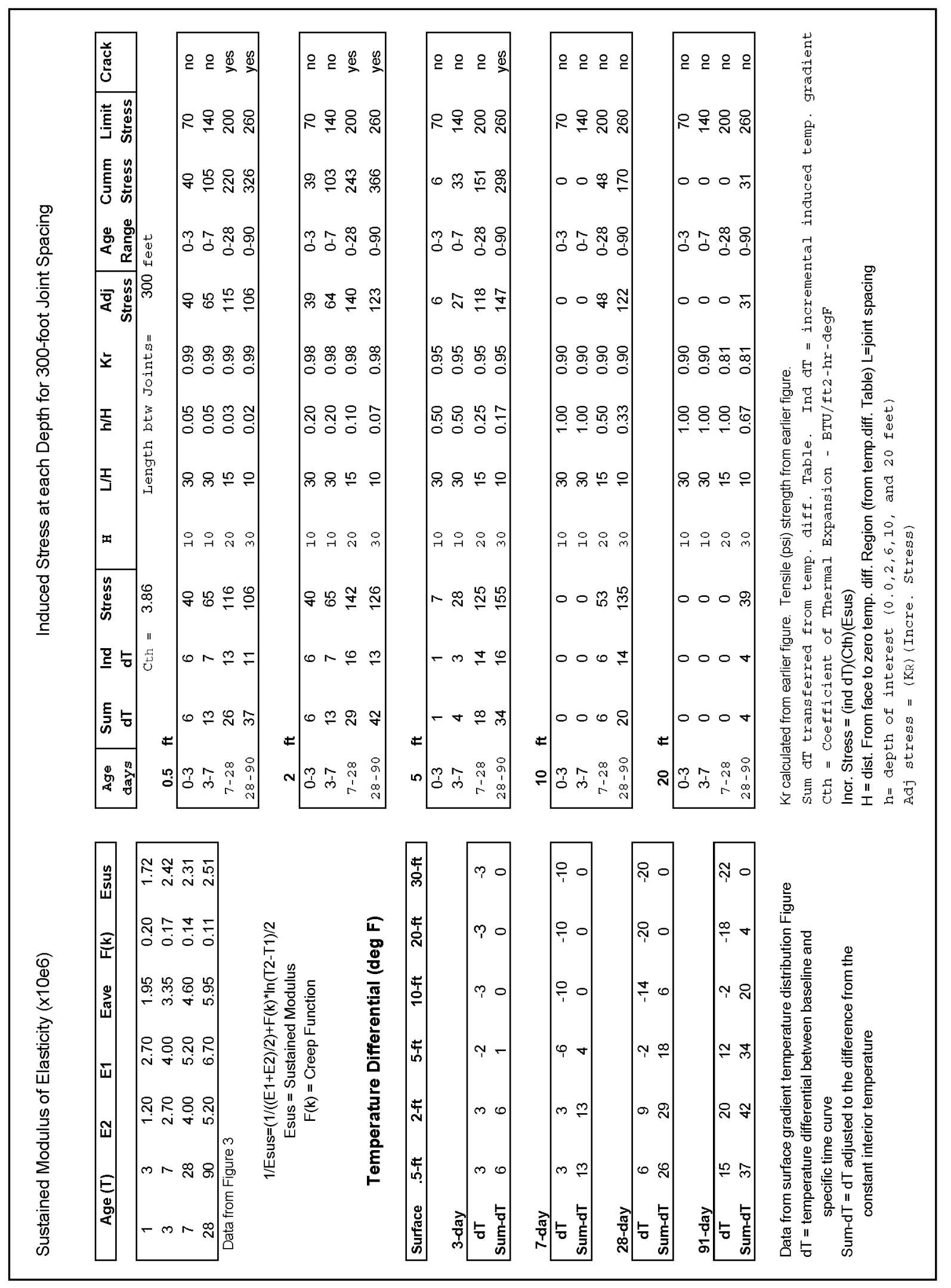

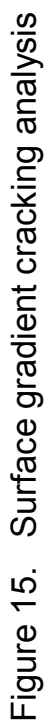


the temperature deviations $(d T)$ from the baseline temperature, as well as the depth at which the temperature gradient approaches 0 . The Sum $d T$ temperature differences are included in Figure 15 as a starting point for calculating induced stresses. "Induced $d T$," or the individual increments of temperature gradient induced with each age period, is calculated from the "Sum $d T$ 's." Sustained modulus of elasticity $\left(E_{\text {sus }}\right)$ is determined in Figure 15 for each age increment. To calculate incremental stress generated by temperature gradients:

$$
\text { Incremental stress }=(\text { Ind } d T)\left(C_{t h}\right)\left(E_{\text {sus }}\right)
$$

b. To determine $K_{R}$, Figure 4.1 of ACI 207.2R or Equation 4.1 or 4.2 of ACI 207.2R are used, requiring calculation of $H, L$, and $h . H$ is the distance from the exterior surface to the stress- and strain-free surface at each incremental time period and is determined from the Temperature Differential Table in Figure 15 (note $H$ for each age increment is the same). $L$ is the joint spacing. $h$ is the distance from the surface to the depth of interest (near surface, $0.6,1.5,3$, and $6 \mathrm{~m}(2,5,10$, and $20 \mathrm{ft}$ ) in the figures), and $h / H$ is the proportion of $H$ from the surface to the depth of interest. $h / H$ largely determines the amount of restraint at any location. For $L / H \geq 2.5, K_{R}$ is calculated as follows:

$$
K_{R}=\left(\frac{\frac{L}{H}-2}{\frac{L}{H}-1}\right)^{h / H}
$$

"Adj stress" is calculated by:

Adj stress $=\left(K_{R}\right)($ Incremental stress $)$

Cumulative stresses are then summed by superposition of stress from each age interval. Crack development is judged by whether the cumulative stress exceeds the tensile strength.

c. From Figure 15 and similar computations for $30-$ and $61-\mathrm{m}$ (100- and 200 -ft) joint spacings, the computations indicate that surface cracking is not likely for a $30-\mathrm{m}(100-\mathrm{ft})$ joint spacing. Surface cracking may increase to a depth of $0.6 \mathrm{~m}(2 \mathrm{ft})$ for joint spacings up to $61 \mathrm{~m}(200 \mathrm{ft})$

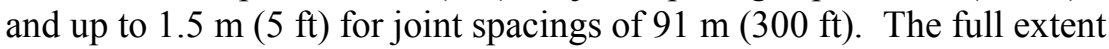
of surface cracking is controlled by the formation of the initial surface

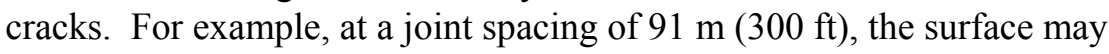
crack at the midpoint. The analysis shows that this crack may propagate to a depth of $1.5 \mathrm{~m}(5 \mathrm{ft})$ after several weeks to months. However, the occurrence of this crack forms a new joint pattern at a spacing of $46 \mathrm{~m}$ (150 ft). While the depth of cracking may not be sufficient to change the restraint conditions $(L / H)$, it may be enough to relieve induced stresses and stabilize the crack growth to depths of $0.6 \mathrm{~m}(2 \mathrm{ft})$. A joint spacing of 
$61 \mathrm{~m}$ (200 ft) may be an optimum spacing for this project based on the occurrence of surface cracking. Evaluation of the combined effects of surface gradient strains with mass gradient strains was not pursued, since the surface gradient strain contribution is not considered to be significant to the overall cracking performance of the structure using joint spacings of 30 and $61 \mathrm{~m}$ (100 and $200 \mathrm{ft})$.

\section{Conclusions and Recommendations}

The maximum temperature differential under full restraint conditions $\left(K_{R}\right.$ $=1.0)$ that will not result in cracking of the RCC is $13.9 \mathrm{deg} \mathrm{C}(25 \mathrm{deg} F)$. Since the final temperature of the RCC will be $15.5 \mathrm{deg} \mathrm{C}$ ( $60 \mathrm{deg} \mathrm{F}$ ) (the average annual temperature), a crack-free peak RCC temperature is $29.4 \mathrm{deg} \mathrm{C}$ ( $85 \operatorname{deg}$ F). This allowable differential of $13.9 \operatorname{deg} \mathrm{C}(25 \mathrm{deg} F)$ increases as the distance of the RCC placements from the foundation increases. After evaluating several placing schedules, it was apparent that the most beneficial conditions occurred when the RCC placement of the lower third of the dam commenced in the fall of the year and was completed during late spring. This means that, for the larger dam sections, the upper two-thirds would then be placed during a hotter time period. The reduction in foundation restraint at this height in the structure, however, more than offsets the effects of the higher temperatures.

Surface gradients were evaluated for several transverse joint intervals. Because the site is located in a relatively temperate area, where cold temperatures are rare, stresses from surface gradients were of little consequence for joint spacings up to $61 \mathrm{~m}(200 \mathrm{ft})$. Greater joint spacings increase the depth of surface cracking.

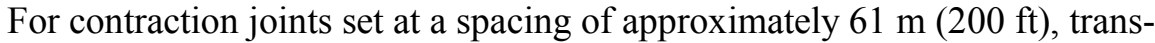
verse cracking of the structure may occur in the lower 6 to $12 \mathrm{~m} \mathrm{(20} \mathrm{to} 40 \mathrm{ft})$ of the structure. Similarly, longitudinal cracking may occur in the lower 6 to $12 \mathrm{~m}$ (20 to $40 \mathrm{ft}$ ) of the structure for sections of the dam having an upstreamdownstream dimension greater than $61 \mathrm{~m}(200 \mathrm{ft})$. Since the occurrence of a longitudinal crack could create serious stability concerns, more rigorous analyses coupling the effects of other simultaneous loadings are necessary to better evaluate the extent of cracking.

An alternate rock source, a nearby quarried limestone aggregate, provides an RCC with a very low coefficient of thermal expansion of 4.5 millionths/deg C ( 2.5 millionths/deg F). The net effect of using this aggregate instead of the damsite amphibolite is to raise the allowable maximum peak temperature from 29.4 to $37.8 \mathrm{deg} \mathrm{C}$ ( 85 to $100 \mathrm{deg} \mathrm{F}$ ). It appears that if this aggregate is used, no further control of aggregate temperatures may be necessary. Without this aggregate, measures are necessary to control placing temperatures so that peak temperatures do not exceed $29.4 \operatorname{deg} \mathrm{C}(85 \mathrm{deg}$ F). This requires a $15.5-\mathrm{deg} \mathrm{C}$ (60-deg F) placing temperature for certain placements. This placing temperature could be raised to $23.9 \operatorname{deg} \mathrm{C}$ (75 $\operatorname{deg} \mathrm{F})$, if the limestone aggregate was used. 
Completion of RCC placements up to a minimum elevation during a fall and winter time period should be required in the construction contract. Otherwise, if these low elevation placements are placed during the spring and summer period, the RCC placing temperature should be specified not to exceed 26.7 to $29.4 \mathrm{deg} \mathrm{C}$ ( 80 to $85 \mathrm{deg}$ F). This will require the use of additional cooling measures. Stockpile sprinkling, water chilling, and possible shading may be sufficient to achieve these temperatures.

The scope of this study was of a limited nature: to identify the potential extent of thermal cracking in the structure. Only generalized conclusions are possible. For a structure of this height, volume, and seismic loadings, a more rigorous study should be performed during design of the structure. Full-section modeling, incorporating foundation properties, restraint conditions, and early-age material properties (time- and temperature-dependent properties) should be done. The structure should be analyzed in sections to ascertain the strain development that may lead to longitudinal cracking and in elevation to ascertain strain development that may lead to transverse cracking. The results of these studies should guide the designer as to whether a 3-D model is necessary. It is presumed that a $3-\mathrm{D}$ analysis will indicate better cracking performance of the structure than a 2-D model would indicate. This analysis should quantify the effects of several load conditions in addition to the thermal loads. It may be that the combined action of these factors will initiate cracking. 


\section{Level 2 Analysis, Locks and Dams 2, 3, and 4 Monongahela River}

\section{General}

An example of each step in the performance of a relatively complex mass gradient and a surface gradient analysis in a Level 2 thermal study of an MCS is presented. This example is based on 2-D analyses performed during design studies for locks and dam facilities on the Monongahela River in Pennsylvania. These studies were conducted to maximize lift heights and determine optimum placement temperatures and to expedite construction and minimize costs. Although numerous lock monolith configurations exist in the project, the most massive section was selected for analysis. Conclusions and recommendations from this analysis could be applied to the other project monoliths. Figure 16 shows a cross section representation of the geometry of a river wall monolith with nominal 3-m (10-ft) lifts used in this example analysis. Two-dimensional FE analysis was used to determine temperature histories and temperature distribution during and following construction. FE analysis was not applied for cracking analysis. Cracking analysis was performed using a strain-based criteria similar to procedures described in ACI 207.2R. Slow-load tensile strain capacity test results (which include creep effects) were used to determine the extent of cracking. Analysis was performed on 15 combinations of several parameters, including three lift heights, two maximum concrete placement temperatures, three construction start times, two lift placement rates, and insulated forms for fall placement.

\section{Input Properties and Parameters}

Step 1: Determine ambient conditions. These data were gathered from local records. Ambient temperature data are shown in Figure 17.

Step 2: Determine material properties. Table 7 contains thermal properties used in the example thermal analysis. Adiabatic temperature rise is shown in Figure 18. This adiabatic temperature rise is characteristic of the heat generation of an exterior concrete in a mass concrete structure and is not characteristic of interior mass concrete. The foundation material is assumed to be limestone of 


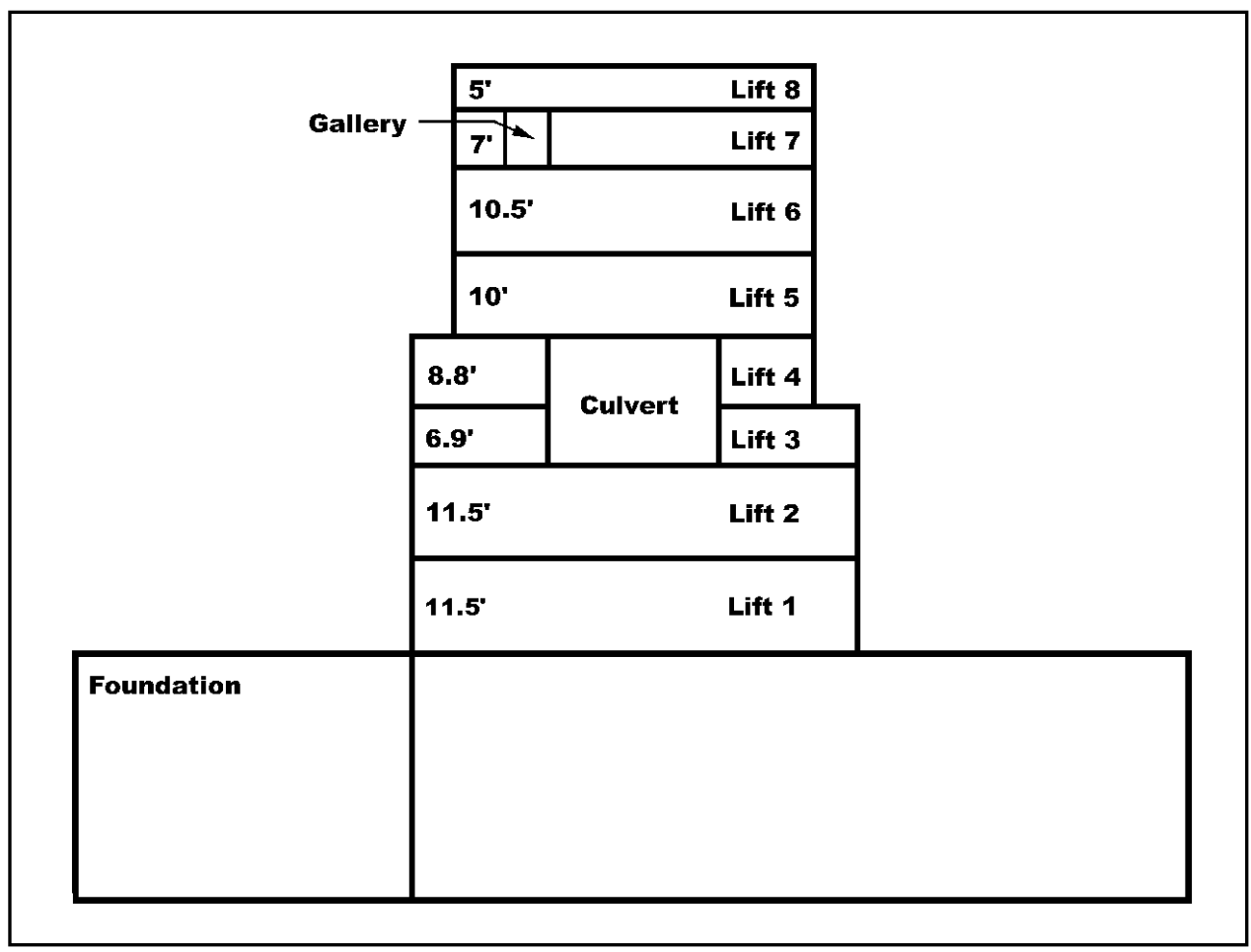

Figure 16. Lock wall section used in example

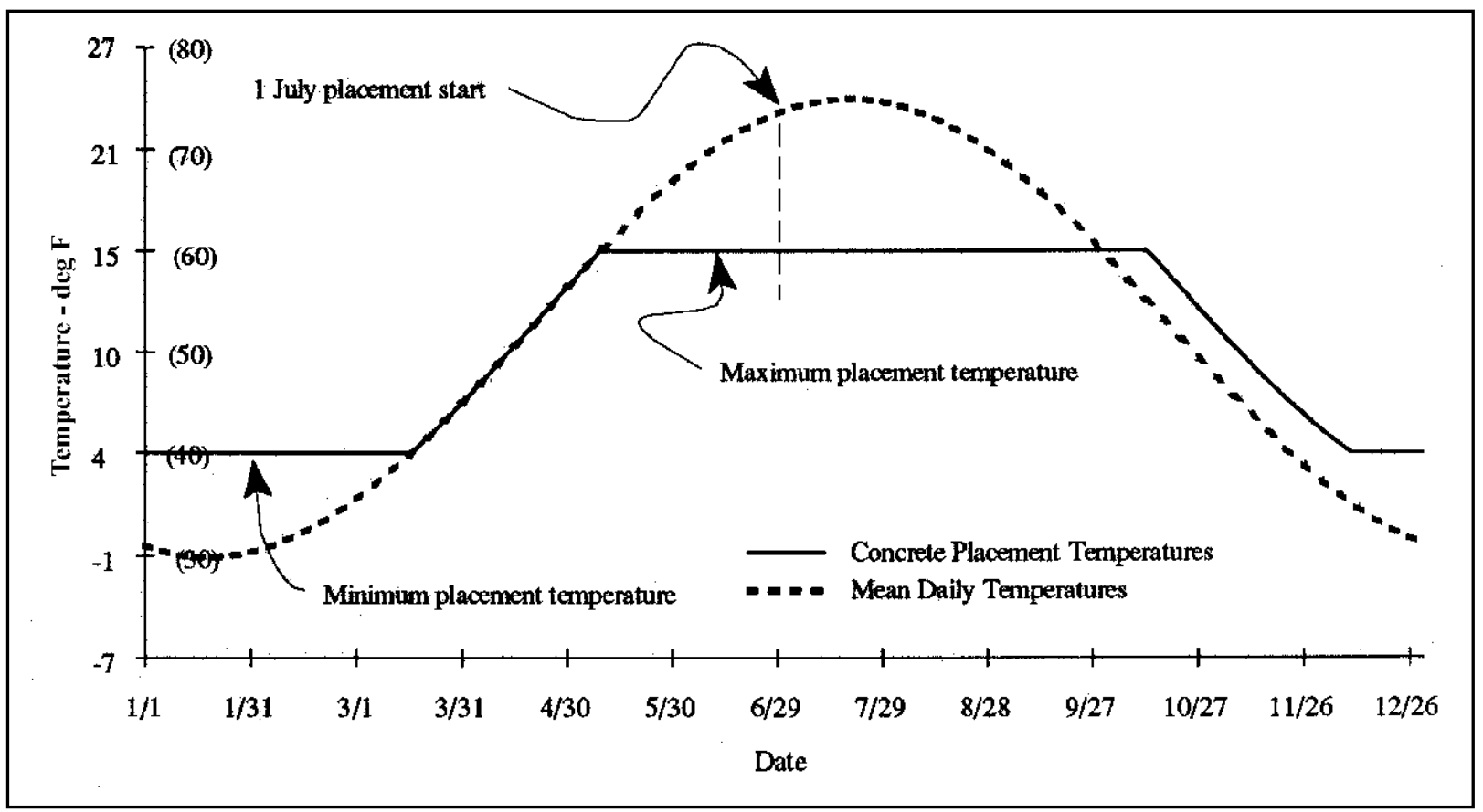

Figure 17. Mean daily ambient temperatures and concrete placement temperatures 


\begin{tabular}{|c|c|c|c|}
\hline \multicolumn{4}{|c|}{$\begin{array}{l}\text { Table } 7 \\
\text { Concrete and Foundation Thermal Properties }\end{array}$} \\
\hline Material & $\begin{array}{l}\text { Thermal Conductivity } \\
\text { W/m-K (Btu/hr-ft-deg F) } \\
\text { (Btu/day-in-deg F) } \\
\end{array}$ & $\begin{array}{l}\text { Specific Heat } \\
\text { kJ/kg-K (Btu/lb-deg F) }\end{array}$ & $\begin{array}{l}\text { Coefficient of Thermal Expansion } \\
\text { millionths/ deg C (millionths/deg F) }\end{array}$ \\
\hline Limestone foundation & $0.86(0.500)(1.000)$ & $0.96(0.230)$ & $9.90(5.50)$ \\
\hline Exterior concrete mixture & $1.75(1.012)(2.025)$ & $0.98(0.235)$ & $10.46(5.81)$ \\
\hline
\end{tabular}

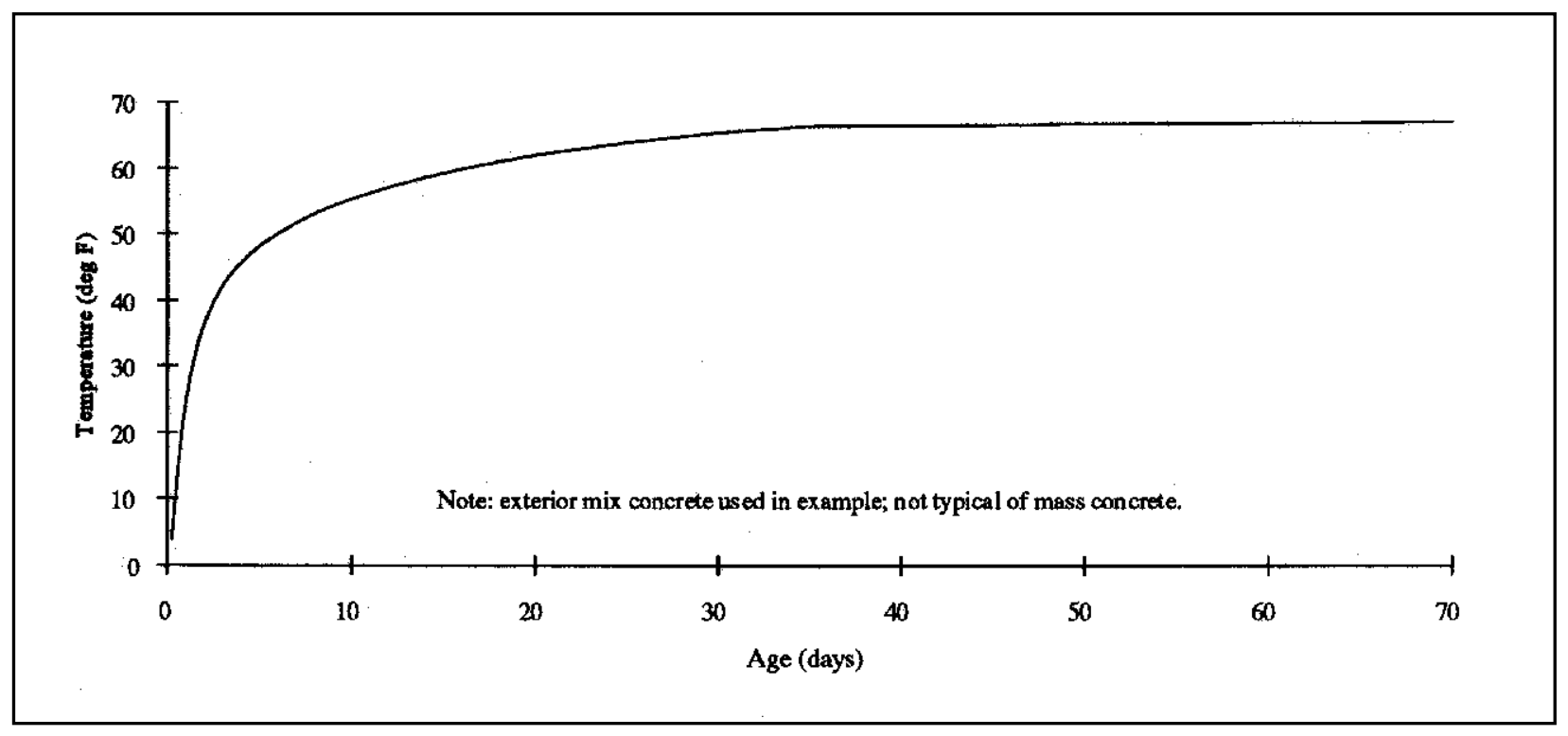

Figure 18. Adiabatic temperature rise for Level 2 thermal analysis 2-D example

moderate strength. Table 8 contains mechanical properties used in the example thermal analysis modulus of elasticity of concrete and foundation materials are required for determination of foundation restraint factors. Slow-load tensile strain capacity values were developed using the methodology described in Appendix A for use in mass and surface gradient cracking analysis as discussed later in this chapter.

\section{Table 8}

Concrete and Foundation Mechanical Properties

\begin{tabular}{|c|c|c|c|}
\hline Material & \begin{tabular}{|l} 
Density \\
$\mathrm{kg} / \mathrm{m}^{3}\left(\mathrm{lb} / \mathrm{ft}^{3}\right)$ \\
\end{tabular} & $\begin{array}{l}\text { Compressive Strength } \\
\text { Mpa (psi) }\end{array}$ & $\begin{array}{l}\text { Modulus of Elasticity } \\
\mathrm{GPa}\left(\times 10^{6} \mathrm{psi}\right) \\
\end{array}$ \\
\hline Limestone & $2,563(160)$ & $103.4(15,000)$ & $48.26(7.00)$ \\
\hline Exterior concrete @ 1 day & $2,243(140)$ & $3.93(570)$ & $12.41(1.80)$ \\
\hline Exterior concrete@ 3 days & same & $7.65(1,110)$ & $20.20(2.93)$ \\
\hline Exterior concrete@7 days & same & $11.24(1,630)$ & $23.44(3.40)$ \\
\hline Exterior concrete@ 28 days & same & $22.48(3,260)$ & $33.65(4.88)$ \\
\hline Exterior concrete @ 90 days & same & $31.10(4,510)$ & $35.51(5.15)$ \\
\hline
\end{tabular}


Step 3: Determine construction parameters. Figure 17 shows the concrete placement temperatures used in the example thermal analysis. Maximum placement temperature during the summer is $15.5 \operatorname{deg} \mathrm{C}(60 \mathrm{deg} \mathrm{F})$, and minimum placement temperature during the winter is $4.4 \operatorname{deg} \mathrm{C}$ ( $40 \mathrm{deg} \mathrm{F}$ ), based on previous specification experience. Placement temperatures are expected to follow mean daily temperatures, except during summer and winter, when temperature controls are typically imposed. Placement temperatures lag mean daily ambient temperatures in the fall by $2.8 \operatorname{deg} \mathrm{C}(5 \operatorname{deg} \mathrm{F})$, until the 4.4-deg C (40-deg F) minimum placement temperature permitted is reached. Other construction parameters assumed are a nominal lift height of $3 \mathrm{~m}(10 \mathrm{ft})$, a construction start date of 1 July, a concrete placement rate of 5 days/lift, with plywood forms removed 2 days after placement, and no insulation.

\section{Temperature Analysis}

Step 4: Prepare temperature model. The ABAQUS FE program (Hibbitt, Karlsson, and Sorensen, Inc. 1994) was used in this example. Details regarding the use of ABAQUS and various ABAQUS and general FE program setup considerations in thermal analyses can be found in ETL 1110-2-365. Figure 19 shows the FE model used for the example. These analyses were performed on the CRAY Supercomputer at the U.S. Army Engineer Research and Development Center (ERDC). A time-step of 0.25 day was used to compute temperature changes, primarily to capture temperature changes during the first 2 days after placement.

a. Surface heat transfer coefficient computations. Equations 3 and 4 were used for computing the surface heat transfer coefficient. Table 9 shows surface heat transfer coefficients computed for various surface treatments at several time periods during the year. The heat transfer coefficients used in this example were those computed for wind only or for wind and plywood forms.

b. Compute temperature histories. Figure 16 shows locations of mass gradient and surface gradient analyses in the structure used in the example. A July 1 start date was assumed for placement of the first lift of mass concrete.

Step 5: Mass gradient temperature analysis. Figure 20 shows temperature histories at the locations of mass gradient analysis in the example.

Step 6: Surface gradient temperature analysis. Surface gradient cracking in the example was analyzed at nominal ages of $0.5,1,2,3,5,7,14,28,60,90$, 120,150 , and 180 days after placement in lift 6 for this example. Table 10 and Figure 21 show the surface gradient temperature distributions across lift 6 in the upper portion of the MSC, determined from FE temperature analysis. Placement time for this lift was 25 days after placement of lift 1. 


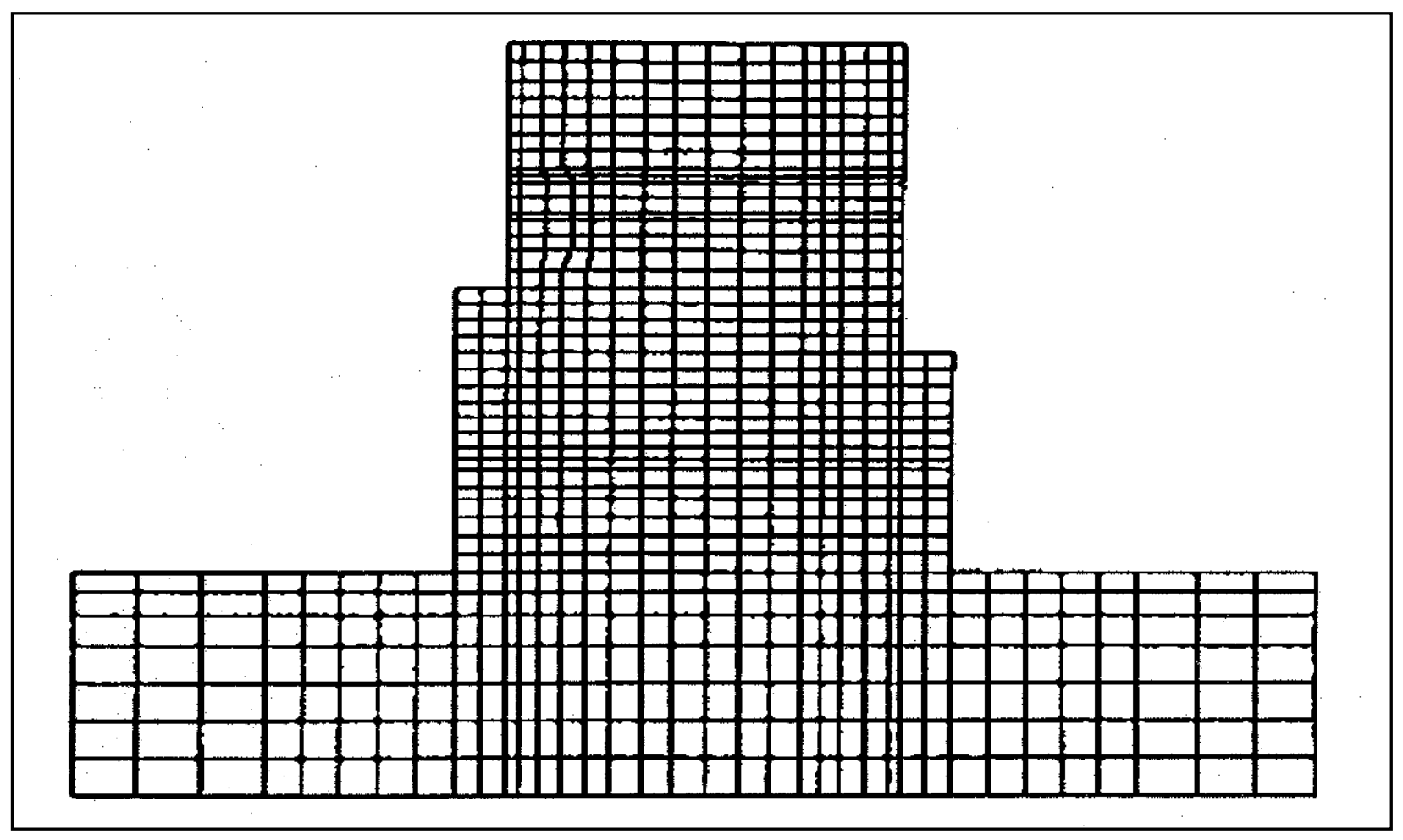

Figure 19. Finite element model of lock wall example

\begin{tabular}{|c|c|c|c|c|c|}
\hline $\begin{array}{l}\text { Table } 9 \\
\text { Summar }\end{array}$ & urface $\mathrm{He}$ & ansfer Coe & cients for & rmal Ana & \\
\hline & Wind Velocity & & $\begin{array}{r}\text { Surface Hea } \\
W / m^{2}-K\end{array}$ & $\begin{array}{l}\text { Isfer Coefficient } \\
\text { //day-in }{ }^{2} \text {-deg F) }\end{array}$ & \\
\hline $\begin{array}{l}\text { Time Span } \\
\text { Months }\end{array}$ & $\begin{array}{l}\mathrm{km} / \mathrm{h} \\
(\mathrm{mi} / \mathrm{hr})\end{array}$ & Wind Velocity Only & $\begin{array}{l}\text { Wind Velocity \& } \\
\text { Plywood }\end{array}$ & $\begin{array}{l}\begin{array}{l}\text { Wind Velocity \& } \\
\text { Insulation }\end{array} \\
\end{array}$ & \begin{tabular}{|l} 
Air, Plywood, \& \\
Insulation
\end{tabular} \\
\hline Nov. - Apr. & $\begin{array}{l}16 \\
(10)\end{array}$ & $\begin{array}{l}25.72 \\
(0.7548)\end{array}$ & $\begin{array}{l}4.913 \\
(0.1442)\end{array}$ & $\begin{array}{l}1.345 \\
(0.03949)\end{array}$ & $\begin{array}{l}1.101 \\
(0.03233)\end{array}$ \\
\hline May-June & $\begin{array}{l}13 \\
(8)\end{array}$ & $\begin{array}{l}22.01 \\
(0.6460)\end{array}$ & \begin{tabular}{|l|}
4.763 \\
$(0.1398)$ \\
\end{tabular} & $\begin{array}{l}1.333 \\
(0.03914)\end{array}$ & $\begin{array}{l}1.094 \\
(0.03210)\end{array}$ \\
\hline \begin{tabular}{|l} 
July - Sept. \\
\end{tabular} & $\begin{array}{l}11 \\
(7)\end{array}$ & $\begin{array}{l}19.71 \\
(0.5785)\end{array}$ & \begin{tabular}{|l|}
4.644 \\
$(0.1363)$
\end{tabular} & $\begin{array}{l}1.324 \\
(0.03887)\end{array}$ & $\begin{array}{l}1.087 \\
(0.03191)\end{array}$ \\
\hline Oct. & $\begin{array}{l}13 \\
(8)\end{array}$ & $\begin{array}{l}21.88 \\
(0.6423)\end{array}$ & $\begin{array}{l}4.756 \\
(0.1396)\end{array}$ & $\begin{array}{l}1.333 \\
(0.03913)\end{array}$ & $\begin{array}{l}1.093 \\
(0.03209)\end{array}$ \\
\hline
\end{tabular}

a. Calculate surface gradient strains. To calculate surface gradient strains requires determination of the depth from the surface of effective interior restraint. This is performed by evaluating the magnitude of temperature change in the interior versus the surface concrete, thereby defining a surface "tension block" described earlier. The following steps illustrate a procedure for determining the distance from the surface where tensile and compressive forces balance, thereby determining the distance from the surface to the point of zero strain, defining the tension block depth. A series of manipulations of temperature history results are used to define the depth " $H$ " of the tension block, where temperature changes causing tension and compression are balanced. 


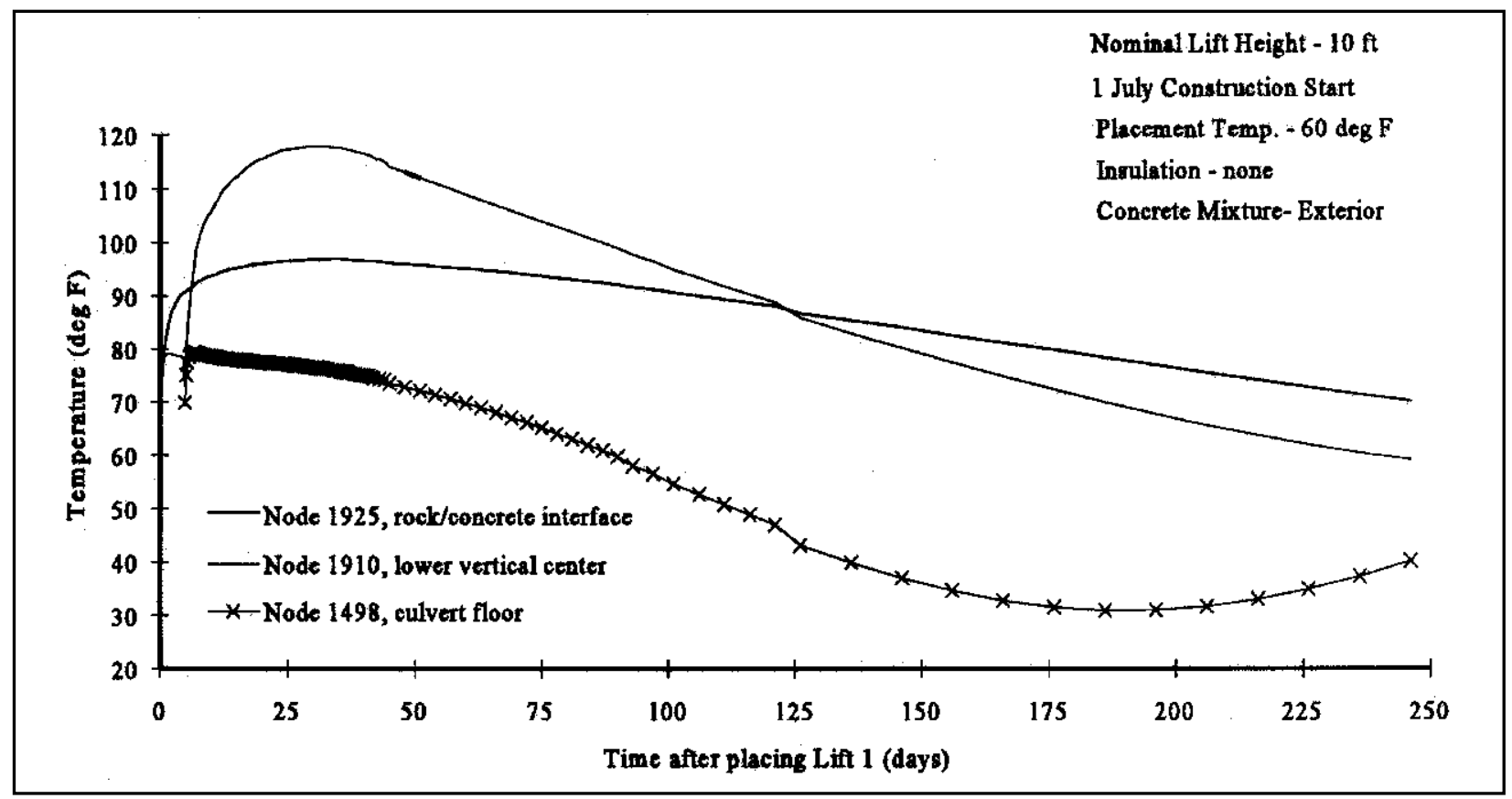

Figure 20. Typical temperature histories at locations of mass gradient analysis

b. Determine reference temperatures. In the example, the reference time was established as 0.5 day after placement of lift 6 (25.5 days after concrete placement start at lift 1). Because the concrete attained a 1-day modulus of elasticity of $12.4 \mathrm{Gpa}\left(1.8 \times 10^{6} \mathrm{psi}\right)$, it was assumed that elastic strains were sustainable in this concrete at an age of 0.5 day.

c. Determine temperature change or differences relative to the reference temperatures. Table 11 shows distributions of temperature difference at all analysis times relative to the reference temperatures at 0.5 day age of lift 6 (25.5 days after lift 1$)$. These are developed by subtracting all of the temperatures in Table 10 from the respective 0.5-day temperatures at the same horizontal coordinates.

$d$. Determine temperature differences relative to surface temperature differences, or "normalized" temperature differences. Table 12 and Figure 22 show temperature differences normalized relative to the surface temperature differences. These normalized temperature differences were developed by subtracting the surface temperature differences (along coordinates 4.0 and 36.0) in Table 11 from the corresponding interior temperature differences at the same time intervals in Table 11, producing the Table 12 normalized temperature differences.

e. Determine offset balance temperatures. To balance tension and compression zones, a balance temperature, $T_{0}$, is determined such that the areas of the normalized temperature distribution above and below $T_{0}$ are equal. Table 13 and Figure 23 show balanced, normalized temperature differences. 


\begin{tabular}{|c|c|c|c|c|c|c|c|c|c|c|c|c|c|}
\hline \multicolumn{14}{|l|}{$\begin{array}{l}\text { Table } 10 \\
\text { Temperat }\end{array}$} \\
\hline \multirow{4}{*}{$\begin{array}{l}\text { Horizontal } \\
\text { Coordinate } \\
\text { m }\end{array}$} & \multicolumn{13}{|c|}{ Age of Concrete in Lift 6 placed 25 days after Lift 1 (days) } \\
\hline & 0.5 & 1 & 2 & 3 & 5 & 7 & 14 & 29 & 59 & 91 & 121 & 151 & 181 \\
\hline & \multicolumn{13}{|c|}{ Elapsed Time ( $T$ ) after Placement of Lift 1 (days) } \\
\hline & 25.5 & 26 & 27 & 28 & 30 & 32 & 39 & 54 & 84 & 116 & 146 & 176 & 206 \\
\hline \multicolumn{14}{|c|}{ Degrees C } \\
\hline 1.2 & 23.3 & 27.8 & 30.5 & 26.6 & 25.8 & 25.4 & 24.4 & 22.3 & 17.0 & 10.1 & 4.1 & 0.1 & -0.9 \\
\hline 1.4 & 23.0 & 28.5 & 32.4 & 30.3 & 29.2 & 28.5 & 26.8 & 24.1 & 18.2 & 11.2 & 5.1 & 0.9 & -0.4 \\
\hline 1.5 & 22.6 & 29.2 & 34.2 & 34.1 & 32.7 & 31.6 & 29.2 & 25.8 & 19.4 & 12.4 & 6.2 & 1.8 & 0.1 \\
\hline 1.8 & 22.4 & 29.2 & 35.4 & 37.2 & 37.2 & 36.2 & 33.3 & 28.9 & 21.6 & 14.5 & 8.1 & 3.3 & 1.0 \\
\hline 2.1 & 22.4 & 29.2 & 35.6 & 38.3 & 39.7 & 39.3 & 36.5 & 31.7 & 23.7 & 16.3 & 9.8 & 4.7 & 1.9 \\
\hline 2.4 & 22.4 & 29.2 & 35.7 & 38.7 & 41.0 & 41.2 & 39.0 & 34.0 & 25.5 & 18.0 & 11.4 & 6.0 & 2.8 \\
\hline 2.7 & 22.4 & 29.2 & 35.7 & 38.8 & 41.5 & 42.3 & 40.8 & 36.0 & 27.2 & 19.6 & 12.9 & 7.3 & 3.7 \\
\hline 3.0 & 22.4 & 29.2 & 35.7 & 38.8 & 41.7 & 42.7 & 41.9 & 37.5 & 28.6 & 20.8 & 14.0 & 8.2 & 4.4 \\
\hline 3.2 & 22.4 & 29.2 & 35.7 & 38.8 & 41.8 & 43.0 & 42.7 & 38.8 & 29.9 & 22.0 & 15.1 & 9.2 & 5.1 \\
\hline 3.5 & 22.4 & 29.2 & 35.7 & 38.8 & 41.9 & 43.1 & 43.4 & 40.0 & 31.2 & 23.2 & 16.2 & 10.2 & 5.8 \\
\hline 3.7 & 22.4 & 29.2 & 35.7 & 38.8 & 41.9 & 43.2 & 43.9 & 41.1 & 32.4 & 24.3 & 17.3 & 11.1 & 6.6 \\
\hline 4.1 & 22.4 & 29.2 & 35.7 & 38.8 & 41.9 & 43.3 & 44.5 & 42.6 & 34.3 & 26.0 & 18.9 & 12.5 & 7.7 \\
\hline 4.5 & 22.4 & 29.2 & 35.7 & 38.8 & 41.9 & 43.3 & 44.9 & 44.0 & 36.0 & 27.6 & 20.4 & 13.9 & 8.7 \\
\hline 4.9 & 22.4 & 29.2 & 35.7 & 38.8 & 41.9 & 43.3 & 45.2 & 45.0 & 37.5 & 29.1 & 21.7 & 15.1 & 9.7 \\
\hline 5.3 & 22.4 & 29.2 & 35.7 & 38.8 & 41.9 & 43.3 & 45.4 & 45.9 & 38.8 & 30.3 & 22.9 & 16.1 & 10.5 \\
\hline 5.7 & 22.4 & 29.2 & 35.7 & 38.8 & 41.9 & 43.3 & 45.4 & 46.5 & 39.9 & 31.4 & 23.8 & 17.0 & 11.2 \\
\hline 6.1 & 22.4 & 29.2 & 35.7 & 38.8 & 41.9 & 43.3 & 45.5 & 47.0 & 40.6 & 32.1 & 24.5 & 17.6 & 11.7 \\
\hline 6.5 & 22.4 & 29.2 & 35.7 & 38.8 & 41.9 & 43.3 & 45.5 & 47.2 & 41.0 & 32.5 & 24.9 & 17.9 & 12.0 \\
\hline 6.9 & 22.4 & 29.2 & 35.7 & 38.8 & 41.9 & 43.3 & 45.5 & 47.1 & 41.0 & 32.5 & 24.9 & 17.9 & 12.0 \\
\hline 7.3 & 22.4 & 29.2 & 35.7 & 38.8 & 41.9 & 43.3 & 45.4 & 46.9 & 40.7 & 32.2 & 24.6 & 17.7 & 11.8 \\
\hline 7.7 & 22.4 & 29.2 & 35.7 & 38.8 & 41.9 & 43.3 & 45.3 & 46.4 & 39.9 & 31.5 & 24.0 & 17.1 & 11.3 \\
\hline 8.1 & 22.4 & 29.2 & 35.7 & 38.8 & 41.9 & 43.3 & 45.1 & 45.7 & 38.8 & 30.5 & 23.0 & 16.2 & 10.6 \\
\hline 8.5 & 22.4 & 29.2 & 35.7 & 38.8 & 41.9 & 43.2 & 44.7 & 44.5 & 37.3 & 29.1 & 21.7 & 15.1 & 9.7 \\
\hline 8.7 & 22.4 & 29.2 & 35.7 & 38.8 & 41.9 & 43.2 & 44.3 & 43.6 & 36.2 & 28.0 & 20.7 & 14.2 & 9.0 \\
\hline 9.0 & 22.4 & 29.2 & 35.7 & 38.8 & 41.8 & 43.0 & 43.7 & 42.4 & 34.8 & 26.7 & 19.5 & 13.1 & 8.2 \\
\hline 9.2 & 22.4 & 29.2 & 35.7 & 38.8 & 41.7 & 42.8 & 42.9 & 41.0 & 33.3 & 25.3 & 18.2 & 12.0 & 7.3 \\
\hline 9.4 & 22.4 & 29.2 & 35.7 & 38.8 & 41.5 & 42.3 & 41.7 & 39.3 & 31.6 & 23.8 & 16.8 & 10.7 & 6.4 \\
\hline 9.8 & 22.4 & 29.2 & 35.7 & 38.7 & 41.0 & 41.2 & 39.7 & 36.8 & 29.3 & 21.6 & 14.8 & 9.0 & 5.1 \\
\hline 10.1 & 22.4 & 29.2 & 35.6 & 38.3 & 39.7 & 39.3 & 37.1 & 34.0 & 26.7 & 19.2 & 12.5 & 7.1 & 3.7 \\
\hline 10.4 & 22.4 & 29.2 & 35.4 & 37.2 & 37.2 & 36.2 & 33.7 & 30.6 & 23.8 & 16.5 & 10.0 & 5.0 & 2.3 \\
\hline 10.7 & 22.6 & 29.2 & 34.2 & 34.1 & 32.7 & 31.6 & 29.4 & 26.8 & 20.7 & 13.6 & 7.3 & 2.7 & 0.8 \\
\hline 10.8 & 22.9 & 28.9 & 32.8 & 31.0 & 29.5 & 28.7 & 27.0 & 24.7 & 19.0 & 12.0 & 5.8 & 1.5 & 0.0 \\
\hline 11.0 & 23.3 & 27.8 & 30.5 & 26.6 & 25.8 & 25.4 & 24.4 & 22.6 & 17.2 & 10.3 & 4.3 & 0.3 & -0.7 \\
\hline
\end{tabular}




\begin{tabular}{|c|c|c|c|c|c|c|c|c|c|c|c|c|c|}
\hline Table 10 & 0 & \multicolumn{11}{|c|}{ Age of Concrete in Lift 6 placed 25 days after Lift 1 (days) } & \\
\hline \multirow{3}{*}{$\begin{array}{l}\text { Horizontal } \\
\text { Coordinate } \\
\mathrm{ft}\end{array}$} & 0.5 & 1 & 2 & 3 & 5 & 7 & 14 & 29 & 59 & 91 & 121 & 151 & 181 \\
\hline & \multicolumn{13}{|c|}{ Elapsed Time ( $\mathrm{T}$ ) after Placement of Lift 1 (days) } \\
\hline & 25.5 & 26 & 27 & 28 & 30 & 32 & 39 & 54 & 84 & 116 & 146 & 176 & 206 \\
\hline \multicolumn{14}{|c|}{ Degrees F } \\
\hline 4.00 & 73.9 & 82.1 & 87.0 & 79.8 & 78.5 & 77.7 & 75.9 & 72.2 & 62.5 & 50.2 & 39.4 & 32.2 & 30.4 \\
\hline 4.50 & 73.3 & 83.4 & 90.3 & 86.6 & 84.6 & 83.3 & 80.2 & 75.4 & 64.7 & 52.2 & 41.3 & 33.7 & 31.3 \\
\hline 5.00 & 72.7 & 84.6 & 93.6 & 93.3 & 90.8 & 88.8 & 84.6 & 78.5 & 66.9 & 54.3 & 43.2 & 35.2 & 32.1 \\
\hline 6.00 & 72.3 & 84.6 & 95.7 & 99.0 & 99.0 & 97.2 & 91.9 & 84.1 & 70.9 & 58.0 & 46.6 & 37.9 & 33.8 \\
\hline 7.00 & 72.3 & 84.5 & 96.2 & 101.0 & 103.5 & 102.8 & 97.7 & 89.0 & 74.6 & 61.4 & 49.7 & 40.5 & 35.4 \\
\hline 8.00 & 72.3 & 84.5 & 96.3 & 101.6 & 105.8 & 106.2 & 102.1 & 93.2 & 77.9 & 64.4 & 52.5 & 42.8 & 37.0 \\
\hline 9.00 & 72.3 & 84.5 & 96.3 & 101.8 & 106.7 & 108.1 & 105.4 & 96.8 & 81.0 & 67.3 & 55.1 & 45.1 & 38.6 \\
\hline 9.81 & 72.3 & 84.5 & 96.3 & 101.9 & 107.1 & 108.9 & 107.4 & 99.5 & 83.5 & 69.5 & 57.2 & 46.8 & 39.9 \\
\hline 10.63 & 72.3 & 84.5 & 96.3 & 101.9 & 107.3 & 109.4 & 108.9 & 101.9 & 85.8 & 71.6 & 59.2 & 48.6 & 41.2 \\
\hline 11.44 & 72.3 & 84.5 & 96.3 & 101.9 & 107.4 & 109.7 & 110.1 & 104.0 & 88.1 & 73.7 & 61.1 & 50.3 & 42.5 \\
\hline 12.25 & 72.3 & 84.5 & 96.3 & 101.9 & 107.4 & 109.8 & 111.0 & 106.0 & 90.3 & 75.8 & 63.1 & 52.0 & 43.8 \\
\hline 13.50 & 72.3 & 84.5 & 96.3 & 101.9 & 107.4 & 109.9 & 112.1 & 108.8 & 93.7 & 78.9 & 66.0 & 54.5 & 45.8 \\
\hline 14.75 & 72.3 & 84.5 & 96.3 & 101.9 & 107.4 & 109.9 & 112.8 & 111.1 & 96.7 & 81.8 & 68.7 & 57.0 & 47.7 \\
\hline 16.00 & 72.3 & 84.5 & 96.3 & 101.9 & 107.4 & 109.9 & 113.3 & 113.1 & 99.5 & 84.4 & 71.1 & 59.1 & 49.4 \\
\hline 17.25 & 72.3 & 84.5 & 96.3 & 101.9 & 107.4 & 109.9 & 113.6 & 114.6 & 101.8 & 86.6 & 73.2 & 61.0 & 50.9 \\
\hline 18.58 & 72.3 & 84.5 & 96.3 & 101.9 & 107.4 & 109.9 & 113.8 & 115.8 & 103.8 & 88.5 & 74.9 & 62.6 & 52.2 \\
\hline 19.92 & 72.3 & 84.5 & 96.3 & 101.9 & 107.4 & 109.9 & 113.9 & 116.5 & 105.1 & 89.8 & 76.1 & 63.6 & 53.1 \\
\hline 21.25 & 72.3 & 84.5 & 96.3 & 101.9 & 107.4 & 109.9 & 113.9 & 116.9 & 105.8 & 90.4 & 76.8 & 64.2 & 53.5 \\
\hline 22.58 & 72.3 & 84.5 & 96.3 & 101.9 & 107.4 & 109.9 & 113.9 & 116.8 & 105.8 & 90.5 & 76.8 & 64.3 & 53.6 \\
\hline 23.88 & 72.3 & 84.5 & 96.3 & 101.9 & 107.4 & 109.9 & 113.8 & 116.4 & 105.2 & 89.9 & 76.3 & 63.8 & 53.2 \\
\hline 25.17 & 72.3 & 84.5 & 96.3 & 101.9 & 107.4 & 109.9 & 113.6 & 115.6 & 103.9 & 88.7 & 75.2 & 62.8 & 52.3 \\
\hline 26.46 & 72.3 & 84.5 & 96.3 & 101.9 & 107.4 & 109.9 & 113.3 & 114.2 & 101.9 & 86.9 & 73.4 & 61.2 & 51.1 \\
\hline 27.75 & 72.3 & 84.5 & 96.3 & 101.9 & 107.4 & 109.8 & 112.5 & 112.1 & 99.2 & 84.3 & 71.1 & 59.1 & 49.4 \\
\hline 28.56 & 72.3 & 84.5 & 96.3 & 101.9 & 107.4 & 109.7 & 111.8 & 110.4 & 97.1 & 82.4 & 69.3 & 57.5 & 48.2 \\
\hline 29.38 & 72.3 & 84.5 & 96.3 & 101.9 & 107.3 & 109.4 & 110.7 & 108.3 & 94.7 & 80.1 & 67.2 & 55.7 & 46.8 \\
\hline 30.19 & 72.3 & 84.5 & 96.3 & 101.9 & 107.1 & 109.0 & 109.1 & 105.7 & 92.0 & 77.6 & 64.8 & 53.6 & 45.2 \\
\hline 31.00 & 72.3 & 84.5 & 96.3 & 101.8 & 106.8 & 108.1 & 107.0 & 102.7 & 89.0 & 74.8 & 62.2 & 51.3 & 43.5 \\
\hline 32.00 & 72.3 & 84.5 & 96.3 & 101.6 & 105.8 & 106.2 & 103.5 & 98.3 & 84.8 & 70.9 & 58.6 & 48.2 & 41.2 \\
\hline 33.00 & 72.3 & 84.5 & 96.2 & 101.0 & 103.5 & 102.8 & 98.8 & 93.1 & 80.1 & 66.6 & 54.5 & 44.7 & 38.7 \\
\hline 34.00 & 72.3 & 84.6 & 95.7 & 99.0 & 99.0 & 97.2 & 92.6 & 87.1 & 74.9 & 61.8 & 50.0 & 41.0 & 36.1 \\
\hline 35.00 & 72.7 & 84.6 & 93.6 & 93.3 & 90.8 & 88.8 & 85.0 & 80.2 & 69.2 & 56.4 & 45.1 & 36.9 & 33.4 \\
\hline 35.50 & 73.3 & 84.0 & 91.0 & 87.8 & 85.2 & 83.6 & 80.7 & 76.5 & 66.2 & 53.6 & 42.5 & 34.8 & 32.1 \\
\hline 36.00 & 73.9 & 82.1 & 87.0 & 79.8 & 78.5 & 77.7 & 76.0 & 72.6 & 63.0 & 50.6 & 39.7 & 32.5 & 30.7 \\
\hline
\end{tabular}




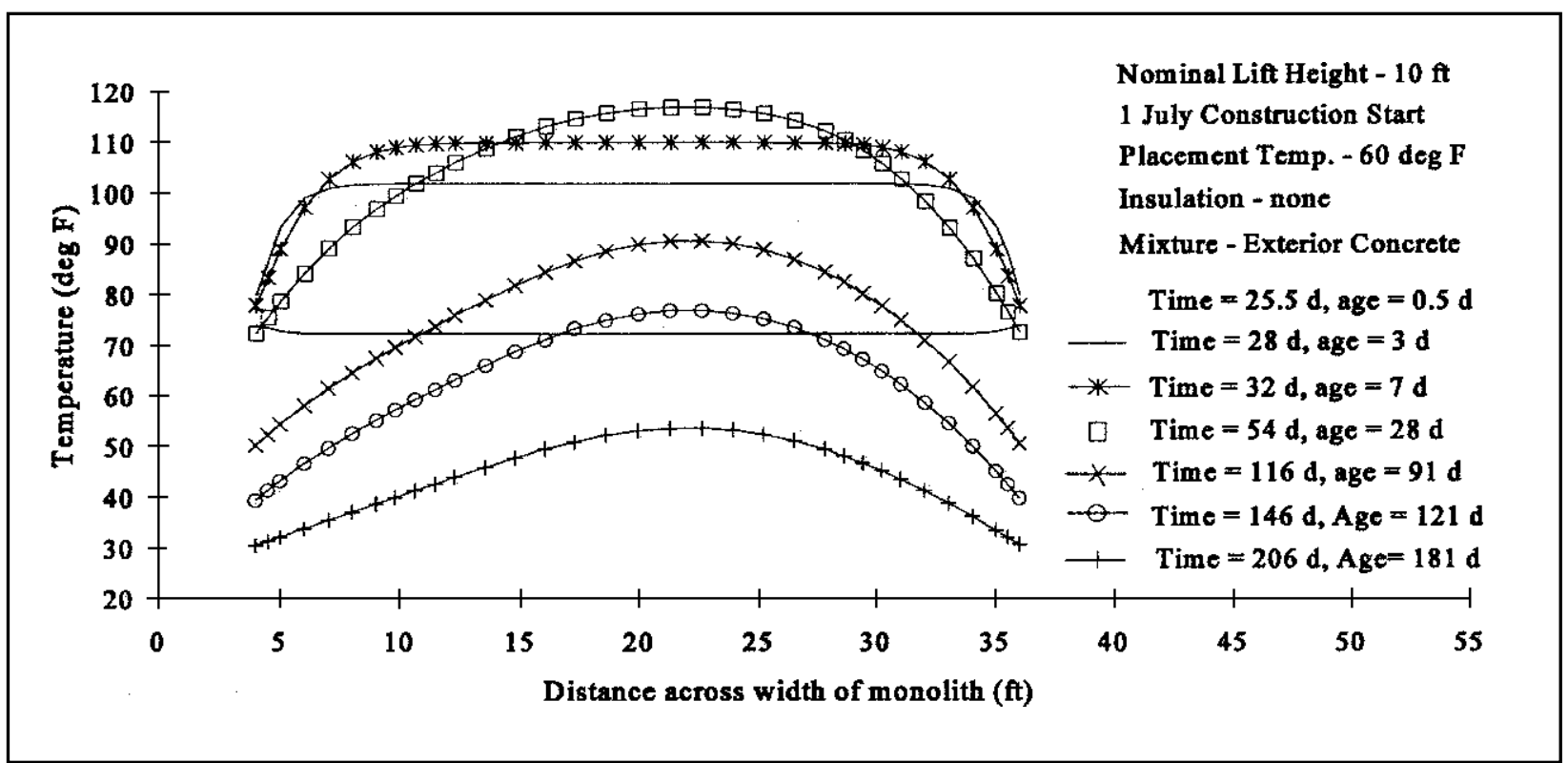

Figure 21. Temperature distributions across lift 6 used in surface gradient analysis

$f$. The depth of $T_{0}$ defines the depth of " $H$ " of the tension block. A formula for the sums of individual areas between temperature points of the normalized temperature difference distribution across a section above and below $T_{0}$ was used for the determination of $H$. These calculations were solved by extensive computer spreadsheet analysis, resulting in tension block " $H$ " values.

\section{Cracking Analysis}

Step 7: Mass gradient cracking analysis. Mass gradient thermal strains are computed from Equation 1. Table 14 summarizes the computations.

a. Foundation restraint factor $\left(K_{f}\right)$. Foundation restraint, based upon relative differences in the stiffness of the foundation material and the concrete, is computed from Equation 5 as shown below.

$$
K_{f}=\frac{1}{1+\frac{A_{g} E_{c}}{A_{f} E_{f}}}=0.64
$$




\begin{tabular}{|c|c|c|c|c|c|c|c|c|c|c|c|c|c|}
\hline \multicolumn{14}{|l|}{$\begin{array}{l}\text { Table } 11 \\
\text { Temperat }\end{array}$} \\
\hline \multirow{4}{*}{$\begin{array}{l}\text { Horizontal } \\
\text { Coordinate } \\
\text { m }\end{array}$} & \multicolumn{13}{|c|}{ Age of Concrete in Lift 6 placed 25 days after Lift 1 (days) } \\
\hline & 0.5 & 1 & 2 & 3 & 5 & 7 & 14 & 29 & 59 & 91 & 121 & 151 & 181 \\
\hline & \multicolumn{13}{|c|}{ Elapsed Time ( $T$ ) after Placement of Lift 1 (days) } \\
\hline & 25.5 & 26 & 27 & 28 & 30 & 32 & 39 & 54 & 84 & 116 & 146 & 176 & 206 \\
\hline \multicolumn{14}{|c|}{ Degrees C } \\
\hline 1.2 & 0.0 & 4.6 & 7.2 & 3.3 & 2.5 & 2.1 & 1.1 & -1.0 & -6.3 & -13.2 & -19.2 & -23.2 & -24.2 \\
\hline 1.4 & 0.0 & 5.6 & 9.4 & 7.4 & 6.3 & 5.5 & 3.9 & 1.1 & -4.8 & -11.7 & -17.8 & -22.0 & -23.4 \\
\hline 1.5 & 0.0 & 6.6 & 11.6 & 11.4 & 10.1 & 9.0 & 6.6 & 3.2 & -3.2 & -10.2 & -16.4 & -20.8 & -22.6 \\
\hline 1.8 & 0.0 & 6.8 & 13.0 & 14.8 & 14.8 & 13.8 & 10.9 & 6.5 & -0.8 & -7.9 & -14.3 & -19.1 & -21.4 \\
\hline 2.1 & 0.0 & 6.8 & 13.3 & 16.0 & 17.4 & 17.0 & 14.1 & 9.3 & 1.3 & -6.1 & -12.5 & -17.7 & -20.5 \\
\hline 2.4 & 0.0 & 6.8 & 13.3 & 16.3 & 18.6 & 18.9 & 16.6 & 11.6 & 3.1 & -4.4 & -11.0 & -16.4 & -19.6 \\
\hline 2.7 & 0.0 & 6.8 & 13.3 & 16.4 & 19.2 & 19.9 & 18.4 & 13.7 & 4.9 & -2.8 & -9.5 & -15.1 & -18.7 \\
\hline 3.0 & 0.0 & 6.8 & 13.3 & 16.4 & 19.4 & 20.4 & 19.5 & 15.1 & 6.2 & -1.5 & -8.4 & -14.1 & -18.0 \\
\hline 3.2 & 0.0 & 6.8 & 13.3 & 16.5 & 19.5 & 20.6 & 20.4 & 16.4 & 7.5 & -0.4 & -7.3 & -13.2 & -17.2 \\
\hline 3.5 & 0.0 & 6.8 & 13.3 & 16.5 & 19.5 & 20.8 & 21.0 & 17.6 & 8.8 & 0.8 & -6.2 & -12.2 & -16.5 \\
\hline 3.7 & 0.0 & 6.8 & 13.3 & 16.5 & 19.5 & 20.9 & 21.5 & 18.8 & 10.0 & 2.0 & -5.1 & -11.3 & -15.8 \\
\hline 4.1 & 0.0 & 6.8 & 13.3 & 16.5 & 19.5 & 20.9 & 22.1 & 20.3 & 11.9 & 3.7 & -3.5 & -9.8 & -14.7 \\
\hline 4.5 & 0.0 & 6.8 & 13.3 & 16.5 & 19.5 & 20.9 & 22.6 & 21.6 & 13.6 & 5.3 & -2.0 & -8.5 & -13.6 \\
\hline 4.9 & 0.0 & 6.8 & 13.3 & 16.5 & 19.5 & 20.9 & 22.8 & 22.7 & 15.1 & 6.7 & -0.6 & -7.3 & -12.7 \\
\hline 5.3 & 0.0 & 6.8 & 13.3 & 16.5 & 19.5 & 20.9 & 23.0 & 23.5 & 16.4 & 8.0 & 0.5 & -6.3 & -11.9 \\
\hline 5.7 & 0.0 & 6.8 & 13.3 & 16.5 & 19.5 & 20.9 & 23.1 & 24.2 & 17.5 & 9.0 & 1.5 & -5.4 & -11.2 \\
\hline 6.1 & 0.0 & 6.8 & 13.3 & 16.5 & 19.5 & 20.9 & 23.1 & 24.6 & 18.2 & 9.7 & 2.2 & -4.8 & -10.7 \\
\hline 6.5 & 0.0 & 6.8 & 13.3 & 16.5 & 19.5 & 20.9 & 23.1 & 24.8 & 18.6 & 10.1 & 2.5 & -4.5 & -10.7 \\
\hline 6.9 & 0.0 & 6.8 & 13.3 & 16.5 & 19.5 & 20.9 & 23.1 & 24.8 & 18.6 & 10.1 & 2.5 & -4.4 & -10.4 \\
\hline 7.3 & 0.0 & 6.8 & 13.3 & 16.5 & 19.5 & 20.9 & 23.1 & 24.6 & 18.3 & 9.8 & 2.3 & -4.7 & -10.6 \\
\hline 7.7 & 0.0 & 6.8 & 13.3 & 16.5 & 19.5 & 20.9 & 23.0 & 24.1 & 17.6 & 9.1 & 1.6 & -5.3 & -11.1 \\
\hline 8.1 & 0.0 & 6.8 & 13.3 & 16.5 & 19.5 & 20.9 & 22.8 & 23.3 & 16.5 & 8.1 & 0.7 & -6.1 & -11.8 \\
\hline 8.5 & 0.0 & 6.8 & 13.3 & 16.5 & 19.5 & 20.9 & 22.4 & 22.2 & 15.0 & 6.7 & -0.6 & -7.3 & -12.7 \\
\hline 8.7 & 0.0 & 6.8 & 13.3 & 16.5 & 19.5 & 20.8 & 22.0 & 21.2 & 13.8 & 5.6 & -1.7 & -8.2 & -13.4 \\
\hline 9.0 & 0.0 & 6.8 & 13.3 & 16.5 & 19.5 & 20.7 & 21.3 & 20.0 & 12.5 & 4.4 & -2.8 & -9.2 & -14.2 \\
\hline 9.2 & 0.0 & 6.8 & 13.3 & 16.4 & 19.4 & 20.4 & 20.5 & 18.6 & 11.0 & 3.0 & -4.1 & -10.4 & -15.0 \\
\hline 9.4 & 0.0 & 6.8 & 13.3 & 16.4 & 19.2 & 19.9 & 19.3 & 16.9 & 9.3 & 1.4 & -5.6 & -11.6 & -16.0 \\
\hline 9.8 & 0.0 & 6.8 & 13.3 & 16.3 & 18.6 & 18.9 & 17.4 & 14.5 & 7.0 & -0.7 & -7.6 & -13.4 & -17.3 \\
\hline 10.1 & 0.0 & 6.8 & 13.3 & 16.0 & 17.4 & 16.9 & 14.7 & 11.6 & 4.3 & -3.2 & -9.9 & -15.3 & -18.6 \\
\hline 10.4 & 0.0 & 6.8 & 13.0 & 14.8 & 14.8 & 13.8 & 11.3 & 8.2 & 1.4 & -5.9 & -12.4 & -17.4 & -20.1 \\
\hline 10.7 & 0.0 & 6.6 & 11.6 & 11.4 & 10.1 & 9.0 & 6.8 & 4.2 & -1.9 & -9.0 & -15.3 & -19.9 & -21.8 \\
\hline 10.8 & 0.0 & 6.0 & 9.9 & 8.1 & 6.6 & 5.7 & 4.1 & 1.8 & -3.9 & -10.9 & -17.1 & -21.4 & -22.9 \\
\hline 11.0 & 0.0 & 4.6 & 7.2 & 3.3 & 2.5 & 2.1 & 1.2 & -0.7 & -6.0 & -12.9 & -19.0 & -23.0 & -24.0 \\
\hline
\end{tabular}




\begin{tabular}{|c|c|c|c|c|c|c|c|c|c|c|c|c|c|}
\hline Table 11 & 1 & \multicolumn{11}{|c|}{ Age of Concrete in Lift 6 placed 25 days after Lift 1 (days) } & \\
\hline \multirow{3}{*}{$\begin{array}{l}\text { Horizontal } \\
\text { Coordinate } \\
\mathrm{ft}\end{array}$} & 0.5 & 1 & 2 & 3 & 5 & 7 & 14 & 29 & 59 & 91 & 121 & 151 & 181 \\
\hline & \multicolumn{13}{|c|}{ Elapsed Time ( $\mathrm{T}$ ) after Placement of Lift 1 (days) } \\
\hline & 25.5 & 26 & 27 & 28 & 30 & 32 & 39 & 54 & 84 & 116 & 146 & 176 & 206 \\
\hline \multicolumn{14}{|c|}{ Degrees F } \\
\hline 4.00 & 0.0 & 8.2 & 13.0 & 5.9 & 4.5 & 3.8 & 2.0 & -1.7 & -11.4 & -23.8 & -34.6 & -41.7 & -43.5 \\
\hline 4.50 & 0.0 & 10.1 & 16.9 & 13.2 & 11.3 & 10.0 & 6.9 & 2.0 & -8.6 & -21.1 & -32.0 & -39.6 & -42.0 \\
\hline 5.00 & 0.0 & 11.9 & 20.9 & 20.6 & 18.1 & 16.1 & 11.9 & 5.8 & -5.8 & -18.4 & -29.5 & -37.5 & -40.6 \\
\hline 6.00 & 0.0 & 12.3 & 23.4 & 26.7 & 26.6 & 24.8 & 19.5 & 11.8 & -1.4 & -14.3 & -25.7 & -34.4 & -38.6 \\
\hline 7.00 & 0.0 & 12.3 & 23.9 & 28.7 & 31.2 & 30.5 & 25.4 & 16.7 & 2.3 & -10.9 & -22.6 & -31.8 & -36.9 \\
\hline 8.00 & 0.0 & 12.3 & 24.0 & 29.4 & 33.5 & 33.9 & 29.9 & 20.9 & 5.7 & -7.8 & -19.7 & -29.4 & -35.2 \\
\hline 9.00 & 0.0 & 12.3 & 24.0 & 29.6 & 34.5 & 35.8 & 33.2 & 24.6 & 8.8 & -5.0 & -17.1 & -27.2 & -33.6 \\
\hline 9.81 & 0.0 & 12.3 & 24.0 & 29.6 & 34.9 & 36.7 & 35.2 & 27.2 & 11.2 & -2.8 & -15.1 & -25.4 & -32.3 \\
\hline 10.63 & 0.0 & 12.3 & 24.0 & 29.6 & 35.0 & 37.1 & 36.7 & 29.6 & 13.6 & -0.6 & -13.1 & -23.7 & -31.0 \\
\hline 11.44 & 0.0 & 12.3 & 24.0 & 29.6 & 35.1 & 37.4 & 37.9 & 31.8 & 15.8 & 1.4 & -11.1 & -22.0 & -29.7 \\
\hline 12.25 & 0.0 & 12.3 & 24.0 & 29.6 & 35.1 & 37.5 & 38.8 & 33.8 & 18.1 & 3.5 & -9.2 & -20.3 & -28.4 \\
\hline 13.50 & 0.0 & 12.3 & 24.0 & 29.6 & 35.2 & 37.6 & 39.8 & 36.5 & 21.4 & 6.6 & -6.3 & -17.7 & -26.4 \\
\hline 14.75 & 0.0 & 12.3 & 24.0 & 29.6 & 35.2 & 37.7 & 40.6 & 38.9 & 24.5 & 9.5 & -3.6 & -15.3 & -24.5 \\
\hline 16.00 & 0.0 & 12.3 & 24.0 & 29.6 & 35.2 & 37.7 & 41.1 & 40.8 & 27.2 & 12.1 & -1.2 & -13.1 & -22.8 \\
\hline 17.25 & 0.0 & 12.3 & 24.0 & 29.6 & 35.2 & 37.7 & 41.4 & 42.4 & 29.6 & 14.3 & 0.9 & -11.3 & -21.3 \\
\hline 18.58 & 0.0 & 12.3 & 24.0 & 29.6 & 35.2 & 37.7 & 41.6 & 43.5 & 31.5 & 16.2 & 2.7 & -9.7 & -20.1 \\
\hline 19.92 & 0.0 & 12.3 & 24.0 & 29.6 & 35.2 & 37.7 & 41.6 & 44.3 & 32.8 & 17.5 & 3.9 & -8.6 & -19.2 \\
\hline 21.25 & 0.0 & 12.3 & 24.0 & 29.6 & 35.2 & 37.7 & 41.6 & 44.6 & 33.5 & 18.2 & 4.5 & -8.0 & -18.7 \\
\hline 22.58 & 0.0 & 12.3 & 24.0 & 29.6 & 35.2 & 37.7 & 41.6 & 44.6 & 33.6 & 18.3 & 4.6 & -8.0 & -18.7 \\
\hline 23.88 & 0.0 & 12.3 & 24.0 & 29.6 & 35.2 & 37.7 & 41.6 & 44.2 & 32.9 & 17.7 & 4.1 & -8.5 & -19.1 \\
\hline 25.17 & 0.0 & 12.3 & 24.0 & 29.6 & 35.2 & 37.7 & 41.4 & 43.4 & 31.6 & 16.5 & 2.9 & -9.5 & -19.9 \\
\hline 26.46 & 0.0 & 12.3 & 24.0 & 29.6 & 35.2 & 37.6 & 41.0 & 42.0 & 29.7 & 14.6 & 1.2 & -11.0 & -21.2 \\
\hline 27.75 & 0.0 & 12.3 & 24.0 & 29.6 & 35.1 & 37.6 & 40.3 & 39.9 & 27.0 & 12.1 & -1.2 & -13.1 & -22.8 \\
\hline 28.56 & 0.0 & 12.3 & 24.0 & 29.6 & 35.1 & 37.4 & 39.5 & 38.2 & 24.9 & 10.1 & -3.0 & -14.7 & -24.1 \\
\hline 29.38 & 0.0 & 12.3 & 24.0 & 29.6 & 35.0 & 37.2 & 38.4 & 36.0 & 22.5 & 7.9 & -5.1 & -16.6 & -25.5 \\
\hline 30.19 & 0.0 & 12.3 & 24.0 & 29.6 & 34.9 & 36.7 & 36.9 & 33.5 & 19.7 & 5.4 & -7.4 & -18.6 & -27.1 \\
\hline 31.00 & 0.0 & 12.3 & 24.0 & 29.6 & 34.5 & 35.9 & 34.8 & 30.5 & 16.7 & 2.6 & -10.0 & -20.9 & -28.8 \\
\hline 32.00 & 0.0 & 12.3 & 24.0 & 29.4 & 33.5 & 34.0 & 31.3 & 26.1 & 12.5 & -1.3 & -13.7 & -24.1 & -31.1 \\
\hline 33.00 & 0.0 & 12.3 & 23.9 & 28.7 & 31.3 & 30.5 & 26.5 & 20.8 & 7.8 & -5.7 & -17.7 & -27.5 & -33.5 \\
\hline 34.00 & 0.0 & 12.3 & 23.4 & 26.7 & 26.6 & 24.8 & 20.3 & 14.8 & 2.6 & -10.6 & -22.3 & -31.3 & -36.2 \\
\hline 35.00 & 0.0 & 11.9 & 20.9 & 20.6 & 18.1 & 16.1 & 12.3 & 7.5 & -3.5 & -16.3 & -27.6 & -35.8 & -39.3 \\
\hline 35.50 & 0.0 & 10.8 & 17.8 & 14.5 & 11.9 & 10.3 & 7.4 & 3.2 & -7.1 & -19.7 & -30.8 & -38.5 & -41.2 \\
\hline 36.00 & 0.0 & 8.2 & 13.0 & 5.9 & 4.5 & 3.8 & 2.1 & -1.3 & -10.9 & -23.3 & -34.2 & -41.4 & -43.2 \\
\hline
\end{tabular}




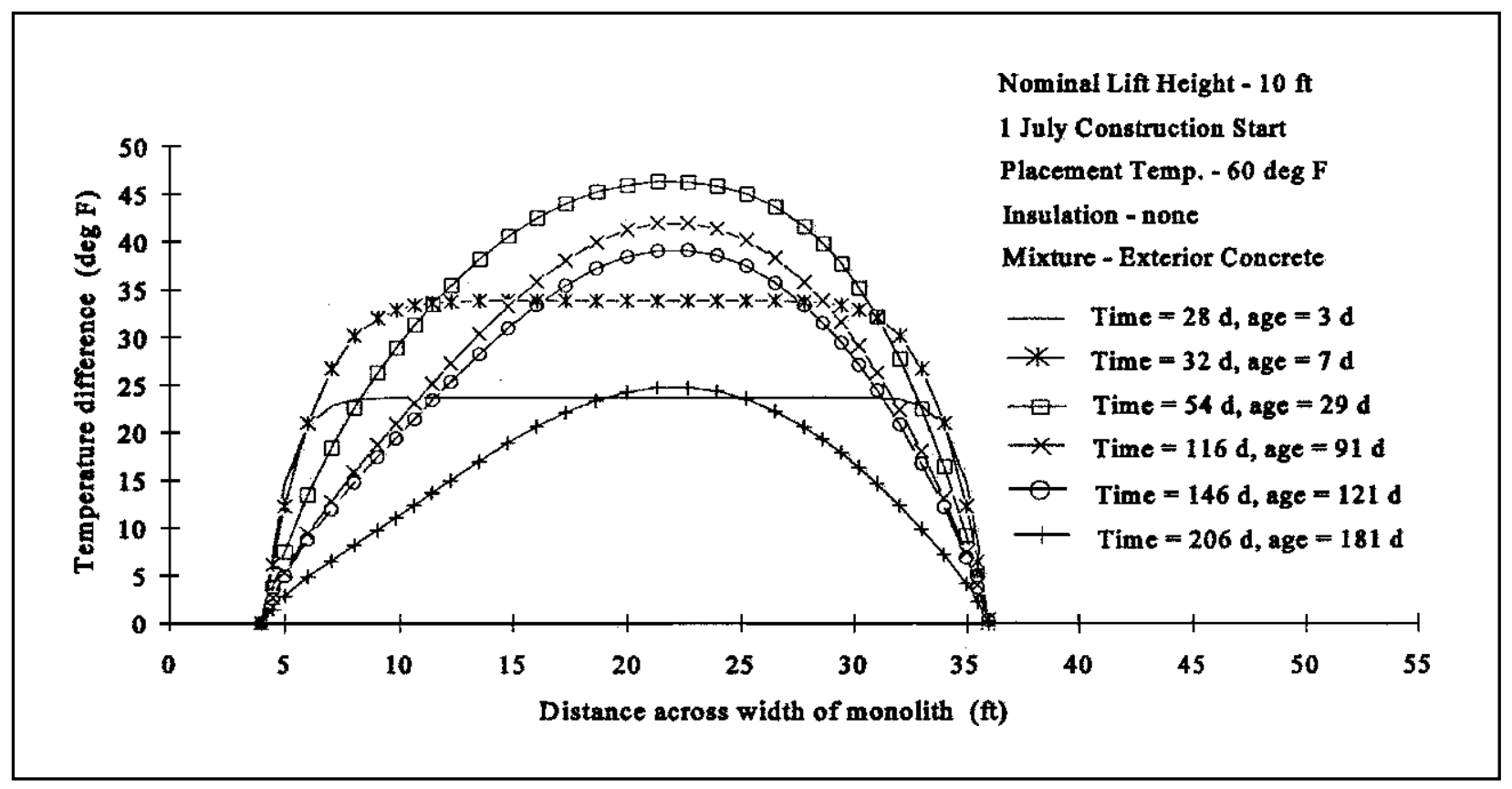

Figure 22. Temperature differences in lift 6 for surface gradient analysis

where

$$
\begin{aligned}
\mathrm{A}_{\mathrm{g}}= & \text { gross area of concrete cross section (relative value) }=1 \\
E_{c}= & \text { modulus of elasticity of mass concrete }(\text { mean value during } \\
& \text { cooling period) }=34.5 \mathrm{Gpa}\left(5.0 \times 10^{6} \mathrm{psi}\right) \\
A_{f}= & 2.5 \text { (area of foundation or zone restraining contraction of } \\
& \text { concrete, generally as a plane surface at contact, recommended } \\
& \text { maximum value is } 2.5) \\
E_{f}= & \text { modulus of elasticity of foundation }=48.3 \mathrm{Gpa}\left(7.0 \times 10^{6} \mathrm{psi}\right)
\end{aligned}
$$

b. Structure restraint factor $\left(K_{R}\right)$. Structure restraint factors are computed at distances, $h$, along the vertical centerline of the structure at $\mathrm{h}=3.5 \mathrm{~m}$ $(11.5 \mathrm{ft})$ and at $h=H=7.0 \mathrm{~m}(23 \mathrm{ft})$ at the base of the culvert. The length, $L$, of the structure is assumed to be $13.4 \mathrm{~m}(44 \mathrm{ft})$ in the axial direction. Note that the mass gradient analysis shown below assumes that the foundation restraint is applied by the foundation material adjacent to the concrete. Therefore, the foundation temperatures used in the analysis are taken at the foundation-concrete interface rather than at the location of

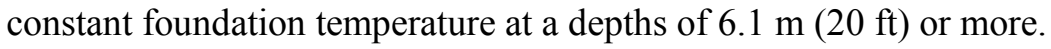

Using Equation 4.2 of $\mathrm{ACI} 207.2 \mathrm{R}$ for $L / H$ less than 2.5 


\begin{tabular}{|c|c|c|c|c|c|c|c|c|c|c|c|c|c|}
\hline \multicolumn{14}{|c|}{$\begin{array}{l}\text { Table } 12 \\
\text { Temperature Differences Normalized in Reference to Surface Temperature Differences } \\
\text { for Surface Gradient Analysis }\end{array}$} \\
\hline \multirow{4}{*}{$\begin{array}{l}\text { Horizontal } \\
\text { Coordinate } \\
\text { m }\end{array}$} & \multicolumn{13}{|c|}{ Age of Concrete in Lift 6 placed 25 days after Lift 1 (days) } \\
\hline & 0.5 & 1 & 2 & 3 & 5 & 7 & 14 & 29 & 59 & 91 & 121 & 151 & 181 \\
\hline & \multicolumn{13}{|c|}{ Elapsed Time ( $T$ ) after Placement of Lift 1 (days) } \\
\hline & 25.5 & 26 & 27 & 28 & 30 & 32 & 39 & 54 & 84 & 116 & 146 & 176 & 206 \\
\hline \multicolumn{14}{|c|}{ Degrees C } \\
\hline 1.2 & 0.0 & 0.0 & 0.0 & 0.0 & 0.0 & 0.0 & 0.0 & 0.0 & 0.0 & 0.0 & 0.0 & 0.0 & 0.0 \\
\hline 1.4 & 0.0 & 1.0 & 2.2 & 4.1 & 3.8 & 3.4 & 2.8 & 2.1 & 1.6 & 1.5 & 1.4 & 1.2 & 0.8 \\
\hline 1.5 & 0.0 & 2.1 & 4.3 & 8.2 & 7.6 & 6.9 & 5.5 & 4.2 & 3.1 & 3.0 & 2.8 & 2.3 & 1.6 \\
\hline 1.8 & 0.0 & 2.3 & 5.7 & 11.6 & 12.3 & 11.7 & 9.8 & 7.5 & 5.6 & 5.3 & 4.9 & 4.0 & 2.7 \\
\hline 2.1 & 0.0 & 2.3 & 6.0 & 12.7 & 14.8 & 14.9 & 13.0 & 10.2 & 7.6 & 7.1 & 6.7 & 5.5 & 3.7 \\
\hline 2.4 & 0.0 & 2.3 & 6.1 & 13.1 & 16.1 & 16.8 & 15.5 & 12.6 & 9.5 & 8.8 & 8.2 & 6.8 & 4.6 \\
\hline 2.7 & 0.0 & 2.3 & 6.1 & 13.2 & 16.6 & 17.8 & 17.3 & 14.6 & 11.2 & 10.4 & 9.7 & 8.1 & 5.5 \\
\hline 3.0 & 0.0 & 2.3 & 6.1 & 13.2 & 16.8 & 18.3 & 18.4 & 16.1 & 12.6 & 11.6 & 10.8 & 9.0 & 6.2 \\
\hline 3.2 & 0.0 & 2.3 & 6.1 & 13.2 & 16.9 & 18.5 & 19.3 & 17.4 & 13.9 & 12.8 & 11.9 & 10.0 & 6.9 \\
\hline 3.5 & 0.0 & 2.3 & 6.1 & 13.2 & 17.0 & 18.7 & 19.9 & 18.6 & 15.1 & 14.0 & 13.0 & 11.0 & 7.6 \\
\hline 3.7 & 0.0 & 2.3 & 6.1 & 13.2 & 17.0 & 18.8 & 20.4 & 19.7 & 16.4 & 15.1 & 14.1 & 11.9 & 8.4 \\
\hline 4.1 & 0.0 & 2.3 & 6.1 & 13.2 & 17.0 & 18.8 & 21.0 & 21.2 & 18.2 & 16.9 & 15.7 & 13.3 & 9.5 \\
\hline 4.5 & 0.0 & 2.3 & 6.1 & 13.2 & 17.0 & 18.8 & 21.5 & 22.6 & 19.9 & 18.5 & 17.2 & 14.7 & 10.5 \\
\hline 4.9 & 0.0 & 2.3 & 6.1 & 13.2 & 17.0 & 18.8 & 21.7 & 23.6 & 21.5 & 19.9 & 18.6 & 15.9 & 11.5 \\
\hline 5.3 & 0.0 & 2.3 & 6.1 & 13.2 & 17.0 & 18.8 & 21.9 & 24.5 & 22.8 & 21.2 & 19.7 & 16.9 & 12.3 \\
\hline 5.7 & 0.0 & 2.3 & 6.1 & 13.2 & 17.0 & 18.8 & 22.0 & 25.1 & 23.8 & 22.2 & 20.7 & 17.8 & 13.0 \\
\hline 6.1 & 0.0 & 2.3 & 6.1 & 13.2 & 17.0 & 18.8 & 22.0 & 25.5 & 24.6 & 22.9 & 21.4 & 18.4 & 13.5 \\
\hline 6.5 & 0.0 & 2.3 & 6.1 & 13.2 & 17.0 & 18.8 & 22.0 & 25.7 & 24.9 & 23.3 & 21.7 & 18.7 & 13.7 \\
\hline 6.9 & 0.0 & 2.3 & 6.1 & 13.2 & 17.0 & 18.8 & 22.0 & 25.7 & 25.0 & 23.3 & 21.7 & 18.7 & 13.8 \\
\hline 7.3 & 0.0 & 2.3 & 6.1 & 13.2 & 17.0 & 18.8 & 22.0 & 25.5 & 24.6 & 23.0 & 21.5 & 18.5 & 13.5 \\
\hline 7.7 & 0.0 & 2.3 & 6.1 & 13.2 & 17.0 & 18.8 & 21.9 & 25.0 & 23.9 & 22.3 & 20.8 & 17.9 & 13.1 \\
\hline 8.1 & 0.0 & 2.3 & 6.1 & 13.2 & 17.0 & 18.8 & 21.7 & 24.3 & 22.8 & 21.3 & 19.9 & 17.0 & 12.4 \\
\hline 8.5 & 0.0 & 2.3 & 6.1 & 13.2 & 17.0 & 18.8 & 21.3 & 23.1 & 21.3 & 19.9 & 18.6 & 15.9 & 11.5 \\
\hline 8.7 & 0.0 & 2.3 & 6.1 & 13.2 & 17.0 & 18.7 & 20.9 & 22.1 & 20.1 & 18.8 & 17.5 & 15.0 & 10.8 \\
\hline 9.0 & 0.0 & 2.3 & 6.1 & 13.2 & 16.9 & 18.6 & 20.2 & 21.0 & 18.8 & 17.6 & 16.4 & 13.9 & 10.0 \\
\hline 9.2 & 0.0 & 2.3 & 6.1 & 13.2 & 16.8 & 18.3 & 19.4 & 19.6 & 17.3 & 16.2 & 15.1 & 12.8 & 9.1 \\
\hline 9.4 & 0.0 & 2.3 & 6.1 & 13.2 & 16.6 & 17.8 & 18.2 & 17.9 & 15.6 & 14.6 & 13.6 & 11.5 & 8.2 \\
\hline 9.8 & 0.0 & 2.3 & 6.1 & 13.1 & 16.1 & 16.8 & 16.3 & 15.4 & 13.3 & 12.5 & 11.6 & 9.8 & 6.9 \\
\hline 10.1 & 0.0 & 2.3 & 6.0 & 12.7 & 14.8 & 14.9 & 13.6 & 12.5 & 10.7 & 10.0 & 9.3 & 7.9 & 5.5 \\
\hline 10.4 & 0.0 & 2.3 & 5.7 & 11.6 & 12.3 & 11.7 & 10.2 & 9.1 & 7.8 & 7.3 & 6.8 & 5.7 & 4.1 \\
\hline 10.7 & 0.0 & 2.1 & 4.3 & 8.2 & 7.5 & 6.9 & 5.7 & 5.1 & 4.4 & 4.2 & 3.9 & 3.3 & 2.3 \\
\hline 10.8 & 0.0 & 1.4 & 2.6 & 4.8 & 4.1 & 3.6 & 3.0 & 2.7 & 2.4 & 2.3 & 2.1 & 1.8 & 1.3 \\
\hline 11.0 & 0.0 & 0.0 & 0.0 & 0.0 & 0.0 & 0.0 & 0.1 & 0.2 & 0.3 & 0.2 & 0.2 & 0.2 & 0.1 \\
\hline
\end{tabular}




\begin{tabular}{|c|c|c|c|c|c|c|c|c|c|c|c|c|c|}
\hline Table 12 & Oم & \multicolumn{11}{|c|}{ Age of Concrete in Lift 6 placed 25 days after Lift 1 (days) } & \\
\hline \multirow{3}{*}{$\begin{array}{l}\text { Horizontal } \\
\text { Coordinate } \\
\mathrm{ft}\end{array}$} & 0.5 & 1 & 2 & 3 & 5 & 7 & 14 & 29 & 59 & 91 & 121 & 151 & 181 \\
\hline & \multicolumn{13}{|c|}{ Elapsed Time ( $\mathrm{T}$ ) after Placement of Lift 1 (days) } \\
\hline & 25.5 & 26 & 27 & 28 & 30 & 32 & 39 & 54 & 84 & 116 & 146 & 176 & 206 \\
\hline \multicolumn{14}{|c|}{ Degrees F } \\
\hline 4.00 & 0.0 & 0.0 & 0.0 & 0.0 & 0.0 & 0.0 & 0.0 & 0.0 & 0.0 & 0.0 & 0.0 & 0.0 & 0.0 \\
\hline 4.50 & 0.0 & 1.9 & 3.9 & 7.4 & 6.8 & 6.2 & 5.0 & 3.8 & 2.8 & 2.7 & 2.5 & 2.1 & 1.4 \\
\hline 5.00 & 0.0 & 3.7 & 7.8 & 14.7 & 13.6 & 12.4 & 9.9 & 7.5 & 5.6 & 5.4 & 5.0 & 4.2 & 2.9 \\
\hline 6.00 & 0.0 & 4.1 & 10.3 & 20.8 & 22.1 & 21.1 & 17.6 & 13.5 & 10.0 & 9.5 & 8.8 & 7.3 & 4.9 \\
\hline 7.00 & 0.0 & 4.1 & 10.8 & 22.8 & 26.7 & 26.7 & 23.5 & 18.4 & 13.7 & 12.9 & 12.0 & 9.9 & 6.6 \\
\hline 8.00 & 0.0 & 4.1 & 11.0 & 23.5 & 29.0 & 30.2 & 27.9 & 22.7 & 17.1 & 15.9 & 14.8 & 12.3 & 8.2 \\
\hline 9.00 & 0.0 & 4.1 & 11.0 & 23.7 & 30.0 & 32.1 & 31.2 & 26.3 & 20.2 & 18.8 & 17.5 & 14.5 & 9.8 \\
\hline 9.81 & 0.0 & 4.1 & 11.0 & 23.7 & 30.3 & 32.9 & 33.2 & 28.9 & 22.6 & 21.0 & 19.5 & 16.3 & 9.8 \\
\hline 10.63 & 0.0 & 4.1 & 11.0 & 23.7 & 30.5 & 33.4 & 34.7 & 31.3 & 24.9 & 23.1 & 21.5 & 18.0 & 11.1 \\
\hline 11.44 & 0.0 & 4.1 & 11.0 & 23.7 & 30.6 & 33.6 & 35.9 & 33.5 & 27.2 & 25.2 & 23.5 & 19.7 & 12.4 \\
\hline 12.25 & 0.0 & 4.1 & 11.0 & 23.7 & 30.6 & 33.8 & 36.8 & 35.5 & 29.5 & 27.3 & 25.4 & 21.4 & 13.7 \\
\hline 13.50 & 0.0 & 4.1 & 11.0 & 23.8 & 30.6 & 33.9 & 37.9 & 38.2 & 32.8 & 30.4 & 28.3 & 24.0 & 15.0 \\
\hline 14.75 & 0.0 & 4.1 & 11.0 & 23.8 & 30.6 & 33.9 & 38.6 & 40.6 & 35.9 & 33.3 & 31.0 & 26.4 & 17.0 \\
\hline 16.00 & 0.0 & 4.1 & 11.0 & 23.8 & 30.6 & 33.9 & 39.1 & 42.5 & 38.6 & 35.9 & 33.4 & 28.6 & 18.9 \\
\hline 17.25 & 0.0 & 4.1 & 11.0 & 23.8 & 30.6 & 33.9 & 39.4 & 44.1 & 41.0 & 38.1 & 35.5 & 30.4 & 20.7 \\
\hline 18.58 & 0.0 & 4.1 & 11.0 & 23.8 & 30.6 & 33.9 & 39.6 & 45.2 & 42.9 & 40.0 & 37.2 & 32.0 & 22.1 \\
\hline 19.92 & 0.0 & 4.1 & 11.0 & 23.8 & 30.6 & 33.9 & 39.6 & 46.0 & 44.2 & 41.3 & 38.4 & 33.1 & 23.4 \\
\hline 21.25 & 0.0 & 4.1 & 11.0 & 23.8 & 30.6 & 33.9 & 39.7 & 46.3 & 44.9 & 41.9 & 39.1 & 33.7 & 24.3 \\
\hline 22.58 & 0.0 & 4.1 & 11.0 & 23.8 & 30.6 & 33.9 & 39.6 & 46.3 & 44.9 & 42.0 & 39.1 & 33.7 & 24.8 \\
\hline 23.88 & 0.0 & 4.1 & 11.0 & 23.8 & 30.6 & 33.9 & 39.6 & 45.9 & 44.3 & 41.4 & 38.6 & 33.2 & 24.4 \\
\hline 25.17 & 0.0 & 4.1 & 11.0 & 23.8 & 30.6 & 33.9 & 39.4 & 45.1 & 43.0 & 40.2 & 37.5 & 32.2 & 23.6 \\
\hline 26.46 & 0.0 & 4.1 & 11.0 & 23.8 & 30.6 & 33.9 & 39.0 & 43.7 & 41.1 & 38.4 & 35.8 & 30.7 & 22.3 \\
\hline 27.75 & 0.0 & 4.1 & 11.0 & 23.7 & 30.6 & 33.8 & 38.3 & 41.6 & 38.4 & 35.8 & 33.4 & 28.6 & 20.7 \\
\hline 28.56 & 0.0 & 4.1 & 11.0 & 23.7 & 30.6 & 33.6 & 37.5 & 39.9 & 36.3 & 33.9 & 31.6 & 26.9 & 19.4 \\
\hline 29.38 & 0.0 & 4.1 & 11.0 & 23.7 & 30.5 & 33.4 & 36.4 & 37.8 & 33.9 & 31.6 & 29.5 & 25.1 & 18.0 \\
\hline 30.19 & 0.0 & 4.1 & 11.0 & 23.7 & 30.3 & 32.9 & 34.9 & 35.2 & 31.1 & 29.1 & 27.1 & 23.0 & 16.4 \\
\hline 31.00 & 0.0 & 4.1 & 11.0 & 23.7 & 30.0 & 32.1 & 32.8 & 32.2 & 28.1 & 26.3 & 24.5 & 20.7 & 14.7 \\
\hline 32.00 & 0.0 & 4.1 & 11.0 & 23.5 & 29.0 & 30.2 & 29.3 & 27.8 & 23.9 & 22.4 & 20.9 & 17.6 & 12.4 \\
\hline 33.00 & 0.0 & 4.1 & 10.9 & 22.8 & 26.7 & 26.7 & 24.5 & 22.6 & 19.2 & 18.1 & 16.8 & 14.2 & 9.9 \\
\hline 34.00 & 0.0 & 4.1 & 10.3 & 20.8 & 22.1 & 21.1 & 18.3 & 16.5 & 14.0 & 13.2 & 12.3 & 10.3 & 7.3 \\
\hline 35.00 & 0.0 & 3.7 & 7.8 & 14.7 & 13.6 & 12.4 & 10.3 & 9.2 & 7.9 & 7.5 & 7.0 & 5.9 & 4.2 \\
\hline 35.50 & 0.0 & 2.6 & 4.7 & 8.6 & 7.4 & 6.5 & 5.4 & 4.9 & 4.3 & 4.1 & 3.7 & 3.2 & 2.3 \\
\hline 36.00 & 0.0 & 0.0 & 0.0 & 0.0 & 0.0 & 0.0 & 0.1 & 0.4 & 0.5 & 0.4 & 0.4 & 0.3 & 0.2 \\
\hline
\end{tabular}




\begin{tabular}{|c|c|c|c|c|c|c|c|c|c|c|c|c|c|}
\hline \multicolumn{14}{|c|}{$\begin{array}{l}\text { Table } 13 \\
\text { Balanced or Effective Temperature Differences to Determine “ } H \text { ” and Surface Gradients } \\
\text { Strains }\end{array}$} \\
\hline \multirow{4}{*}{$\begin{array}{l}\text { Horizontal } \\
\text { Coordinate } \\
\text { m }\end{array}$} & \multicolumn{13}{|c|}{ Age of Concrete in Lift 6 placed 25 days after Lift 1 (days) } \\
\hline & 0.5 & 1 & 2 & 3 & 5 & 7 & 14 & 29 & 59 & 91 & 121 & 151 & 181 \\
\hline & \multicolumn{13}{|c|}{ Elapsed Time ( $T$ ) after Placement of Lift 1 (days) } \\
\hline & 25.5 & 26 & 27 & 28 & 30 & 32 & 39 & 54 & 84 & 116 & 146 & 176 & 206 \\
\hline \multicolumn{14}{|c|}{ Degrees C } \\
\hline 1.2 & 0.0 & -2.2 & -5.8 & -12.3 & -15.4 & -16.6 & -17.9 & -18.5 & -16.6 & -15.5 & -14.4 & -12.3 & -8.8 \\
\hline 1.4 & 0.0 & -1.2 & -3.6 & -8.2 & -11.6 & -13.1 & -15.1 & -16.4 & -15.1 & -14.0 & -13.0 & -11.1 & -8.0 \\
\hline 1.5 & 0.0 & -0.1 & -1.4 & -4.2 & -7.8 & -9.7 & -12.4 & -14.3 & -13.5 & -12.5 & -11.7 & -10.1 & -7.2 \\
\hline 1.8 & 0.0 & 0.1 & 0.0 & -0.8 & -3.1 & -4.9 & -8.1 & -11.0 & -11.1 & -10.2 & -9.5 & -8.3 & -6.1 \\
\hline 2.1 & 0.0 & 0.1 & 0.2 & 0.3 & -0.5 & -1.7 & -4.8 & -8.3 & -9.0 & -8.4 & -7.8 & -6.8 & -5.2 \\
\hline 2.4 & 0.0 & 0.1 & 0.3 & 0.7 & 0.7 & 0.2 & -2.4 & -5.9 & -7.1 & -6.7 & -6.2 & -5.5 & -4.3 \\
\hline 2.7 & 0.0 & 0.1 & 0.3 & 0.8 & 1.3 & 1.2 & -0.5 & -3.9 & -5.4 & -5.1 & -4.7 & -4.2 & -3.4 \\
\hline 3.0 & 0.0 & 0.1 & 0.3 & 0.8 & 1.5 & 1.7 & 0.6 & -2.4 & -4.1 & -3.9 & -3.6 & -3.3 & -2.7 \\
\hline 3.2 & 0.0 & 0.1 & 0.3 & 0.9 & 1.6 & 2.0 & 1.4 & -1.1 & -2.8 & -2.7 & -2.5 & -2.3 & -1.9 \\
\hline 3.5 & 0.0 & 0.1 & 0.3 & 0.9 & 1.6 & 2.1 & 2.1 & -0.1 & -1.5 & -1.5 & -1.4 & -1.3 & -1.2 \\
\hline 3.7 & 0.0 & 0.1 & 0.3 & 0.9 & 1.6 & 2.2 & 2.6 & 1.2 & -0.2 & -0.4 & -0.3 & -0.4 & -0.5 \\
\hline 4.1 & 0.0 & 0.1 & 0.3 & 0.9 & 1.6 & 2.3 & 3.2 & 2.7 & -1.6 & 1.4 & 1.3 & -1.0 & -0.6 \\
\hline 4.5 & 0.0 & 0.1 & 0.3 & 0.9 & 1.6 & 2.3 & 3.6 & 4.0 & 3.3 & 3.0 & 2.8 & 2.4 & 1.7 \\
\hline 4.9 & 0.0 & 0.1 & 0.3 & 0.9 & 1.6 & 2.3 & 3.9 & 5.1 & 4.8 & 4.4 & 4.1 & 3.6 & 2.6 \\
\hline 5.3 & 0.0 & 0.1 & 0.3 & 0.9 & 1.6 & 2.3 & 4.0 & 6.0 & 6.1 & 5.7 & 5.3 & 4.6 & 3.5 \\
\hline 5.7 & 0.0 & 0.1 & 0.3 & 0.9 & 1.6 & 2.3 & 4.1 & 6.6 & 7.2 & 6.7 & 6.2 & 5.5 & 4.2 \\
\hline 6.1 & 0.0 & 0.1 & 0.3 & 0.9 & 1.6 & 2.3 & 4.2 & 7.0 & 7.9 & 7.4 & 6.9 & 6.1 & 4.6 \\
\hline 6.5 & 0.0 & 0.1 & 0.3 & 0.9 & 1.6 & 2.3 & 4.2 & 7.2 & 8.3 & 7.8 & 7.3 & 6.4 & 4.9 \\
\hline 6.9 & 0.0 & 0.1 & 0.3 & 0.9 & 1.6 & 2.3 & 4.2 & 7.2 & 8.4 & 7.8 & 7.3 & 6.4 & 4.9 \\
\hline 7.3 & 0.0 & 0.1 & 0.3 & 0.9 & 1.6 & 2.3 & 4.1 & 7.0 & 8.0 & 7.5 & 7.0 & 6.2 & 4.7 \\
\hline 7.7 & 0.0 & 0.1 & 0.3 & 0.9 & 1.6 & 2.3 & 4.0 & 6.5 & 7.3 & 6.8 & 6.4 & 5.6 & 4.3 \\
\hline 8.1 & 0.0 & 0.1 & 0.3 & 0.9 & 1.6 & 2.3 & 3.8 & 5.8 & 6.2 & 5.8 & 5.4 & 4.7 & 3.6 \\
\hline 8.5 & 0.0 & 0.1 & 0.3 & 0.9 & 1.6 & 2.2 & 3.4 & 4.6 & 4.7 & 4.4 & 4.1 & 3.6 & 2.6 \\
\hline 8.7 & 0.0 & 0.1 & 0.3 & 0.9 & 1.6 & 2.1 & 3.0 & 3.6 & 3.5 & 3.3 & 3.1 & 2.7 & 1.9 \\
\hline 9.0 & 0.0 & 0.1 & 0.3 & 0.9 & 1.6 & 2.0 & 2.4 & 2.5 & 2.2 & 2.1 & 1.9 & 1.6 & 1.1 \\
\hline 9.2 & 0.0 & 0.1 & 0.3 & 0.8 & 1.5 & 1.7 & 1.5 & 1.0 & 0.7 & 0.7 & 0.6 & 0.5 & 0.3 \\
\hline 9.4 & 0.0 & 0.1 & 0.3 & 0.8 & 1.3 & 1.3 & 0.4 & -0.6 & -1.0 & -0.9 & -0.8 & -0.8 & -0.7 \\
\hline 9.8 & 0.0 & 0.1 & 0.3 & 0.7 & 0.7 & 0.2 & -1.6 & -3.1 & -3.3 & -3.0 & -2.8 & -2.5 & -1.9 \\
\hline 10.1 & 0.0 & 0.1 & 0.3 & 0.4 & -0.5 & -1.7 & -4.2 & -6.0 & -5.9 & -5.5 & -5.1 & -4.4 & -3.3 \\
\hline 10.4 & 0.0 & 0.1 & 0.0 & -0.8 & -3.1 & -4.9 & -7.7 & -6.4 & -8.9 & -8.2 & -7.6 & -6.6 & -4.8 \\
\hline 10.7 & 0.0 & -0.1 & -1.4 & -4.2 & -7.8 & -9.7 & -12.1 & -13.4 & -12.2 & -11.3 & -10.6 & -9.0 & -6.5 \\
\hline 10.8 & 0.0 & -0.8 & -3.1 & -7.5 & -11.3 & -12.9 & -14.9 & -15.8 & -14.2 & -13.2 & -12.4 & -10.5 & -7.6 \\
\hline 11.0 & 0.0 & -2.2 & -5.8 & -12.3 & -15.4 & -16.6 & -17.8 & -18.3 & -16.3 & -15.3 & -14.2 & -12.1 & -8.7 \\
\hline
\end{tabular}




\begin{tabular}{|c|c|c|c|c|c|c|c|c|c|c|c|c|c|}
\hline \multicolumn{14}{|c|}{ Table 13 (Concluded) } \\
\hline \multirow{4}{*}{$\begin{array}{l}\text { Horizontal } \\
\text { Coordinate } \\
\mathrm{ft}\end{array}$} & \multicolumn{13}{|c|}{ Age of Concrete in Lift 6 placed 25 days after Lift 1 (days) } \\
\hline & 0.5 & 1 & 2 & 3 & 5 & 7 & 14 & 29 & 59 & 91 & 121 & 151 & 181 \\
\hline & \multicolumn{13}{|c|}{ Elapsed Time ( $\mathrm{T}$ ) after Placement of Lift 1 (days) } \\
\hline & 25.5 & 26 & 27 & 28 & 30 & 32 & 39 & 54 & 84 & 116 & 146 & 176 & 206 \\
\hline \multicolumn{14}{|c|}{ Degrees F } \\
\hline 4.00 & 0.0 & -3.9 & -10.4 & -22.2 & -27.7 & -29.8 & -32.2 & -33.3 & -29.9 & -27.9 & -26.0 & -22.1 & -15.9 \\
\hline 4.50 & 0.0 & -2.1 & -6.5 & -14.8 & -20.9 & -23.6 & -27.2 & -29.6 & -27.1 & -25.2 & -23.5 & -20.1 & -14.5 \\
\hline 5.00 & 0.0 & -0.2 & -2.6 & -7.5 & -14.1 & -17.5 & -22.2 & -25.8 & -24.3 & -22.5 & -21.0 & -18.0 & -13.0 \\
\hline 6.00 & 0.0 & 0.2 & -0.1 & -1.4 & -5.6 & -8.8 & -14.6 & -19.8 & -19.9 & -18.4 & -17.2 & -14.9 & -11.0 \\
\hline 7.00 & 0.0 & 0.1 & 0.4 & 0.6 & -1.0 & -3.1 & -8.7 & -14.9 & -16.2 & -15.0 & -14.0 & -12.3 & -9.3 \\
\hline 8.00 & 0.0 & 0.1 & 0.6 & 1.3 & 1.3 & 0.4 & -4.2 & -10.7 & -12.9 & -12.0 & -11.2 & -9.9 & -7.7 \\
\hline 9.00 & 0.0 & 0.1 & 0.6 & 1.5 & 2.3 & 2.2 & -1.0 & -7.0 & -9.7 & -9.1 & -8.5 & -7.6 & -6.1 \\
\hline 9.81 & 0.0 & 0.1 & 0.6 & 1.5 & 2.7 & 3.1 & 1.0 & -4.4 & -7.3 & -6.9 & -6.5 & -5.9 & -4.8 \\
\hline 10.63 & 0.0 & 0.1 & 0.6 & 1.5 & 2.8 & 3.6 & 2.6 & -2.0 & -5.0 & -4.8 & -4.5 & -4.1 & -3.5 \\
\hline 11.44 & 0.0 & 0.1 & 0.6 & 1.5 & 2.9 & 3.8 & 3.7 & -0.2 & -2.7 & -2.7 & -2.5 & -2.4 & -2.2 \\
\hline 12.25 & 0.0 & 0.1 & 0.6 & 1.5 & 2.9 & 4.0 & 4.7 & 2.2 & -0.4 & -0.6 & -0.6 & -0.7 & -0.9 \\
\hline 13.50 & 0.0 & 0.1 & 0.6 & 1.5 & 3.0 & 4.1 & 5.7 & 4.9 & 2.9 & 2.5 & 2.3 & 1.8 & 1.1 \\
\hline 14.75 & 0.0 & 0.1 & 0.6 & 1.5 & 3.0 & 4.1 & 6.5 & 7.3 & 6.0 & 5.4 & 5.0 & 4.2 & 3.0 \\
\hline 16.00 & 0.0 & 0.1 & 0.6 & 1.5 & 3.0 & 4.1 & 7.0 & 9.2 & 8.7 & 8.0 & 7.4 & 6.4 & 4.7 \\
\hline 17.25 & 0.0 & 0.1 & 0.6 & 1.5 & 3.0 & 4.1 & 7.3 & 10.7 & 11.0 & 10.2 & 9.5 & 8.3 & 6.2 \\
\hline 18.58 & 0.0 & 0.1 & 0.6 & 1.5 & 3.0 & 4.1 & 7.4 & 11.9 & 13.0 & 12.1 & 11.2 & 9.8 & 7.5 \\
\hline 19.92 & 0.0 & 0.1 & 0.6 & 1.5 & 3.0 & 4.1 & 7.5 & 12.7 & 14.3 & 13.4 & 12.5 & 10.9 & 8.4 \\
\hline 21.25 & 0.0 & 0.1 & 0.6 & 1.5 & 3.0 & 4.1 & 7.5 & 13.0 & 15.0 & 14.0 & 13.1 & 11.5 & 8.8 \\
\hline 22.58 & 0.0 & 0.1 & 0.6 & 1.5 & 3.0 & 4.1 & 7.5 & 13.0 & 15.0 & 14.1 & 13.2 & 11.6 & 8.9 \\
\hline 23.88 & 0.0 & 0.1 & 0.6 & 1.5 & 3.0 & 4.1 & 7.4 & 12.6 & 14.4 & 13.5 & 12.6 & 11.1 & 8.5 \\
\hline 25.17 & 0.0 & 0.1 & 0.6 & 1.5 & 3.0 & 4.1 & 7.2 & 11.7 & 13.1 & 12.3 & 11.5 & 10.1 & 7.7 \\
\hline 26.46 & 0.0 & 0.1 & 0.6 & 1.5 & 3.0 & 4.1 & 6.9 & 10.4 & 11.1 & 10.5 & 9.8 & 8.5 & 6.4 \\
\hline 27.75 & 0.0 & 0.1 & 0.6 & 1.5 & 2.9 & 4.0 & 6.1 & 8.3 & 8.4 & 7.9 & 7.4 & 6.4 & 4.7 \\
\hline 28.56 & 0.0 & 0.1 & 0.6 & 1.5 & 2.9 & 3.8 & 5.4 & 6.5 & 6.3 & 6.0 & 5.6 & 4.8 & 3.5 \\
\hline 29.38 & 0.0 & 0.1 & 0.6 & 1.5 & 2.8 & 3.6 & 4.3 & 4.4 & 3.9 & 3.7 & 3.5 & 3.0 & 2.1 \\
\hline 30.19 & 0.0 & 0.1 & 0.6 & 1.5 & 2.7 & 3.1 & 2.8 & 1.9 & 1.2 & 1.2 & 1.1 & 0.9 & 0.5 \\
\hline 31.00 & 0.0 & 0.1 & 0.6 & 1.5 & 2.3 & 2.3 & 0.7 & -1.1 & -1.8 & -1.6 & -1.5 & -1.4 & -1.2 \\
\hline 32.00 & 0.0 & 0.1 & 0.6 & 1.3 & 1.3 & 0.4 & -2.9 & -5.5 & -6.0 & -5.5 & -5.1 & -4.5 & -3.5 \\
\hline 33.00 & 0.0 & 0.1 & 0.5 & 0.6 & -1.0 & -3.1 & -7.6 & -10.8 & -10.7 & -9.8 & -9.2 & -8.0 & -6.0 \\
\hline 34.00 & 0.0 & 0.2 & -0.1 & -1.4 & -5.6 & -8.8 & -13.8 & -16.9 & -15.9 & -14.7 & -13.7 & -11.8 & -8.6 \\
\hline 35.00 & 0.0 & -0.2 & -2.6 & -7.5 & -14.0 & -17.5 & -21.8 & -24.1 & -22.0 & -20.4 & -19.0 & -16.3 & -11.7 \\
\hline 35.50 & 0.0 & -1.4 & -5.7 & -13.6 & -20.3 & -23.3 & -26.7 & -28.4 & -25.6 & -23.8 & -22.2 & -19.0 & -13.7 \\
\hline 36.00 & 0.0 & -3.9 & -10.4 & -22.2 & -27.7 & -29.8 & -32.1 & -32.9 & -29.4 & -27.5 & -25.6 & -21.8 & -15.7 \\
\hline
\end{tabular}




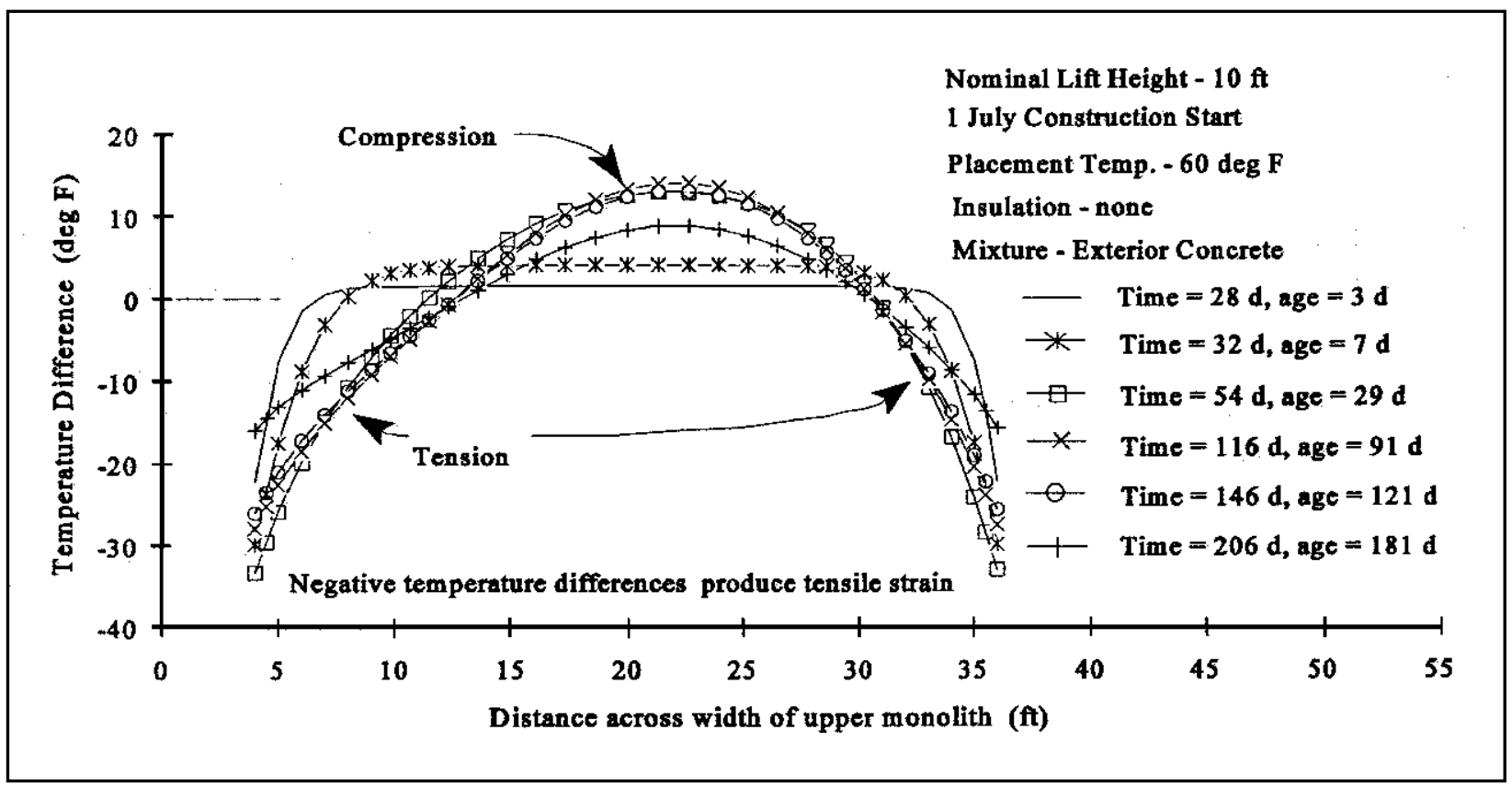

Figure 23. Balanced temperature difference distributions in lift 6 for surface gradient analysis

\begin{tabular}{|c|c|c|c|c|c|c|c|c|c|c|c|}
\hline \multicolumn{12}{|c|}{$\begin{array}{l}\text { Table } 14 \\
\text { Mass Gradient Cracking Analysis }\end{array}$} \\
\hline \multicolumn{12}{|c|}{1 July start, $15.5 \mathrm{deg} C(60 \mathrm{deg} F)$ placement temperature, no insulation, exterior mix } \\
\hline \multirow[b]{2}{*}{$\begin{array}{l}\text { Analysis } \\
\text { Location/ } \\
\text { Node No. }\end{array}$} & \multirow[b]{2}{*}{$\begin{array}{l}\text { T(max) } \\
\operatorname{deg} C \\
(\operatorname{deg} F)\end{array}$} & \multirow[b]{2}{*}{$\begin{array}{l}T(\min ) \\
\operatorname{deg} C \\
(\operatorname{deg} F)\end{array}$} & \multirow[b]{2}{*}{$\begin{array}{l}d T \odot \\
\operatorname{deg} \mathrm{C} \\
(\operatorname{deg} \mathrm{F})\end{array}$} & \multicolumn{3}{|c|}{$\begin{array}{l}\text { Rock/Concrete Interface } \\
\text { (Node 1925) }\end{array}$} & \multirow{2}{*}{$\begin{array}{l}d T= \\
d T(c)- \\
d T(r) \\
\operatorname{deg} C \\
\text { (deg F) }\end{array}$} & \multirow[b]{2}{*}{$\begin{array}{l}\text { Restraint } \\
\text { Factor } \\
K_{r} \\
K_{f}=0.64\end{array}$} & \multirow[b]{2}{*}{$\begin{array}{l}\text { Thermal } \\
\text { Strain } \\
\text { millionths }\end{array}$} & \multirow[b]{2}{*}{$\begin{array}{l}\text { Slow Load } \\
\text { TSC } \\
\text { millionths }\end{array}$} & \multirow[b]{2}{*}{$\begin{array}{l}\text { Cracking } \\
\text { yes/no }\end{array}$} \\
\hline & & & & $\begin{array}{l}\mathrm{T}(\max ) \\
\operatorname{deg} \mathrm{C} \\
(\operatorname{deg} \mathrm{F})\end{array}$ & $\begin{array}{l}\mathrm{T}(\mathrm{min}) \\
\operatorname{deg} \mathrm{C} \\
(\operatorname{deg} \mathrm{F})\end{array}$ & $\begin{array}{l}d T(r) \\
\operatorname{deg} C \\
(\operatorname{deg} F)\end{array}$ & & & & & \\
\hline A / 1910 & $\begin{array}{c}47.8 \\
(118)\end{array}$ & $\begin{array}{l}12.8 \\
(55)\end{array}$ & $\begin{array}{l}35.0 \\
(63)\end{array}$ & \begin{tabular}{|l}
36.1 \\
$(97)$
\end{tabular} & \begin{tabular}{|l|}
15.0 \\
$(59)$
\end{tabular} & $\begin{array}{l}21.1 \\
(38)\end{array}$ & $\begin{array}{l}13.9 \\
(25)\end{array}$ & 0.28 & 41 & 144 & no \\
\hline B / 1498 & \begin{tabular}{|l|}
26.1 \\
$(79)$
\end{tabular} & \begin{tabular}{|l|}
-0.6 \\
$(31)$
\end{tabular} & $\begin{array}{l}26.7 \\
(48)\end{array}$ & \begin{tabular}{|l|}
33.3 \\
$(92)$
\end{tabular} & \begin{tabular}{|l}
25.5 \\
$(78)$
\end{tabular} & $\begin{array}{c}7.8 \\
(14)\end{array}$ & \begin{tabular}{|l}
18.9 \\
$(34)$
\end{tabular} & 0.08 & 16 & 144 & no \\
\hline
\end{tabular}

$$
K_{R}=K_{f}\left(\frac{\frac{L}{H}-1}{\frac{L}{H}+10}\right)^{h / H}=0.28
$$

where

$$
\begin{aligned}
& L / H=13.4 \mathrm{~m} / 7.0 \mathrm{~m}[44 \mathrm{ft} / 23 \mathrm{ft}]=1.9 \\
& h / H=3.5 \mathrm{~m} / 7.0 \mathrm{~m}[11.5 \mathrm{ft} / 23 \mathrm{ft}]=0.5
\end{aligned}
$$

c. Calculate tensile strains. 


$$
\varepsilon=\left(C_{t h}\right)(d T)\left(K_{R}\right)=41 \text { millionths }
$$

where

$$
\begin{aligned}
& C_{t h}=10.5 \text { millionths } / \operatorname{deg} \mathrm{C}(5.81 \text { millionths } / \operatorname{deg} \mathrm{F}) \\
& d T=13.9 \mathrm{deg} \mathrm{C}(25 \mathrm{deg} \mathrm{F}) \\
& K_{R}=0.28
\end{aligned}
$$

d. Estimate cracking. TSC information is shown in Table 15 for various

\begin{tabular}{|c|c|c|c|c|c|c|c|c|c|c|c|c|}
\hline \multicolumn{13}{|c|}{$\begin{array}{l}\text { Table } 15 \\
\text { Surface Gradient Cracking Analysis }\end{array}$} \\
\hline \multicolumn{13}{|c|}{$\begin{array}{l}\text { Example of Surface Gradient Analysis using Temperature Difference Distributions through Center of Lift 6, } 3 \mathrm{~m} \text { (10 ft) lifts, } 1 \text { July Start, } 15.5 \\
\operatorname{deg} \mathrm{C}(60 \mathrm{deg} F) \text { Placement Temperature, No Insulation, } C_{t h}=\text { millionths } / \mathrm{deg} C(5.81 \text { millionths/deg F) }\end{array}$} \\
\hline \multicolumn{2}{|c|}{ Construction (days) } & 27 & \begin{tabular}{l|l} 
& 2 \\
\end{tabular} & \begin{tabular}{l|l}
30 \\
\end{tabular} & \begin{tabular}{l|l|}
32 \\
\end{tabular} & \begin{tabular}{l|l|} 
& 39 \\
\end{tabular} & \begin{tabular}{l|l} 
& 54 \\
\end{tabular} & \begin{tabular}{l|l}
84 \\
\end{tabular} & 116 & 146 & 176 & 206 \\
\hline \multicolumn{2}{|c|}{ Concrete Age (days) } & 2 & 3 & 5 & 7 & 14 & 29 & 59 & 91 & 121 & 151 & 181 \\
\hline \multicolumn{2}{|c|}{ Tension Block Width: } & \multicolumn{11}{|c|}{ See Figure 9} \\
\hline $\mathrm{H}$ (left) & $\mathrm{m}(\mathrm{ft})$ & $\begin{array}{l}0.6 \\
(2.1) \\
\end{array}$ & $\begin{array}{l}0.8 \\
(2.7) \\
\end{array}$ & $\begin{array}{l}1.0 \\
(3.4) \\
\end{array}$ & $\begin{array}{l}1.2 \\
(3.9) \\
\end{array}$ & $\begin{array}{l}1.6 \\
(5.4)\end{array}$ & $\begin{array}{l}2.2 \\
(7.4)\end{array}$ & $\begin{array}{l}2.6 \\
(8.4)\end{array}$ & $\begin{array}{l}2.6 \\
(8.5) \\
\end{array}$ & $\begin{array}{l}2.6 \\
(8.5) \\
\end{array}$ & $\begin{array}{l}2.6 \\
(8.6) \\
\end{array}$ & $\begin{array}{l}2.7 \\
(8.8) \\
\end{array}$ \\
\hline $\mathrm{H}$ (right) & $\mathrm{m}(\mathrm{ft})$ & $\begin{array}{l}0.6 \\
(2.1) \\
\end{array}$ & $\begin{array}{l}0.8 \\
(2.7) \\
\end{array}$ & $\begin{array}{l}1.0 \\
(3.4) \\
\end{array}$ & $\begin{array}{l}1.2 \\
(3.9) \\
\end{array}$ & $\begin{array}{l}1.5 \\
(4.8) \\
\end{array}$ & $\begin{array}{l}1.6 \\
(5.3) \\
\end{array}$ & $\begin{array}{l}1.7 \\
(5.5) \\
\end{array}$ & $\begin{array}{l}1.7 \\
(5.5) \\
\end{array}$ & $\begin{array}{l}11.7 \\
(5.5) \\
\end{array}$ & $\begin{array}{l}1.7 \\
(5.5) \\
\end{array}$ & $\begin{array}{l}1.7 \\
(5.6) \\
\end{array}$ \\
\hline \multicolumn{13}{|c|}{ RESTRAINT FACTORS FOR $K_{R}$ AT SURFACES FOR $L$} \\
\hline $\begin{array}{l}\text { Monolith } \\
\text { Analysis } \\
\text { Location }\end{array}$ & $\begin{array}{l}\text { Joint } \\
\text { Spacing } \\
\mathrm{m}(\mathrm{ft})\end{array}$ & \multicolumn{11}{|c|}{ For $L / H \leq 2.5$, Use equation $\mathrm{K}_{\mathrm{r}}=[(L / H-2) /(L / H+1)] \exp (h / H)$, where $h=H$ at surface } \\
\hline Left-side & $11.0(36)$ & 0.83 & 0.79 & 0.74 & 0.71 & 0.61 & 0.49 & 0.43 & 0.43 & 0.43 & 0.42 & 0.41 \\
\hline Outer & $12.2(40)$ & 0.85 & 0.81 & 0.76 & 0.73 & 0.64 & 0.53 & 0.48 & 0.47 & 0.47 & 0.47 & 0.46 \\
\hline Surface & $13.4(44)$ & 0.86 & 0.83 & 0.78 & 0.76 & 0.67 & 0.57 & 0.52 & 0.51 & 0.51 & 0.51 & 0.50 \\
\hline Right-side & $11.0(36)$ & 0.83 & 0.79 & 0.74 & 0.71 & 0.65 & 0.61 & 0.60 & 0.61 & 0.61 & 0.60 & 0.60 \\
\hline Outer & $12.2(40)$ & 0.85 & 0.81 & 0.76 & 0.73 & 0.68 & 0.65 & 0.64 & 0.64 & 0.64 & 0.64 & 0.63 \\
\hline Surface & $13.4(44)$ & 0.86 & 0.83 & 0.78 & 0.76 & 0.70 & 0.68 & 0.67 & 0.67 & 0.67 & 0.67 & 0.66 \\
\hline \multicolumn{13}{|c|}{ EFFECTIVE TEMPERATURE DIFFERENCES AT SURFACE } \\
\hline \multicolumn{13}{|c|}{ Eff. Temp.Diff. (Table 13) } \\
\hline & eft) (deg F) & $\begin{array}{l}-55 \\
(-10) \\
\end{array}$ & $\begin{array}{l}-12.2 \\
(-22)\end{array}$ & $\begin{array}{l}-15.5 \\
(-28)\end{array}$ & $\begin{array}{l}-16.7 \\
(-30)\end{array}$ & $\begin{array}{l}-17.8 \\
(-32)\end{array}$ & $\begin{array}{l}-18.3 \\
(-33)\end{array}$ & $\begin{array}{l}-16.7 \\
(-30)\end{array}$ & $\begin{array}{l}-15.6 \\
(-28)\end{array}$ & $\begin{array}{l}-14.4 \\
(-26)\end{array}$ & $\begin{array}{l}-12.2 \\
(-22)\end{array}$ & $\begin{array}{l}-7.8 \\
(-14)\end{array}$ \\
\hline$d T(\mathrm{r}$ & ght) (deg F) & $\begin{array}{l}-55 \\
(-10) \\
\end{array}$ & $\begin{array}{l}-12.2 \\
(-22) \\
\end{array}$ & $\begin{array}{l}-15.5 \\
(-28) \\
\end{array}$ & $\begin{array}{l}-16.7 \\
(-30) \\
\end{array}$ & $\begin{array}{l}-17.8 \\
(-32) \\
\end{array}$ & $\begin{array}{l}-18.3 \\
(-33) \\
\end{array}$ & $\begin{array}{l}-16.1 \\
(-29) \\
\end{array}$ & $\begin{array}{l}-15.0 \\
(-27) \\
\end{array}$ & $\begin{array}{l}-14.4 \\
(-26) \\
\end{array}$ & $\begin{array}{l}-12.2 \\
(-22) \\
\end{array}$ & $\begin{array}{l}-7.8 \\
(-14) \\
\end{array}$ \\
\hline \multicolumn{13}{|c|}{ SLOW LOAD TENSILE STRAIN CAPACITY } \\
\hline \multicolumn{2}{|c|}{ Concrete age (days) } & 2 & 3 & 5 & 7 & 14 & 28 & 61 & 90 & 125 & 155 & 185 \\
\hline \multicolumn{2}{|c|}{$\begin{array}{l}\text { Slow-load TSC } \\
\text { (millionths) }\end{array}$} & 86 & 95 & 104 & 108 & 116 & 124 & 134 & 140 & 144 & 146 & 149 \\
\hline \multicolumn{13}{|c|}{ SURFACE TENSILE STRAIN CORRECTED FOR INTERNAL RESTRAINS $\left(K_{R}\right)$} \\
\hline $\begin{array}{l}\text { Monolith } \\
\text { Analysis } \\
\text { Location }\end{array}$ & $\begin{array}{l}\text { Joint } \\
\text { Spacing } \\
\mathrm{m}(\mathrm{ft})\end{array}$ & \multicolumn{11}{|c|}{$\begin{array}{l}\text { (Assume cracking when tensile strains exceed slow-load tensile strain capacity (TSC) for respective age, indicated in } \\
\text { bold) }\end{array}$} \\
\hline Left-side & $11.0(36)$ & 50 & 102 & 119 & 122 & 114 & 95 & 75 & \begin{tabular}{|l|}
69 \\
\end{tabular} & 64 & 54 & 38 \\
\hline Outer & $12.2(40)$ & 51 & 105 & 123 & 127 & 120 & 103 & 83 & 77 & 71 & 60 & 42 \\
\hline Surface & $13.4(44)$ & 52 & 107 & 126 & 131 & 126 & 110 & 90 & 83 & 78 & 66 & 46 \\
\hline Right-side & $11.0(36)$ & 50 & 102 & 119 & 122 & 121 & 119 & 105 & 98 & 91 & 78 & 55 \\
\hline Outer & $12.2(40)$ & 51 & 105 & 123 & 127 & 127 & 126 & 111 & 104 & 97 & 82 & 59 \\
\hline Surface & $13.4(44)$ & 52 & 107 & 126 & 131 & 132 & 131 & 116 & 108 & 101 & 86 & 61 \\
\hline
\end{tabular}
ages. Comparison of mass gradient tensile strains with the slow- load TSC for equivalent time periods indicates no anticipated cracking under the given conditions. 


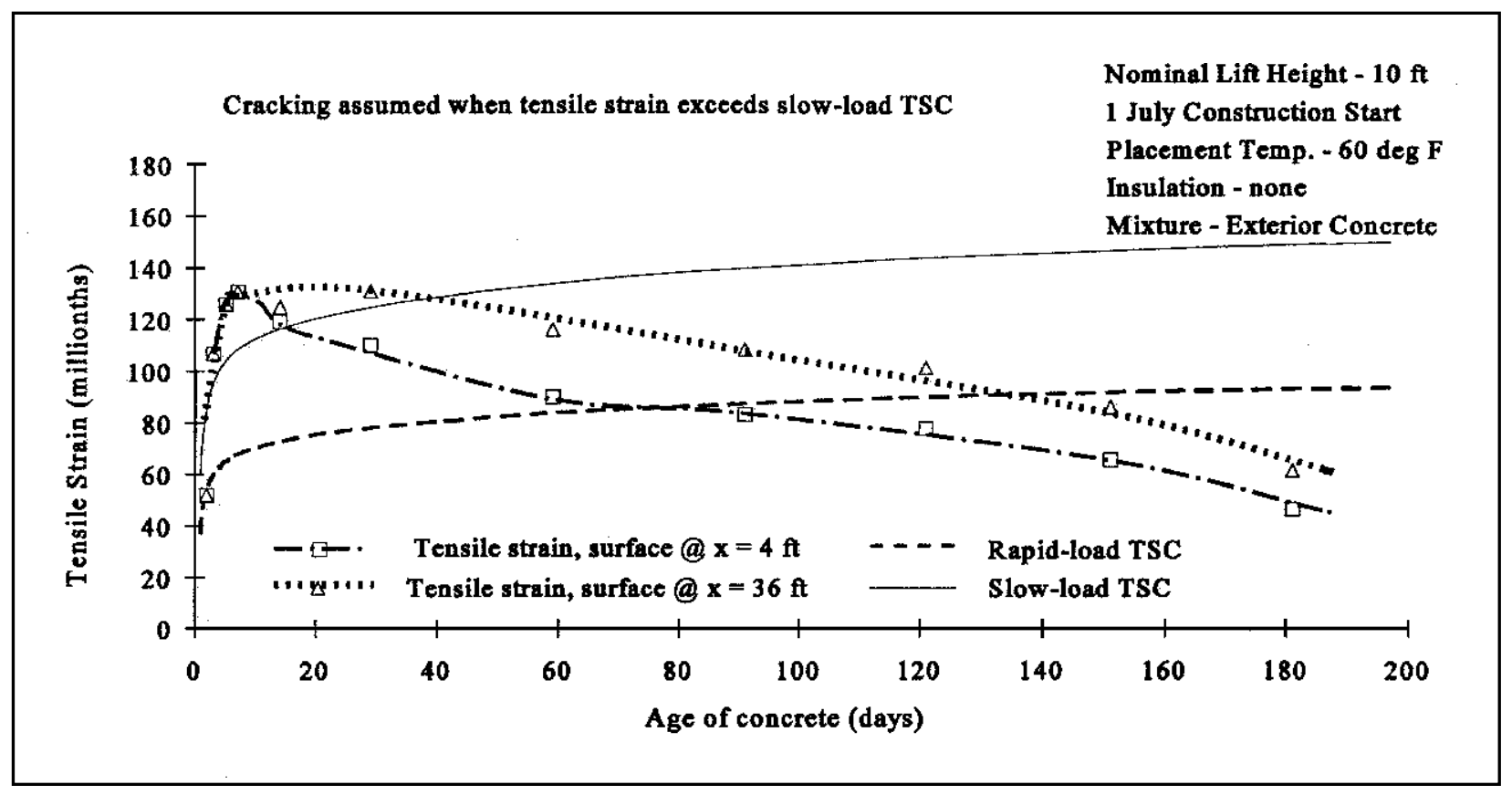

Figure 24. Evaluation of surface gradient cracking potential by comparing induced tensile strain with slow-load tensile strain capacity

Step 8: Surface gradient cracking analysis. Table 15 presents the surface gradient cracking calculations. The upper portion of the table shows the determination of restraint factors based on time and location. The lower portion shows calculation of strains using Equation 1, and comparison of calculated strains with slow-load TSC values for the appropriate time period. Figure 24 compares the development of tensile strains at the lock wall surface and concrete TSC with time.

a. Internal restraint factor $\left(K_{R}\right)$. Internal restraint factors are based on the depth of the tension block, " $H$." " $H$ " is determined from Table 13 by observing the depth where temperatures change from negative to positive, which shows where effective strains are balanced between tension and compression. These depths are shown in Table 15 as the tension block width. $K_{R}$ is calculated based on Equation 2, as shown in the table.

b. Calculate tensile strains. Surface gradient tensile strains shown in Table 15 are based on the use of Equation 1, shown below:

$$
\varepsilon=\left(C_{t h}\right)(d T)\left(K_{R}\right)\left(K_{f}\right)
$$

where

$$
K_{f}=\text { foundation restraint factor equals } 1 \text { for surface gradient analysis }
$$

$d T$ is taken from the surface effective temperature differences in Table 13, at the exterior surfaces at each time period. These are shown in Table 15 for each lock wall face. For this example, only strains at the exterior 
surface are calculated and are shown in Table 15. Exterior surface strains are shown in this table for $K_{R}=1.0$, for comparison assuming the surface is completely restrained, and for various lengths $(L=11.0,12.2$, and $13.4 \mathrm{~m})(L=36,40$, and $44 \mathrm{ft})$ between vertical joints in the lock wall, where the surface restraint is less than 1.0. Strain variation with depth from the surface could be developed using corresponding $K_{R}$ for interior locations.

c. Estimate cracking. Comparison of strains with slow-load TSC provides an estimation of where and when surface gradient cracking may develop, as shown in Table 14. The estimated depth of cracking could be evaluated using $K_{R}$ at varying depths from the surface, and comparing with slow-load TSC.

\section{Conclusions and Recommendations}

Some of the conclusions and recommendations from this thermal study included the following:

\section{Conclusions}

a. $\quad$ Maximum lift height $=1.5 \mathrm{~m}(5 \mathrm{ft})$.

b. $\quad$ Maximum concrete placement temperature $=15.5 \operatorname{deg} \mathrm{C}(60 \mathrm{deg} \mathrm{F})$ producing a $35.0 \mathrm{deg} \mathrm{C}(95 \mathrm{deg} \mathrm{F})$ interior temperature.

\section{Recommendations}

a. Conduct additional mixture proportioning studies to further reduce the cement content.

b. Insulate all exposed concrete surfaces placed between 15 October and 1 March.

c. Remove insulation only when ambient temperatures are above mean daily temperatures, to aid thermal shock.

d. Open culvert space to cool air slowly to avoid thermal shock. 


\section{References}

American Concrete Institute. ACI manual of concrete practice. Detroit, MI.

ACI 116R-90, “Cement and concrete terminology," Part 1.

ACI 207.1R-87, "Mass concrete for dams and other massive structures," Part 1.

ACI 207.2R-90, "Effect of restraint, volume change, and reinforcement of cracking of massive concrete," Part 1.

ACI 207.4R-93, "Cooling and insulating systems for mass concrete," Part 1.

ACI 207.5R-89, "Roller compacted mass concrete," Part 1.

American Society of Heating, Refrigerating and Air-Conditioning Engineers. (1977). ASHRAE handbook and product directory - 1977 fundamentals, New York.

Fintel, M. (1985). Handbook of concrete engineering. 2nd ed., Van Nostrand Reinhold, New York.

Headquarters, Department of the Army. "Standard practice for concrete for civil works structures," EM 1110-2-2000, Washington, DC.

. "Nonlinear, incremental structural analysis of massive concrete structures," ETL 1110-2-365, Washington, DC.

Hibbitt, Karlsson, and Sorensen, Inc. (1994). ABAQUS user's manual, version 5.3., Pawtucket, RI.

Hollenbeck, R. E., and Tatro, S. B. (2000). "Nonlinear, incremental structural analysis of Zintel Canyon Dam," ERDC/SL TR-00-7, U.S. Army Engineer Research and Development Center, Vicksburg, MS.

Houghton, D. L. (1976). "Determining tensile strain capacity of mass concrete." ACI Journal Proceedings, Vol 73, No. 12, 691-700. 
U.S. Army Engineer Waterways Experiment Station. (1949). "Standard test method for ultimate tensile strain capacity of concrete." Handbook for Concrete and Cement (with periodic supplements), Designation CRD C 71-80. Vicksburg, MS.

Wilson, E. L. (1968). "The determination of temperatures within mass concrete structures," SESM Report No. 68-17, University of California, Berkeley. 


\section{Appendix A Determination of Tensile Strain Capacity (TSC)}

\section{Purpose}

Tensile strain capacity (TSC) is the change in length per unit length that can be sustained in concrete prior to cracking. This property is used with the results of temperature analysis to determine whether a mass concrete structure (MCS) will crack and the extent of cracking. This appendix describes testing to determine TSC, methods to estimate TSC, and methodology for its use in thermal analysis.

\section{Background}

The Corps of Engineers introduced TSC testing of concrete several decades ago to provide a basis for evaluating crack potential for strain-based thermal studies of MCS (Houghton 1976). This property is also used to compare different aggregates and different concrete mix proportions in MCS. TSC varies primarily based on age, strength, aggregate type, shape, and texture. TSC tests are conducted on large concrete beams instrumented to measure strain to failure. TSC is determined in a series of tests, including rapid and slow loading of beams. The slow-load test was designed to simulate the strain conditions occurring in a mass concrete structure during long-term cooling. By conducting tests at several loading ages, TSC data can be used to evaluate mass gradient cracking resistance in a structure under long-term cooling. Surface gradients generally develop during the first several days or weeks after placement of concrete, particularly following the removal of insulated forms. Hence, strains due to surface gradients develop more rapidly than tested using the slow-load TSC test, and more slowly than a standard TSC test failed at a normal loading rate. This appendix describes one method used to estimate TSC for surface gradient analyses. 


\section{Description of Test Method}

Tensile strain capacity is determined according to test method CRD-C 71 (WES 1949). The test method requires a minimum of three beams for each test, and generally a minimum of three tests is recommended for each test set to allow for variation in the test results. Rapid-load $(0.28 \mathrm{Mpa} / \mathrm{min})(40 \mathrm{psi} / \mathrm{min})$ and slow-load $(0.17 \mathrm{Mpa} /$ week) ( $25 \mathrm{psi} /$ week) tests are usually conducted in test series consisting of three beam tests each. TSC test specimens are $300-\mathrm{mm}$ by $300-\mathrm{mm}$ by 1,680 -mm-long (12-in. by 12 -in. by 66 -in.-long) beams tested in third-point loading. Strain gauges are located at or near the top and bottom (compression and tension) surfaces to measure strain during the tests. At the age of test, a rapid-load test is conducted and a slow-load test is begun. Loading continues at the prescribed rate until failure. During the slow-load beam test, strain measurements are made on the beam under load. In addition, measurements of autogenous strain are made on the third beam. The autogenous shrinkage strains are used to correct the strain measurements on the beam under slow load. Upon failure of the slowly loaded beam, a rapid-load test is performed on the third beam. A TSC test series usually contains a suite of rapid- and slow-load tests typically initiated at 3, 7, 28 days, and/or other ages. The differences in TSC capacity from the slow- and rapid-load beams provide an indication of the cumulative creep strain during the slow-load test. The strains measured in the slow-load beam test containing both elastic and creep strains are expressed in millionths $\left(1 \times 10^{-6}\right.$ in./in. $)$.

\section{Tensile Strain Capacity Test Results}

TSC test results can vary widely depending on a variety of factors. Test results for the specific materials and mixture(s) to be used in an MCS should be used whenever possible. Actual values for TSC of mass concrete for slow-load tests for specimens loaded at 7 days and failing at about 90 days range from 88 to 237 millionths. Corresponding values for rapid-load tests conducted at 7 days range from 40 to 105 millionths. For tests conducted upon failure of the slowload beam, rapid-load results range from 73 to 136 millionths. Ratios of slowload tensile strain capacity to rapid-load tensile strain capacity tested at the same age as the slow-load specimens range from 1.0 to 2.0 and averages 1.4. This average is relatively insensitive to age.

\section{Use of TSC for Mass Gradient Cracking Analyses}

Mass gradient tensile loading in an MCS occurs over an extended period of time. The standard slow-load TSC test was specifically designed for this condition. Standard slow-load TSC tests provide a reasonable limiting strain in mass gradient cracking analyses for the condition of restrained slow loading of mass concrete which occurs in a slowly cooling mass. Using an appropriate loading time period, the slow-load TSC can be used directly for mass gradient cracking analysis. 


\section{Use of TSC for Surface Gradient Cracking Analyses}

\section{Surface gradient strains}

Surface gradient strains can be initiated at a very early age, particularly after the removal of insulated formwork, and can develop over a few days or weeks of loading due to the initial temperature rise and subsequent development of the surface temperature gradient. Because loading under surface gradient conditions is more rapid than the standard TSC slow-load test, the results of that test may not well represent surface gradient conditions. Very accurate TSC values may not be necessary for surface gradient analysis, except for critical situations. For most situations, the standard test values will suffice for surface gradient cracking analysis as well as mass gradient cracking analysis. In some structures, concrete mixtures placed near the surface of the MCS may differ significantly from internal concrete mixtures. Tests for TSC used in surface gradient analysis should be conducted on the appropriate concrete mixture(s).

\section{Simulated surface gradient strains}

For critical situations, slow-load TSC tests conducted at more rapid rates of loading than the standard slow-load test may be conducted to simulate the development of surface gradient thermal strains. In lieu of such special load rate testing, an estimate can be made of TSC for use in preliminary surface gradient TSC determinations, using the ratio of 1.4 described above. An estimate of TSC for surface gradient analysis is determined by testing TSC at the rapid load rate and at the age of interest. This value is then multiplied by 1.4 , to determine a TSC under the slow loading reflective of surface gradient strain development. This estimate is believed to be reasonably conservative at ages from 1 to 14 days. Because creep rates are greatest at early ages, it is possible that slow-load TSC may be considerably higher especially from 1 to 7 days. Until test data are available, this may be used for developing surface gradient tensile strain capacity values. 


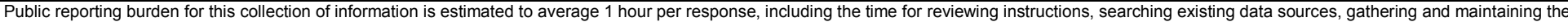

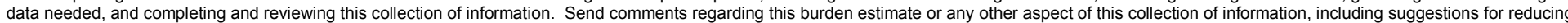

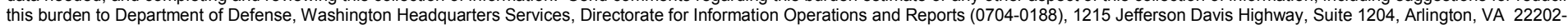

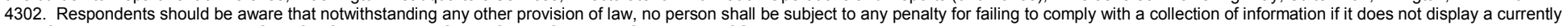
valid OMB control number. PLEASE DO NOT RETURN YOUR FORM TO THE ABOVE ADDRESS

\begin{tabular}{l|l|l} 
1. REPORT DATE (DD-MM-YYYY) & 2. REPORT TYPE & 3. DATES COVERED (FrOm - TO)
\end{tabular}

September 2000 Final report

4. TITLE AND SUBTITLE

5a. CONTRACT NUMBER

Case Histories of Mass Concrete Thermal Studies

5b. GRANT NUMBER

5c. PROGRAM ELEMENT NUMBER

6. AUTHOR(S)

5d. PROJECT NUMBER

Stephen B. Tatro, Anthony A. Bombich, John R. Hess

5e. TASK NUMBER

5f. WORK UNIT NUMBER

7. PERFORMING ORGANIZATION NAME(S) AND ADDRESS(ES)

8. PERFORMING ORGANIZATION REPORT NUMBER

U.S. Army Engineer Research and Development Center

3909 Halls Ferry Road

Vicksburg, MS 39180-6199

ERDC/SL TR-00-8

9. SPONSORING / MONITORING AGENCY NAME(S) AND ADDRESS(ES)

10. SPONSOR/MONITOR'S ACRONYM(S)

U.S. Army Corps of Engineers

Washington, DC 20314-1000

11. SPONSOR/MONITOR'S REPORT

NUMBER(S)

\section{DISTRIBUTION / AVAILABILITY STATEMENT}

Approved for public release; distribution is unlimited.

\section{SUPPLEMENTARY NOTES}

\section{ABSTRACT}

This report presents examples of mass concrete thermal studies for several U.S. Army Corps of Engineers projects. The examples are preceded by a brief explanation of the components of each study and other relevant information.

The example thermal studies were generally performed as outlined in ETL 1110-2-542, Thermal Studies of Mass Concrete Structures. This ETL is no longer in print, but the major elements of the document are now contained in EM 1110-2-2000, Standard Practice for Concrete for Civil Works Structures. This report serves as a companion document to the EM. More detailed explanation of the general provisions for performing mass concrete thermal studies are contained in the EM 1110-2-2000.

The performance of thermal analyses can be grouped by level of complexity. This report provides explanations and examples of Levels 1 and 2 thermal studies. The most complex, Level 3, is not illustrated in this report. The procedure for a Level 1 analysis is presented along with an example of the thermal study for Cache Creek Detention Basin. The procedure for a Level 2 analysis is also presented. The preliminary thermal analysis for the American River Dam provides an example of a one-dimensional Level 2 thermal analysis, including an example using simple finite element (FE), one-dimensional strip models. The thermal analysis for Locks and Dams 2 , 3, and 4

(Continued)

\section{SUBJECT TERMS}

See reverse.

16. SECURITY CLASSIFICATION OF:
\begin{tabular}{l|l|l|}
\hline a. REPORT & b. ABSTRACT & c. THIS PAGE \\
UNCLASSIFIED & UNCLASSIFIED & UNCLASSIFIED \\
\hline
\end{tabular}

17. LIMITATION OF ABSTRACT

\begin{tabular}{|c|l|}
$\begin{array}{c}\text { 18. NUMBER } \\
\text { OF PAGES }\end{array}$ & 19a. NAME OF RESPONSIBLE PERSON \\
\cline { 2 - 2 } & $\begin{array}{l}\text { 19b. TELEPHONE NUMBER (include area } \\
\text { code) }\end{array}$ \\
\end{tabular}

Standard Form 298 (Rev. 8-98)

Prescribed by ANSI Std. 239.18 
14. (Concluded)

on the Monongahela River provides an example of a Level 2 analysis using more complex two-dimensional FE methodology. Appendix A presents the current practice for determination of concrete tensile strain capacity for use in cracking analysis.

The analyses illustrated by the examples in this report are recommended to evaluate thermal behavior of mass concrete structures. The analyses are useful in establishing the type and degree of control measures necessary to control thermal cracking.

\section{SUBJECT TERMS}

Adiabatic temperature rise

American River Dam

Cache Creek Detention Basin Weir

Concrete

Cracking

Dams

Finite element method

Insulation

Joints

Lock and Dam 2,3,4

Mass concrete

Mass gradient

Restraint

Roller compacted concrete

Surface gradient

Temperature

Thermal analysis

Tensile strain capacity

Thermal strain

Thermal stress 